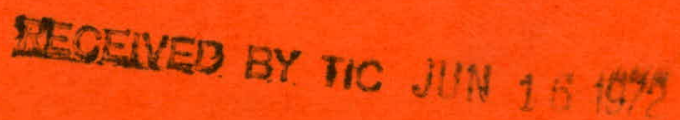

THESIS

\section{RESPONSE OF SHORTGRASS PLAINS VEGETATION TO CHRONIC AND SEASONALLY ADMINISTERED GAMMA RADIATION}

Submitted by

Leslie Fraley, Jr.

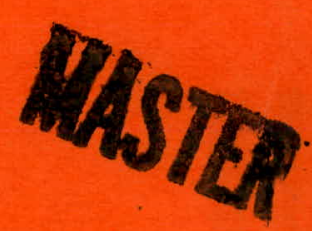

\author{
In partial fulfillment of the requirements \\ for the Degree of Doctor of Philosophy \\ Department of Radiology and Radiation Biology \\ Colorado State University \\ Fort Collins, Colorado
}

August 1971 


\section{DISCLAIMER}

This report was prepared as an account of work sponsored by an agency of the United States Government. Neither the United States Government nor any agency Thereof, nor any of their employees, makes any warranty, express or implied, or assumes any legal liability or responsibility for the accuracy, completeness, or usefulness of any information, apparatus, product, or process disclosed, or represents that its use would not infringe privately owned rights. Reference herein to any specific commercial product, process, or service by trade name, trademark, manufacturer, or otherwise does not necessarily constitute or imply its endorsement, recommendation, or favoring by the United States Government or any agency thereof. The views and opinions of authors expressed herein do not necessarily state or reflect those of the United States Government or any agency thereof. 


\section{DISCLAIMER}

Portions of this document may be illegible in electronic image products. Images are produced from the best available original document. 
THIS PAGE

\section{WAS INTENTIONALLY LEFT BLANK}




\section{ABSTRACT OF THESIS \\ RESPONSE OF SHORTGRASS PLAINS VEGETATION \\ TO. CHRONIC AND SEASONALLY ADMINISTERED GAMMA RADIATION}

In order to determine the effect of radiation on the structure of native shortgrass plains vegetation, an $8750 \mathrm{Ci}{ }^{137} \mathrm{Cs}$ source was Installed on the Central Plains Experimental Range near Nunn, Colorado The experimental area was divided into 6 treatment sectors, a control, 2 sectors for chronic exposure (irradiation initiated Apri1 1969 and continuing as of August 1971), and one each for spring, summer and late fall seasonal semi-acute ( 30 day), exposures which were adminIstered during April, July and December, 1969, respectively.

Community structure was measured by coefficient of community and diversity index. Yield was determined by clipping plots in September 1970 and visual estimates in September 1969 and 1970 for the grasssedge component of the vegetation. Individual species sensitivity was determined by density data recorded in April, June and September of 1969 and 1970 and by a phenological index recorded at weekly intervals during the 1969 and 1970 growing seasons.

The response of the vegetation was similar whether determined by coefficient of community or diversity with diversity being a more sensitive measure of effects. In the chronically exposed sectors, the exposure rate which resulted in a 50 per cent reduction in these 2 parameters ( $C C 50$ or D50) was still decreasing the second growing season and was approximately $18 \mathrm{R} / \mathrm{hr}$ for the CC50 as of June 1970 and $10 \mathrm{R} / \mathrm{hr}$ for the $\mathrm{D} 50$ as of September 1970. For the seasonally exposed sectors, the late fall period (December, 1969) was the most 
Jensitive, summer (July, 1969) the least sensitive and spring (April, 1969) Intermediate with CC50 and D50 values of 195 and 90,240 and 222 , and 120 and $74 \mathrm{R} / \mathrm{hr}$ for the spring, summer and late fall exposed sectors, respectively.

Yield and density data indicated a rapid revegetation of the spring and summer exposed sectors during 1970 as a result of an influx of invader species such as Salsola kali tenuifolia, Chenopodium leptophyllum and Lepidium densiflorum and the reappearance of perennlals with underground perennating organs such as Lygodesmia juncea, Gaura coccinea and Denothera coronopifolia.

The most sensitive indicator of radiation damage was the phenological index with a chronic exposure rate of $1 \mathrm{R} / \mathrm{hr}$ delaying the development of Tradescantia occidentalis and Opuntia polyacantha.

The shortgrass plains vegetation appears to be one of the most resistant community types studied to date with semi-acute exposures of 45 to $75 \mathrm{kR}$ necessary to decrease diversity to 50 per cent of the control value.

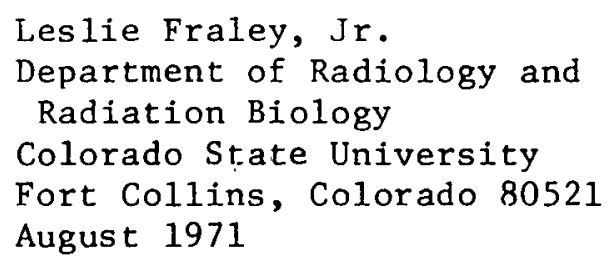




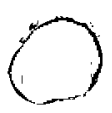

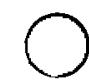

()

$(1)$ 
FRONTISPIECE. Top section. General view of the study area in late March 1969 prior to inftiation of irradiation. The view is to the west looking over the study area, the drainage area, towards a ridge with the Front Range of the Rocky Mountains in the background. Photo taken with Canon FTQL SLR $35 \mathrm{~mm}$ camera using a Canon FL $200 \mathrm{~mm}$ lens. Bottom section. Closer view of irradiator and study area as of 4 August 1970, nearly two growing seasons after initiation of 1rradlation. The late fall exposed sector is in the lower foreground with the summer exposed sector to the left. The chronically exposed sectors extend towards the upper right from beyond the irradiator. Note the heavy growth of Invader species in the summer exposed area near the source and almost complete lack of recovery in the late fall exposed sector. Insect pitfall traps can be seen in the late fall exposed sector. Lower photo taken with a Canon FTQL SLR $35 \mathrm{~mm}$ camers using a Canon FL $28 \mathrm{~mm}$ lens. Details of the lead brick arrangement used for the sky-shine shield, contour of the lead filled rim extending down from the sky-shine shield and the stacking of the lead brick used for shielding various sectors can be seen in both photos. 


\section{FRONTISPIECE}

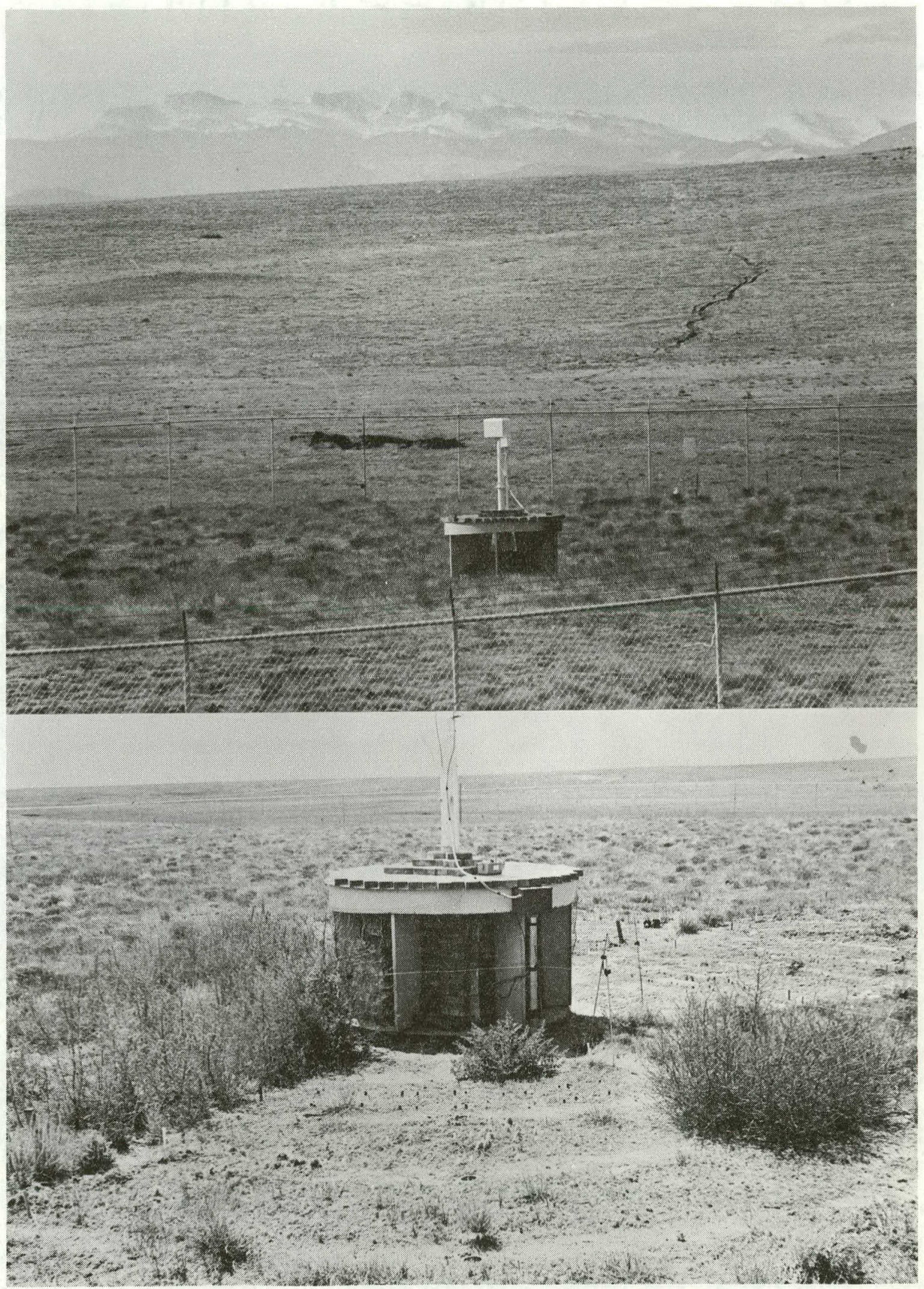




\section{Submitted by}

Leslie Fraley, Jr.

This report was prepared as an account of work
sponsored by the United States Government. Neither
the United States nor the United States Atomic Energy
Commission, nor any of their employees, nor any of
their contractors, subcontractors, or their employees,
makes any warranty, express or implied, or assumes any
legal liability or responsibility for the accuracy, com-
pleteness or usefulness of any information, apparatus,
product or process disclosed, or represents that its use
would not infringe privately owned rights.

In partial fulfillment of the requirements

for the Degree of Doctor of Philosophy

Colorado State University

Fort Collins, Colorado

'August, 1971 
COLORADO STATE UNIVERSITY

AUGUST $\quad 1971$

WE BEREBY RECOMMEND THAT THE THESIS PREPARED UNDER OUR SUPERVISION

BY

LESLIE FRALEY, JR.

ENTITLED RESPONSE OF SHORTGRASS PLAINS VEGETATION TO CHRONIC AND

SEASONALLY ADMINISTERED GAMMA RADIATION

BE ACCEPTED AS FULFILLING IN PART REQUIREMENTS FOR THE DEGREE OF DOCTOR OF PHILOSOPHY

Committee on Graduate Work

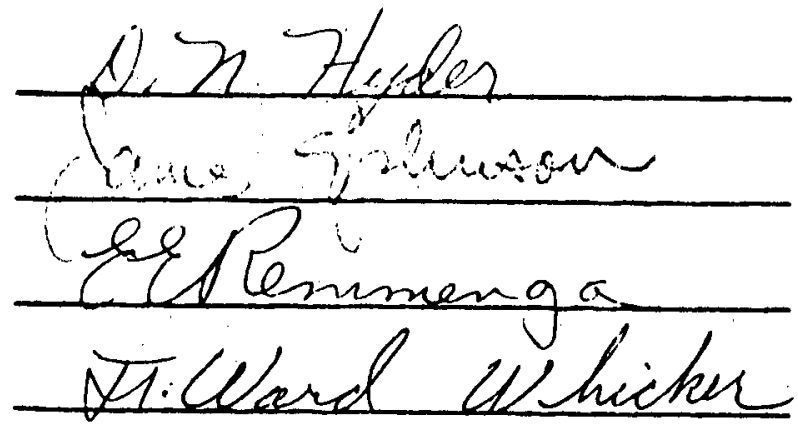

Adviser

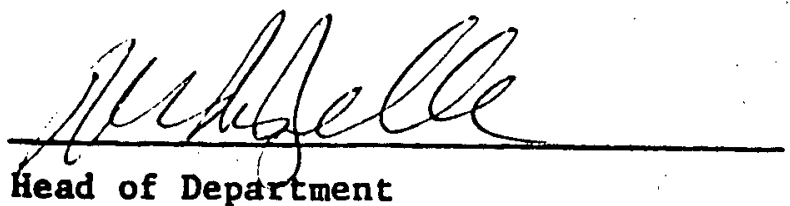




\section{ABSTRACT OF THESIS \\ RESPONSE OF SHORTGRASS PLAINS VEGETATION \\ TO CHRONIC AND SEASONALLY ADMINISTEREDD GAMMA RADIATION}

In order to determine the effect of radiation on the structure of native shortgrass plains vegetation, an $8750 \mathrm{Ci}{ }^{137} \mathrm{Cs}$ source was installed on the Central Plains Experimental Range near Nunn, Colorado. The experimental area was divided into 6 treatment sectors, a control, 2 sectors for chronic exposure (irradiation initiated Apri1 1969 and continuing as of August 1971), and one each for spring, summer and late fall seasonal semi-acute ( 30 day) exposures which were admin1stered during April, July and December, 1969, respectively.

Community structure was measured by coefficient of community and diversity index. Yield was determined by clipping plots in September 1970 and visual estimates in September 1969 and 1970 for the grasssedge component of the vegetation. Individual species sensitivity was determined by density data recorded in April, June and September of 1969 and 1970 and by a phenological index recorded at weekly intervals during the 1969 and 1970 growing seasons.

The response of the vegetation was similar whether determined by coefficient of community or diversity with diversity being a more sensitive measure of effects. In the chronically exposed sectors, the exposure rate which resulted in a 50 per cent reduction in these 2 parameters (CC50 or D50) was still decreasing the second growing season and was approximately $18 \mathrm{R} / \mathrm{hr}$ for the CC50 as of June 1970 and $10 \mathrm{R} / \mathrm{hr}$ for the $\mathrm{D} 50$ as of September 1970. For the seasonally exposed sectors, the late fall period (December, 1969) was the most 
sensitive, summer (July, 1969) the least sensitive and spring (April, 1969) intermediate with CC50 and D50 values of 195 and 90,240 and 222, and 120 and $74 \mathrm{R} / \mathrm{hr}$ for the spring, summer and late fall exposed sectors, respectively.

Yield and density data indicated a rapid revegetation of the spring and summer exposed sectors during 1970 as a result of an influx of invader species such as Salsola kali tenuifolia, Chenopodium leptophyllum and Lepidium densiflorum and the reappearance of perennlals with underground perennating organs such as Lygodesmia juncea, Gaura coccinea and Oenothera coronopifolia.

The most sensitive indicator of radiation damage was the phenological index with a chronic exposure rate of $1 \mathrm{R} / \mathrm{hr}$ delaying the development of Tradescantia occidentalis and Opuntia polyacantha.

The shortgrass plains vegetation appears to be one of the most resistant community types studied to date with semi-acute exposures of 45 to $75 \mathrm{kR}$ necessary to decrease diversity to 50 per cent of the control value.

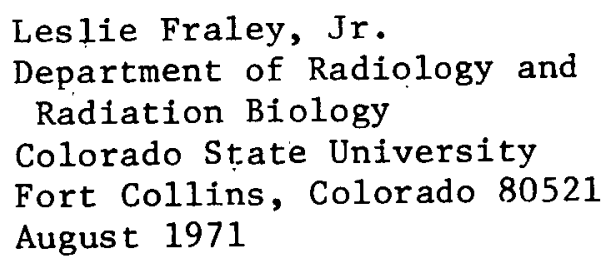




\section{ACKNOWLEDGEMENTS}

I wish to extend my sincere thanks to my advisor and committee chairman, Dr. Ward Whicker, for the original concept of this study, his hours of desk work during the early design phases, his many suggestions during the course of the experiment, and his suggestions and critical evaluation of this thesis, sometimes at hours most inappropriate for his personal schedule. A very special thanks to him for his patience when my rate of output was somewhat below his expectations.

I wish to thank the members of my graduate committee, Drs. Don Hyder, Jim Johnson and Elmer Remmenga, for their help and suggestions during the planning of this experiment and for their critical evaluation of this thesis.

I wish to thank the personnel of the Central Plains Experimental Range, in particular Drs. Bob Bement and Don Hyder, for their cooperation and the use of their herbarium. A special thanks to Dr. Don Hyder, who spent several hours in the field teaching me to identify most of the species of grassland plants I know today. My thanks to Joe Doerges for his assistance in laying out the experimental plots, collecting data and data processing during 1969 and 1970. Also, my thanks to Cindy Bauman for her help in laboratory work, to Bill Alldredge and Roger B. Smith for help with some of the early survey work at the study site and to members of the Radioecology group of the Department of Radiology and Radiation Biology for their encouragement during this study.

A very special thanks to my family who gave up a beautiful home in McPherson, Kansas to support me in every way possible for the 
duration of my graduate program and in particular to my wife, Barbara A. Fraley, who gave me moral support during my studies, earned bread for our family and typed ny thesis.

This study was supported by the U.S. Atomic Energy Commission on contract AT (11-1)-1156, the U.S. Department of Agriculture, Agricultural Research Service and the Department of Radiology and Radiation Biology cooperating.

Leslie 7raleyfor

Leslie Fraley, Jr.

August 1971

vi 
TABLE OF CONTENTS

Chapter

Page

1

BACKGROUND................... 1

Introduction............... 1

Effects of ionizing radiation on plant communities.............. 4

objectives................. 7

MATERIALS AND METHODS............ 8

Site description............. 8

Radiation source............. 12

Radiation field............... 19

Experimental design............ 23

Methods................... 29

RESULTS .................... 32

Zonation.................. 32

Coefficient of community........ 35

Chronic irradiation......... 35

Seasonal irradiation........ 39

Diversity index............. 48

Chronic irradiation......... 48

Seasonal irradiation......... 57

Yield..................... 67

Phenology.................. 84

Density................... 89

DISCUSSION.................. 106 
TABLE OF CONTENTS - - Continued

Chapter

Page

Effects................ 106

Zonation............... 106

Coefficient of community...... 107

Chronic irradiation...... 108

Seasonal irradiation..... 109

Diversity index.......... 110

Chronic irradiation...... 112

Seasonal irradiation..... 112

Yield................. 113

Phenology and density....... 114

Bouteloua gracilis....... 115

Opuntia polyacantha...... $\quad 117$

Eriogonum effusum...... 118

Tradescantia occidentalis. $\quad 119$

Recovery.................. 120

Coefficient of community..... 122

Diversity index.......... 122

Yield............... 123

Total yield........... 123

Visual estimates of grasssedge yield............ 124

Density............... 125

ConCLUSions................... 127

LITERATURE CITED................ 139 
TABLE OF CONTENTS - - Concluded

Chapter

APPENDIX 1 (Checklist of plants

identified in study area).............. 142

APPENDIX 2 (Operation of grassland radiation facility: procedures).......... 147

APPENDIX 3 (Miscellaneous Data)......... 157 
Frequency of occurrence of plant species in the study area on 19 September 1968 for 200

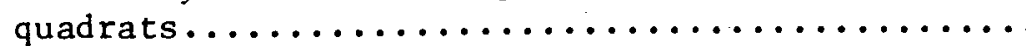

Coefficient of community as a function of exposure rate for chronic irradiation treatment at selected sampling dates...........

Parameters for fitted line $\mathrm{y}=\mathrm{b}_{0}+\mathrm{b}_{1} \log \mathrm{x}$ using data from Table $2 a . \ldots \ldots \ldots \ldots \ldots \ldots \ldots$

Fitted parameters for coefficient of community as a function of exposure rate for the equation $y=\pi / 2 k+1 / k$ arctan $(-x / A+B)$ for all irradiation treatments at selected sampling

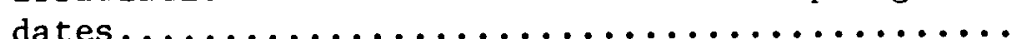

Pre and post irradiation coefficient of community as a function of exposure rate for

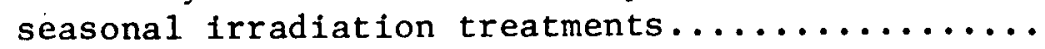

Parameters for fitted line $y=b_{0}+b_{1} \log x$ using data from Table $4 a \ldots \ldots \ldots \ldots \ldots \ldots \ldots$

Fitted parameters for diversity index as a function of exposure rate for the equation $y=\pi / 2 k+1 / k$ arctan $(-x / A+B)$ for all irradiation treatments at selected sampling dates...........

Pre and post irradiation diversity index as a function of exposure rate for seasonal irrad-

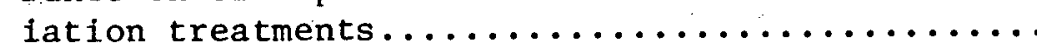

Parameters for fitted line $\mathrm{y}=\mathrm{b}_{0}+\mathrm{b}_{1} \log \mathrm{x}$ using data from Table $7 a \ldots . . \ldots \ldots \ldots \ldots \ldots \ldots$

September 1970 yield for the grass-sedge component of the vegetation following chronic and seasonally administered irradiation...........

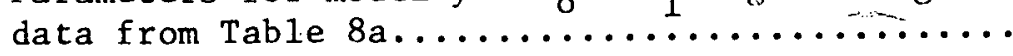
grass-sedge component of the vegetation following chronic and spring administered irradiation. 


\section{LIST OF TABLES - - Continued}

$\underline{\text { Table }}$

$9 b$

$10 a$

$1.0 \mathrm{~b}$

$11 a$

$11 b$

$12 a$

$13 b$

$14 a$

$14 \mathrm{~b}$

$15 a$

Parameters for model $\mathrm{y}=\mathrm{b}_{0}+\mathrm{b}_{1} \log \mathrm{x}$ using data from Table $9 a . \ldots . \ldots \ldots \ldots \ldots \ldots . . .$.

September 1970 visual yield estimates of the grass-sedge component of the vegetation following chronic and seasonally administered

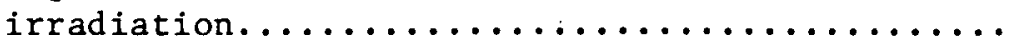

Parameters for model $y=b_{0}+b_{1} \log x$ using data from Table $10 a \ldots \ldots \ldots \ldots \ldots \ldots \ldots . . . \ldots$

Cover of Bouteloua gracilis, as per cent of pre-irradiation cover, as a function of exposure rate for selected sampling dates for chronic irradiation treatment...................

Parameters for model $\mathrm{y}=\mathrm{b}_{0}+\mathrm{b}_{1} \log \mathrm{x}$ using data from Table lla.....................

Cover of Bouteloua gracilis, as per cent of pre-irradiation cover, as a function of exposure rate for selected sampling dates for spring irradiation treatment...................

Parameters for model $\mathrm{y}=\mathrm{b}_{0}+\mathrm{b}_{1} \log \mathrm{x}$ using

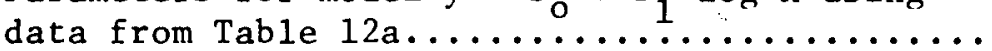

Cover of Bouteloua gracilis, as per cent of pre-irradiation cover, as a function of exposure rate for selected sampling dates for summer irradiation treatment..............

Parameters for model $y=b_{0}+b_{1} \log x$ using data from Table $13 a \ldots \ldots \ldots \ldots \ldots \ldots \ldots \ldots$

Cover of Bouteloua gracilis, as per cent of pre-irradiation cover, as a function of exposure rate for selected sampling dates for

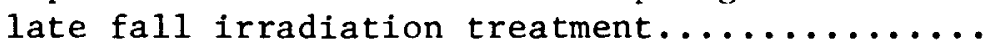

Parameters for model $y=b_{0}+b_{1} \log x$ using data from Table $14 a \ldots \ldots \ldots \ldots \ldots \ldots \ldots . . . \ldots$

Opuntia polyacantha density, expressed as a per cent of pre-irradiation values, as a function of exposure rate for selected sampling dates for chronic irradiation treatment.... 
15b Parameters for model $\mathrm{y}=\mathrm{b}_{0}+\mathrm{b}_{1} \log \mathrm{x}$ using

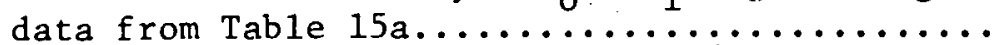
ation treatment, expressed as a per cent of pre-irradiation values, as a function of exposure rate for selected sampling dates.....

16b Parameters for model $y=b_{0}+b_{1} \log x$ using

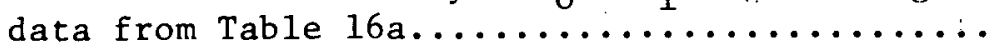

17a Opuntia polyacantha density for summer irradiation treatment expressed as a per cent of pre-irradiation values, as a function of exposure rate for selected sampling dates.....

Parameters for model $y+b_{0}+b_{1} \log x$ using
data from Table $17 a \ldots \ldots \ldots \ldots \ldots \ldots \ldots \ldots \ldots$

Density of Opuntia polyacantha for late fall irradiation treatment, expressed as per cent of pre-irradiation density, as a function of exposure rate for selected sampling dates......

Density of Eriogonum effusum for chronic irradiation treatment as a function of exposure rate for June 1969 and 1970 sampling

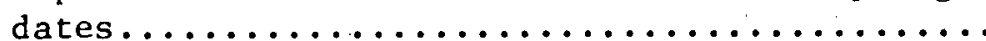

Density of Eriogonum effusum for seasonal irradiation treatments as a function of exposure rate for June 1969 and 1970 sampling dates except for late fall exposed sector which was first sampled $9-69 . \ldots \ldots \ldots \ldots \ldots \ldots$

21 Density of Tradescantia occidentalis for chronic irradiation treatment as a function of exposure rate for June 1969 and 1970 sampling

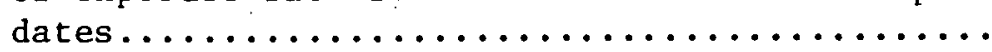

Density of Tradescantia occidentalis for seasonal irradiation treatment as a function of exposure rate for June 1969 and ' 1970 sampling dates except for the late fall exposed sector which was first sampled $4-70 \ldots \ldots \ldots \ldots \ldots \ldots$. 


\section{LIST OF TABLES - - Concluded}

$\underline{\text { Table }}$

Page

APPENDIX 3

23

Temperature and precipitation for April 1968 through December 1970 at the grasslands irradi-

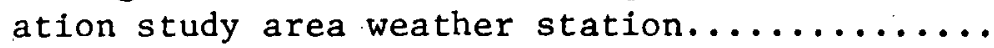

Coefficient of community as a function of exposure rate in sector 2 for selected sampling

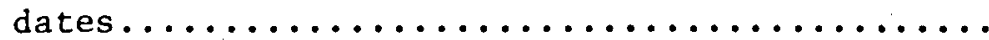

Coefficient of community as a function of exposure rate in sector 3 for selected sampling

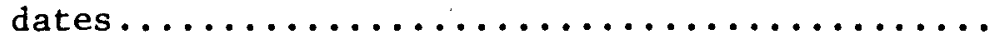

Coefficient of community as a function of exposure rate in sector 4 for selected sampling dates.............................

Coefficient of community as a function of exposure rate in sector 5 for selected sampling

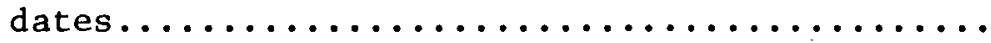

Coefficient of community as a function of exposure rate in sector 6 for selected sampling

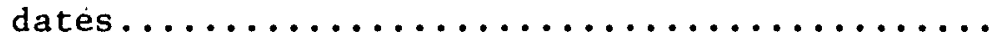

Diversity index as a function of exposure rate in sector 1 for selected sampling dates........

Diversity index as a function of exposure rate in sector 2 for selected sampling dates.......

Diversity index as a function of exposure rate in sector 3 for selected sampling dates.......

Diversity index as a function of exposure rate in sector 4 for selected sampling dates........

Diversity index as a function of exposure rate in sector 5 for selected sampling dates....... 


\section{LIST OF FIGURES}

F1gure

1.

2

3

4

5

6

7

8

9

10

11

Cross-section of irradiator installation showing details of foundation, source, "pig" sky-shine shield and lifting mechanism........

$\underline{\text { Page }}$

Overall design of gamma field showing outer fence perimeter, lane and control house, security fence perimeter and layout of the

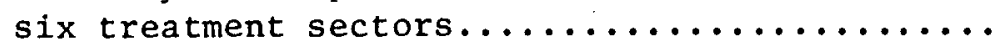

Exposure rate vs distance for open and shielded sectors at the grassland irradiation gamma field and the theoretical curve for 8750 ci of $137 \mathrm{Cs}$ attenuated by 0.237 inches of

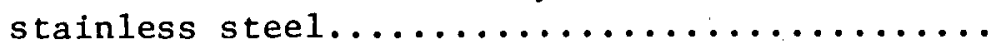

Exposure rates at selected soil depths relative to surface value as a function of distance from

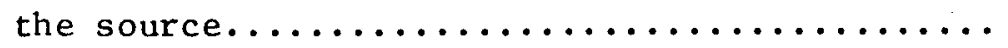

Typical treatment sector plan showing location of macroplots within the sector..............

Coefficient of community as a function of exposure rate for the chronic irradiation treatment at selected sampling dates..............

Coefficient of community as a function of exposure rate and time after initiation of the

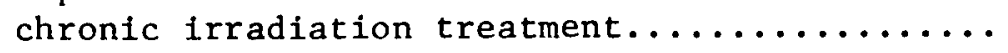

Coefficient of community as a function of exposure rate for seasonal irradiation treat-

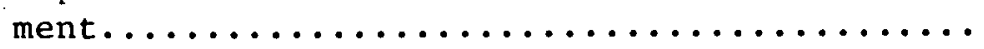

Coefficient of community as a function of exposure rate and time for the spring irradi-

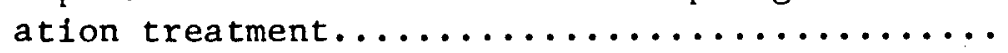

Coefficient of community as a function of exposure rate and time for the summer irradi-

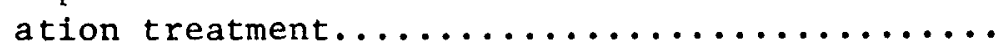

Coefficient of community as a function of exposure rate and time for the late fall irra-

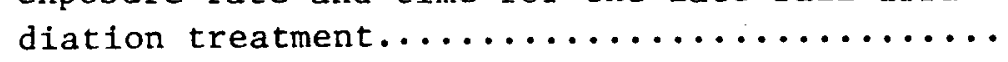


Diversity index as a function of exposure rate for chronic irradiation treatment at

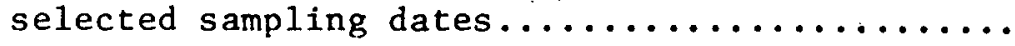

Diversity index as a function of exposure rate and time after initiation of the chronic

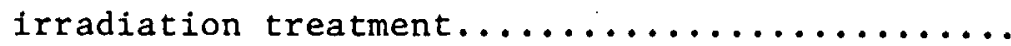

14 Diversity index as a function of exposure rate and time after initiation of the chronic

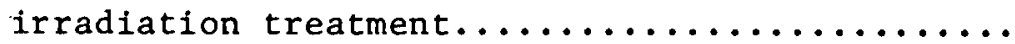

Diversity index as a function of exposure rate for spring, summer and late fall exposure to radiation..........................

Diversity index as a function of exposure rate and time for the spring irradiation treat-

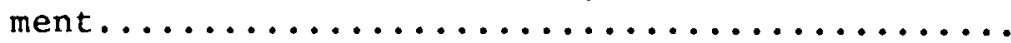

Diversity index as a function of exposure rate and time for the summer irradiation treat-

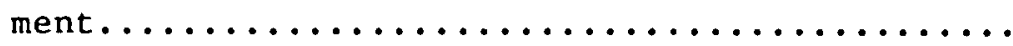

Diversity index as a function of exposure rate and time for the late fall irradiation

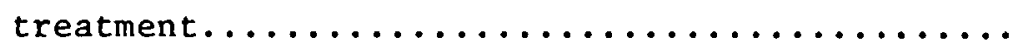

Total vegetative yield as a function of exposure rate for the chronic and seasonal irradiation treatments, September $1970 . . . \ldots \ldots$.

September 1970 yield for the grass-sedge component of the vegetation following chronic and seasonally administered irradiation...........

September 1969 visual yield estimates of the grass-sedge component of the vegetation following chronic and spring administered irradiation.

September 1970 visual yield estimates of the grass-sedge component of the vegetation following chronic and seasonally administered

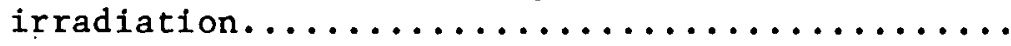




\section{LIST OF FIGURES - - Concluded}

Figure

$\underline{\text { Page }}$

23

1969 Phenological index as a function of time for selected species and selected chronic

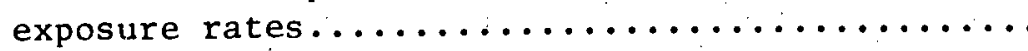

1970 Phenological index as a function of time for selected species and selected chronic exposure rates........................

Photo of chronically irradiated area (sector

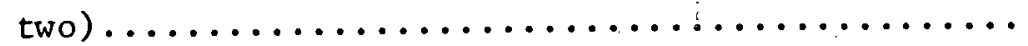

Photo of the spring exposed sector showing the

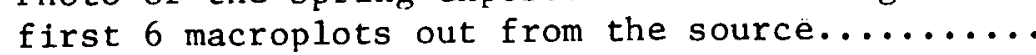

Photo of the summer exposed sector showing the first 6 macroplots out from the source..........

Photo of the late fall exposed sector showing the first 6 macroplots out from the source...... 
CHAPTER 1

BACKGROUND

\section{Introduction}

Man has evolved with radiation as a part of his environment. During the time of modern man, the apparent natural radiation levels have been approximately 100 to $200 \mathrm{mR} / \mathrm{yr}$ (Morgan \& Turner, 1967). It has not been possible to evaluate the effect of this amount of radiation on the various components of the world ecosystem, but man and other biological components of the biosphere have apparently been able to survive and function without serious limitations placed on. them by this level of background radiation.

During the past few decades changes have occurred which seem likely to increase the levels of radiation to many, if not ali, components of the biosphere. Some of these changes are, (a) a rapid Increase in world population, (b) an increase in the per-capita consumption of energy and material goods and (c) a stockpiling of nuclear weapons by some countries, partially as a result of political pressures due to items (a) and (b) above.

There appear to be at least 6 potential sources of contamination of the biosphere or certain ecosystems by radioactive materials. These are weapons testing or other nuclear explosions, operational releases by power reactors, reactor fuel processing, waste disposal, reactor accidents, and nuclear war.

At the present time the testing of nuclear explosions is limited to underground shots (except for countries not restricted by the Nuclear Test Ban Treaty) and does not appear to be a serious threat 
for widespread contamination in the near future although this could change.

I'he release of radioactive materials during the normal operation of power reactors apparently has not resulted in exposures at the level under consideration in this study. This is not meant to imply that the resulting exposures from this source are insignificant. Possible concentration of radionuclides in the food chain must be considered (Tamplin, 1970). The total amount of activity released during reactor operation, fuel processing and/or waste disposal could increase during the next few years as more reactors become operable (Lyer1y and Mitche11, 1969).

Nuclear reactor accidents, such as the one at Windscale, England in October 1957, could result in high level contamination and the resulting exposures could be high enough to cause measurable changes in ecosystems. Actual exposures are difficult to predict but the Windscale release might have resulted in a thyroid dose of 16 rad for one child (Morgan and Turner, 1967). The area receiving high level exposures from reactor accidents would be relatively small and the capacity for recovery should be high since resources could be moved in from outside the affected area.

The most serious threat of widespread, high level contamination is nuclear war. Both the United States and Russia have large stockpiles of nuclear weapons. As of 1 January 1971 the United States had approximately 2000 megatons equivalent of weapons delegated for use on missiles and Russia had approximately 6000 megatons equivalent. Neither of these values include the weapons designated for delivery by 1 ng and medtum range bombers (Scoville, 1971 and U.S. Department of Defense, 1969). 
While one would like to assume that these weapons would never be used, the very fact of their availability poses a threat that must be considered. Based on past political decisions that have led to military involvement it appears that some of the decisions made were not In the best interests of natural biological systems, including man. Further, if a nuclear attack (or counter-attack) were actually carried out, I believe it is reasonable to assume that the maximum number of weapons possible would be used by all nations involved. Therefore, the resulting contamination would likely be heavy and widespread.

Miller and LeRiviere (1966) presented estimates of 1200 and 6000 $\mathrm{R} / \mathrm{hr}$ at $1 \mathrm{hr}$ isoexposure rate lines on maps of the contiguous 48 states for possible intermediate and heavy level attacks. I combined the approximate areas on the heavy attack map with the fallout decay power functions (U.S. Department of Health, Education and Welfare, 1960) to obtain estimates of the total integrated exposures for the 48 contiguous states of the United States and the Western Great P1ains area of the United States originally dominated by shortgrass and mixed prairle. I have projected that approximately 900,000 square miles of the United States and 214,000 square miles of the shortgrass prairie could receive exposures equal to or in excess of $4.4 \mathrm{kR}$ and that approximately 300,000 square miles of the United States and 75,000 square miles of the shortgrass prairie could receive exposures equal to or in excess of $45 \mathrm{kR}$. In each case presented, approximately 50 per cent of the exposure would be received in the first 30 days. With the above areas and levels of exposures, inputs of all types (i.e., biological, such as seed, manpower, communications, and 
other physical resources) from outside areas would be much more diffloult than when small areas are exposed and recovery of ecological, polltical and economic systems may be very difficult and slow. Exposures at these levels have been shown to severely damage some plant communities (McCormick, 1969).

\section{Effects of Ionizing Radiation On Plant Communities}

Studies on the effects of ionizing radiation on natural plant communities have been limited by the availability of suitable sources, suitable areas in which to carry out the studies and availability of other resources such as personnel and funding. A radiation field was constructed on the campus of Emory University (Platt, 1963). McCormick (1963) used this source to irradiate island communities of the granite outcrops of the southeastern United States for a period of 17 weeks. Exposures of more than $40 \mathrm{kR}$ resulted in a marked decrease in the density of spring flora the following year. In areas receiving 8 to $23 \mathrm{kR}$ there was an increase in the density of one species and a decrease in the density of another, resulting in a shift in the ecotone. Such a shift was not present the second year after irradiation. Irradiation of the summer flora resulted in the more resistant species becoming dominant at the higher exposures (approximately $40 \mathrm{kR}$ ) and maintaining that dominance over the next two years.

At Brookhaven National Laboratory a large $60^{\circ}$ Co source (Sparrow and Singleton, 1953) was used to irradiate first and second year old field communities (Woodwell and Oosting, 1965). These authors reported a decrease in diversity (as measured by the number of species per square meter) from 6.8 for the control to 0.1 at an exposure rate of $3.2 \mathrm{kR} / 20 \mathrm{hr}$ day with some indication of a possible increase of diversity 
at intermediate levels of exposure rates, 49 and $110 \mathrm{R} / 20 \mathrm{hr}$ day. The coefficient of community also decreased with increasing exposure rates with a 50 per cent change corresponding to a three fold change in exposure rate.

Also at Brookhaven, a large ${ }^{137} \mathrm{Cs}$ source was installed in a near climax oak-pine forest (Woodwe11, 1963). Woodwell and Rebuck (1967) reported the development of 5 zones during 4 years of irradiation which were related to the stratification patterns of the vegetation. They also reported a decrease in diversity (measured as the number of species per square meter) of about 5.5 at less than $17 \mathrm{R} /$ day to zero at exposure rates of above $300 \mathrm{R} /$ day for 1962 . There was a slight decrease in diversity for a given exposure rate for 1963 with very little change for 1964. There appeared to develop, at somewhat lower exposure rates (approximately $10 \mathrm{R} / \mathrm{day}$ ) a small increase in diversity. The coefficient of community for the oak-pine forest decreased in manner similar to diversity and at about the same exposure rate levels.

More recently, a portable ${ }^{137} \mathrm{Cs}$ source was developed at the University of Georgia Institute of Radiation Ecology (McCormick and Golly, 1966) for use on various ecosystems and at various times of the year. McCormick $(1966,1969)$ used this source to irradiate a pine forest for a 200 hour exposure. He reported a decrease in diversity, percentage similarity and community coefficient with increasing exposure rates but not always in the same linear manner reported in other studies. Monk (1966) used this source to irradiate an old field community for 400 hours. Again, there was a decrease in diversity, percentage similarity and coefficient of community with increasing exposure and Monk reported that an exposure of $8.5 \mathrm{kR}(22 \mathrm{R} / \mathrm{hr}$ exposure rate - my 
calculation) resulted in a diversity of 50 per cent when compared to the diversity of the same plots before irradiation. Both percentage similarity and diversity data were fit to a straight line against the logarithm of the exposure. No clear pattern of change in the coefficient of community was reported. Miller (1968) used this same portable source to irradiate an old field community in each of four seasons for 696 hours. He reported decreases in diversity, percentage similarity and coefficient of community with increasing exposures for all seasons of exposure with the greatest reduction in the spring and the smallest reduction in the fall.

In addition to studies conducted with large gamma sources, some studies have been carried out near unshielded reactors that were constructed in a natural plant community. The 10 megawatt reactor at the U.S. Air Force Plant 67 near Dawsonville, Georgia and operated by Lockheed Aircraft Corporation provided a mixed gamma-neutron flux for a study conducted by Daniel (1963). In general, the ratio of gamma to neutron radiation doses varied from approximately $2: 1$ to $7: 1$; increasing with distance from the reactor (Cowan and Platt, 1963). Daniel reported a reversal or a prolongation of successional stages as a result of the radiation. Witherspoon $(1965,1969)$ studied the forest around the Health Physics Research Reactor at Oak Ridge National Laboratory, Oak Ridge, Tennessee. The ratio of gamma to neutron radiation dose was 0.1 at a distance of 3 to $4 \mathrm{~m}$ from the reactor core. Witherspoon reported the sensifivities of selected.tree species and compared these to results using gamma irradiation. No effects on community structure were reported. 


\section{Objectives}

More information is needed about the sensitivities of additional plant communities and how their sensitivities vary with season. The study presented in this thesis was designed to accomplish the following objectives:

1. to determine the effects of a wide range of exposure rates of radiation on the structure of native shortgrass plains vegetation.

2. to evaluate the effect of season on the structural sensitivity of shortgrass plains vegetation to shorter term gamma radiation.

3. to determine the sensitivity of specific species found in a native shortgrass plains plant stand to gamma radiation. 4. to determine early recovery patterns of shortgrass plains vegetation after damage by gamma radiation. 
CHAPTER 2

MATERIALS \& METHODS

\section{Site Description}

The study area is located approximately 6 miles north and 2 miles east of Nunn, Colorado in the northeast quarter of Section 34, Township 10 North, Range 66 West of the Sixth P.M. of Weld County. The area is owned by the U.S. Department of Agriculture, is administered by the Agricultural Research Service (ARS) and is on the Central Plains Experimental Range (CPER). It is part of an allotment used by the Crow Valley Grazlng Association. The ARS and the grazing association agreed to the withdrawal of a circular area of 31.5 acres for this study. The study area is approximately 1.5 miles southeast of the headquarters of the Grasslands Biome, International Biological Program for the Pawnee site and is typical of the IBP study area.

The selection criteria for the site were availability, uniformity of slope, soil and vegetation and natural shielding features. The area chosen has a fairly uniform slope of 3 per cent towards the southsoutheast. The soil type, typical of uplands on the CPER, is Ascalon sandy loam with the top 3 feet composed of sandy silt, which is underlain by a fine sand to a depth of 6 feet when a gravel lense occurs which extends to a depth of 7.5 feet (Whicker and Dah 1, 1968).

The terrain around the site lended itself to natural shielding. The site was bounded on the north by a small rise, on the east and south by a ridge and on the west by a sma11 rise followed by a slope leading downward to a flood plain and creek. These features, combined with a sky-shine shield at the source considerably reduced the radlation levels at the outer fence. 
The vegetation was a native shortgrass plains stand dominated by blue grama (Bouteloua gracilis) and was characteristic of upland Aoll types (Hyder et a1., 1966). An area 200 feet wide and 100 feet Jong in the study area was frequency sampled in September 1968 using a stratified sample of 200 quadrats.

Blue grama was sampled using a $5 \times 5 \mathrm{~cm}$ quadrat and all other species using a $25 \times 25 \mathrm{~cm}$ quadrat. Twenty six species were recorded (Table 1) although some species characteristic of the area were probably missed due to the sampling date. See Appendix 1 for a list of all species identified in the study area.

The general climate of the area was typified by strong winds, variable precipitation and a wide temperature range. The Central Plains Experimental Range climatic records show that winds of 30-50 mile/hour are common from November to May (K1ipple and Costello, 1960). The average annual precipitation is 12 inches but is characterized by large yearly as well as monthly variations. The three wettest months, May, June and July, produce 50 per cent of the annual precipitation while the four driest months, November, December, January and February, produce only 8 per cent of the precipitation. Eighty per cent of the annual prectpitation comes during the months of AprilSeptember, inclusive. The mean maximum and minimum daily temperatures for January and February during 1959-1963 were $5.8^{\circ} \mathrm{Celcius}$ and $-11.1^{\circ} \mathrm{C}$ respectively (Vaughn, 1967). Mean maximum and minimum temperatures for July and August during $1959-1963$ were $28^{\circ} \mathrm{C}$ and $11.5^{\circ} \mathrm{C}$ respectively.

A photograph of the general area can be viewed in the Frontispiece. 
Table 1. Frequency of occurrence of plant species in the study area on 19 September 1968 for 200 quadrats.

\begin{tabular}{|c|c|}
\hline species & frequency \\
\hline Bouteloua gracilis (blue grama) & $80 \pm 3 *$ \\
\hline Sphaeralcea coccinea (scarlet globemallow) & $40 \pm 4$ \\
\hline Opuntia polyacantha (plains pricklypear) & $30 \pm 5$ \\
\hline Lygodesmia juncea (rush skeletonplant) & $23 \pm 4$ \\
\hline Eriogonum effusum (buckwheat) & $14 \pm 3$ \\
\hline Tradescantia occidentalis (prairie spiderwort) & $6 \pm 2$ \\
\hline Euphorbia glypotsperma (ridgeseed euphorbia) & $6 \pm 1$ \\
\hline Aristida longiseta (red threeawn) & $5 \pm 2$ \\
\hline Thelesperma megapotamicum & 4 \\
\hline Chrysothamnus nauseosus (rubber rabbitbrush) & 4 \\
\hline Sporobolus cryptandrus (sand dropseed) & 4 \\
\hline Oenothera coronopifolla (evening primrose) & 4 \\
\hline Senecio tridenticulatus & 3 \\
\hline Carex heliophila (sun sedge) & 2 \\
\hline Gutierrezia sarothrae (broom snakeweed) & 2 \\
\hline Parme1ia $\underline{\text { sp. }}$ & 2 \\
\hline Gaura coccinea (scarlet gaura) & 2 \\
\hline Thelesperma trifidum & 2 \\
\hline Chenopodium leptophyllum (slimleaf goosefoot) & 1 \\
\hline Lithospermum incisum (gromwe11) & 1 \\
\hline Psoralea tenuiflora (slimflower scurfpea) & 1 \\
\hline Chrysopsis villosa (hairy goldaster) & 1 \\
\hline Cirsium undulatum (wavyleaf thistle) & 1 \\
\hline
\end{tabular}


Table 1. (continued)

\begin{tabular}{l|c}
\hline \multicolumn{1}{c|}{ species } & frequency \\
\hline Muhlenbergia torreyi (ring muhly) & 1 \\
\hline Plantago purshii (woolly indianwheat) & 1 \\
Sitanion hystrix (bottlebrush squirreltail) & 1 \\
\hline
\end{tabular}

* \pm one standard error as calculated by method of Hyder, et a1. (1965)

for the eight most frequently sampled species. 


\section{Radiation Source}

The source consisted of $8750 \mathrm{Cl}$ (as of September 1968) of ${ }^{137} \mathrm{Cs}$ as $\mathrm{CsCl}$ packed in a stainless steel cylinder 1 inch in diameter and 7.5 inches 1ong. The container was mounted in the irradiator formerly used at Blandy Experimental Farm, University of Virginia (Singleton, et a1., 1961). Source fabrication and mounting was done by Oak Ridge National Laboratory. Minor modifications were made to the irradiator by personnel of the Colorado State University Physical Plant to make it compatible with the present installation. The irradiator was set in a foundation designed to support the lead "pig" and shielding associated with the sky-shine and treatment sector shields (F1g. I and Frontispiece) without appreciable settling. Approximately . 10 ton of lead brick, 1 ton of lead shot and the 2 ton lead pig comprised the weight of the irradiator and sky-shine shield. The control house was constructed 500 feet to the north (magnetic) of the source. A winch and control panel box were mounted in the control house and a winch drum mounted on the irradiator mast. A wire rope was wound around the winch drum on the mast, through a 2.5 inch diameter plastic pipe located approximately 18 inches underground, to the control house, up through the floor, around the winch drum, to a spring loaded pulley on the ceiling, back to the floor and through the underground pipe and connected to the loose end at the winch drum on the mast. Spring tension on the ceiling pulley was adjusted to minimize slippage on the drums. This arrangement gave a positive two-way drive at the mast drum. An additional wire rope was fastened to the mast drum, up a guide pipe, over a pulley at the top of the mast and down to the top 
0

0

O

O 
F1g. 1. Cross-section of irradiator installation showing detalls of foundation, source, "pig", sky-shine shield and lifting mechanism. Depth of the shot filled rim varied to match contour of study area in order to confine the primary radiation beam within the study area. Mast extends $2.9 \mathrm{~m}$ above the lead pig. 
0

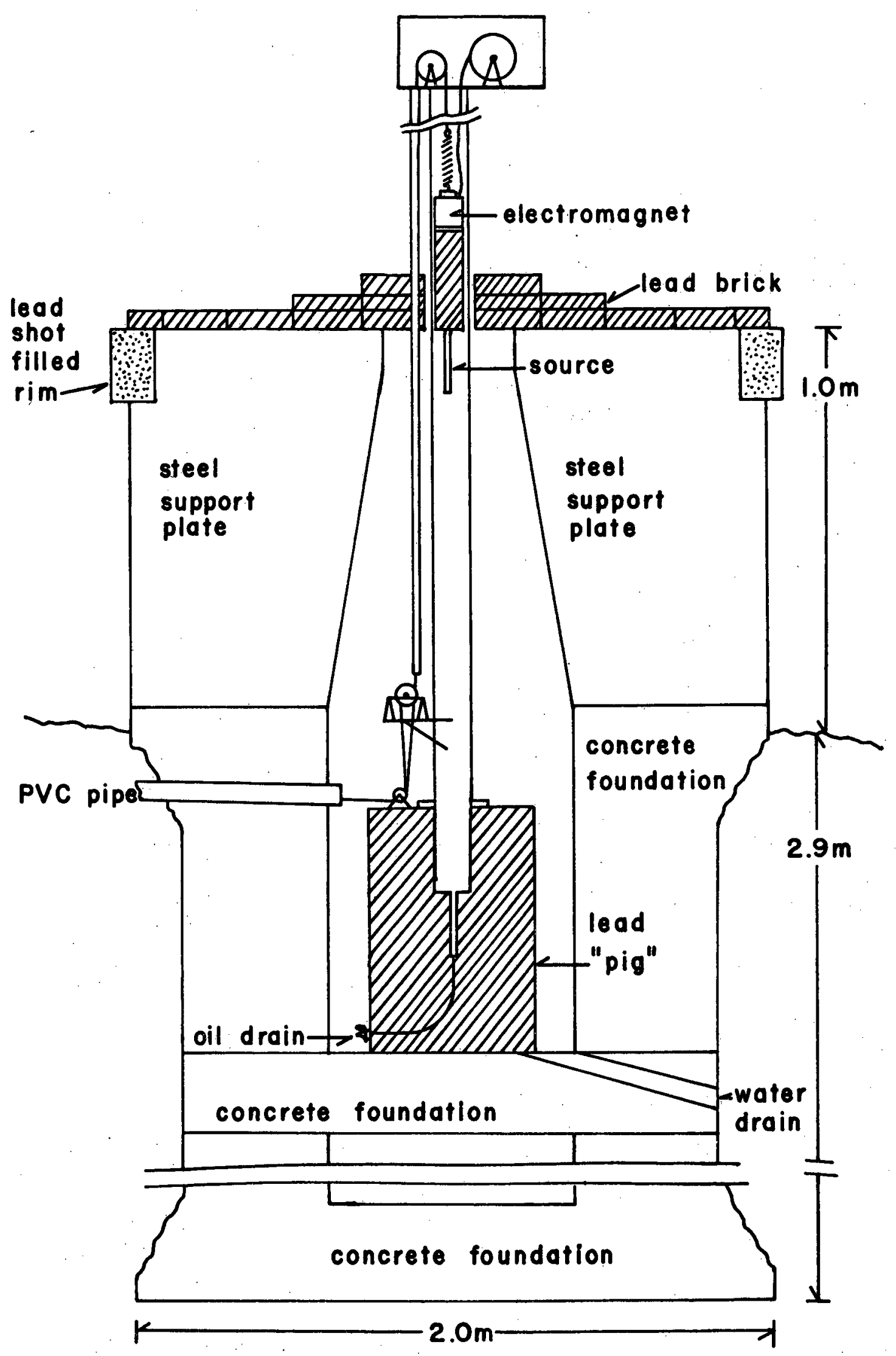


of a heavy duty implement type spring ( $k=100 \mathrm{lb} /$ inch). The lower end of the spring was fastened to a 12 volt DC (approximately 4 amperes) electromagnet which mated with a steel, 1 Inch thick, plate on top of the lead plug in the lead pig. The source container was mounted to the lower end of the lead plug. A "mole" was clamped to the wire rope in the guide pipe which actuated a microswitch at either end to energize either a "source up" or "source down" light on the control panel in the control house. The electrical system for the source consisted of a 110 volt, 60 Hertz to 12 volt DC float charger (LaMARCHE Manufacturing Co., Model A-11) as a main power source for the electromagnet. Two heavy duty NAPA7222 twelve volt batteries were placed in parallel to the output of the charger as a backup power source. These batteries had the capability of furnishing necessary power for the electromagnet for up to 48 hours. The charger would recharge the batteries after a perlod of use. The 12 volt DC line furnished power for 3 indicator lamps on the control panel, the 2 previously mentioned plus an "electromagnet energized" lamp. The line was also connected to a relay which actuated the electromagnet. The relay coil was in series with 2 switches and a \#14 electrical wire mounted on the security fence. One switch was a toggle switch mounted under a locked plate on the control panel with the key hung in a cabinet in the control house. The other switch was mounted between the two sections of the double gate leading into the gamma field and acted as a safety interlock. With both switches on and the wire around the security fence intact (indicating no gross damage to the security fence) the 
electromagnet could be energized and the source raised. As the source was raised a bar, which ${ }^{-} \bar{w}$ as coupled to the winch, moved across the control house door leading toward the gamma field preventing opening of the door. As the source was lowered, the bar moved back allowing the door to be opened. When the source was lowered, a padlock was fastened to the winch drum by each worker entering the radiation field. The key to the padlock was retained by the worker until he left the field and then he removed the appropriate padlock. Duplicate keys to the padlocks, as well as all other locks at the facility, were kept in a locked key box in office of the Principle Investigator, Dr. F.W. Whicker, Biochemistry and Radiation Biology Building, Colorado State University.

Lowering (and raising) of the source was monitored at the control house with a GM survey meter. The first person going into the gamma field carried the survey meter to the source to insure that the source was completely lowered into the lead pig.

The fencing around the radiation field included a 9 foot high chain link security fence topped with 3 strands of barbed wire (F1g. 2). This fence was located at a radius of 200 feet from the source and had a double gate at the lane which extends directly from . the control house to the source. A 4 strand barbed wire fence was located at a radius of 660 feet from the source. This fence served as a mild barrier to keep humans and livestock away from the study area. The lane leading from the barbed wire. fence, past the control house, to the security fence was also bordered by a 4 strand barbed wire fence. In addition to these șafety features, others were locked doors on the control house except when in use, heavy metal grills over 
0

0

(1)

0 
Fig. 2. Overall design of gamma field showing outer fence perimeter, lane and control house, securlty fence perimeter and layout of the six treatment sectors. The outer fence (barbed wire) enclosed 12.7 hectares ( 31.4 acres) and the security fence ( 9 feet high chain link) enclosed 1.17

hectares ( 2.88 acres). 
$(3)$

(1)

0

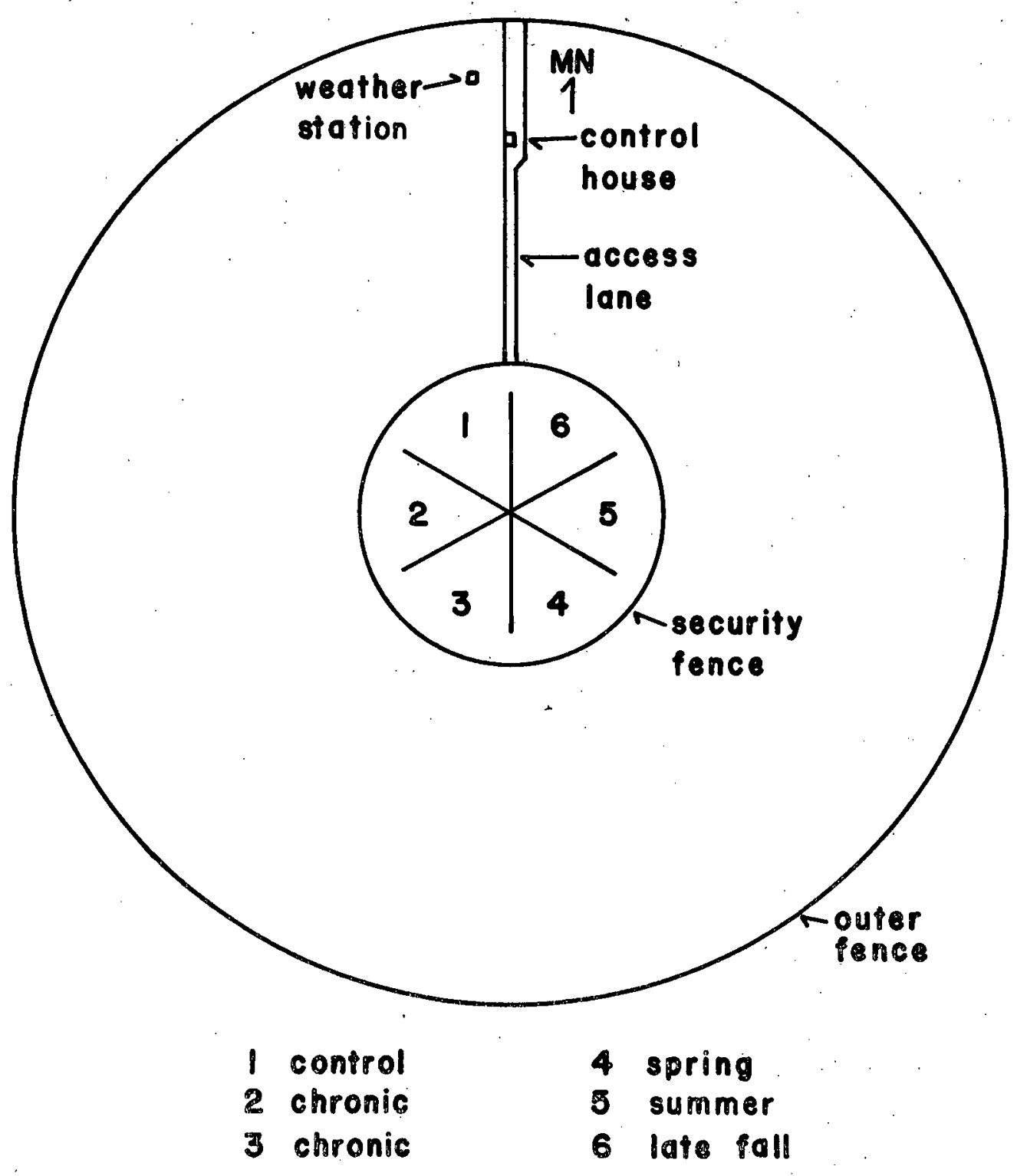

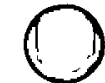


all windows of the control house, all gates fastened with a heavy chain and padlocked except when in use, radiation area warning signs no less than 50 feet apart on the security fence nor 100 feet apart on the barbed wire fence, a large illuminated warning sign at the entrance gate of the barbed wire fence and operation of the source only by authorized persons who were familiar with the details of the insta11ation. Many of these precautions were necessary because the source was left in the up position almost continually with up to 7 days between visits by department personnel. (See Appendix 2 for a copy of the operating procedures.)

A complete record was maintained of the use of the facility on a $\log$ sheet which was filled out each time a visit was made to the facility. Information on the $\log$ sheet included the name of persons visiting the area, initial and final radiation survey and time of lowering and raising the source (See Appendix 2 for a copy of the log sheet.)

\section{$\underline{\text { Radiation Field }}$}

The nature of the radiation field was a result of the size and configuration of the source combined with the modifying effects of the sky-shine shield and supporting structures.

Mapping of the radiation field was done using $1.4 \times 1.4 \times 7 \mathrm{~mm}$ LIF rod thermoluminescent dosimeters (TLDs) obtained from the Harshaw Chemical Company (type 100). The TLDs were calibrated using a $50 \mathrm{Ci}$ ${ }^{60}$ Co source. During calibration and use all dosimeters were left in their original plastic vials and the vial was placed in a plastic holder which supported the TLD $2.5 \mathrm{~cm}$ above the soil surface. The 
total plastic thickness was $2 \mathrm{~mm}$ or more around the TLD to insure electronfc equilibrium.

Initial mapping of the radiation field was done on 9 January and 3 February 1969 to give information about the change in exposure rate with distance and angle. This information was used to finalize the experfmental design. More mapping was done during the course of the experiment and results from all readings were used to determine the characteristics of the radiation field (Fig. 3). The exposure rate versus distance curve, as measured with sky-shine shield in place and sectors. $1,4,5 \& 6$ shielded, is shown along with the theoretical inverse-square curve and the exposure rate curve for the shielded sectors. The measured values were from the center line of each sector. The higher actual values close to the source as compared to the theoretical values were probably due to the scatter from the large amount of lead used to shield some sectors. The measured values decreased with distance faster than the theoretical values because of the lead shot-filled rim on the sky-shine shield. There was a decrease in the fraction of the primary beam that reached the ground with increasing distance, starting from full primary beam up to approximately $7 \mathrm{~m}$, decreasing to no primary beam at approximately $32 \mathrm{~m}$. Beyond $32 \mathrm{~m}$ the radiation was composed entirely of scattered photons. Results of a preliminary study using a $1 \mathrm{CI}$ source of ${ }^{137} \mathrm{Cs}$ with a sky-shine shield configuration similar to the one used at the grassland study area indicated that the effective photon energy decreased with distance and was $.5 \mathrm{MeV}$ at $10.7 \mathrm{~m}, .35 \mathrm{MeV}$ at $30.6 \mathrm{~m}$ and $.28 \mathrm{MeV}$ at $42.7 \mathrm{~m}$ (Whicker and Dah1, 1968). 
21

0

(8)

0

0 
F1g. 3. Exposure rate vs distance for open and shielded sectors at the grassland irradiation gamma field and the theoretical (inverse square) curve for $8750 \mathrm{ci}$ of $137 \mathrm{Cs}$ attenuated by 0.237 inches of stainless steel. 
0

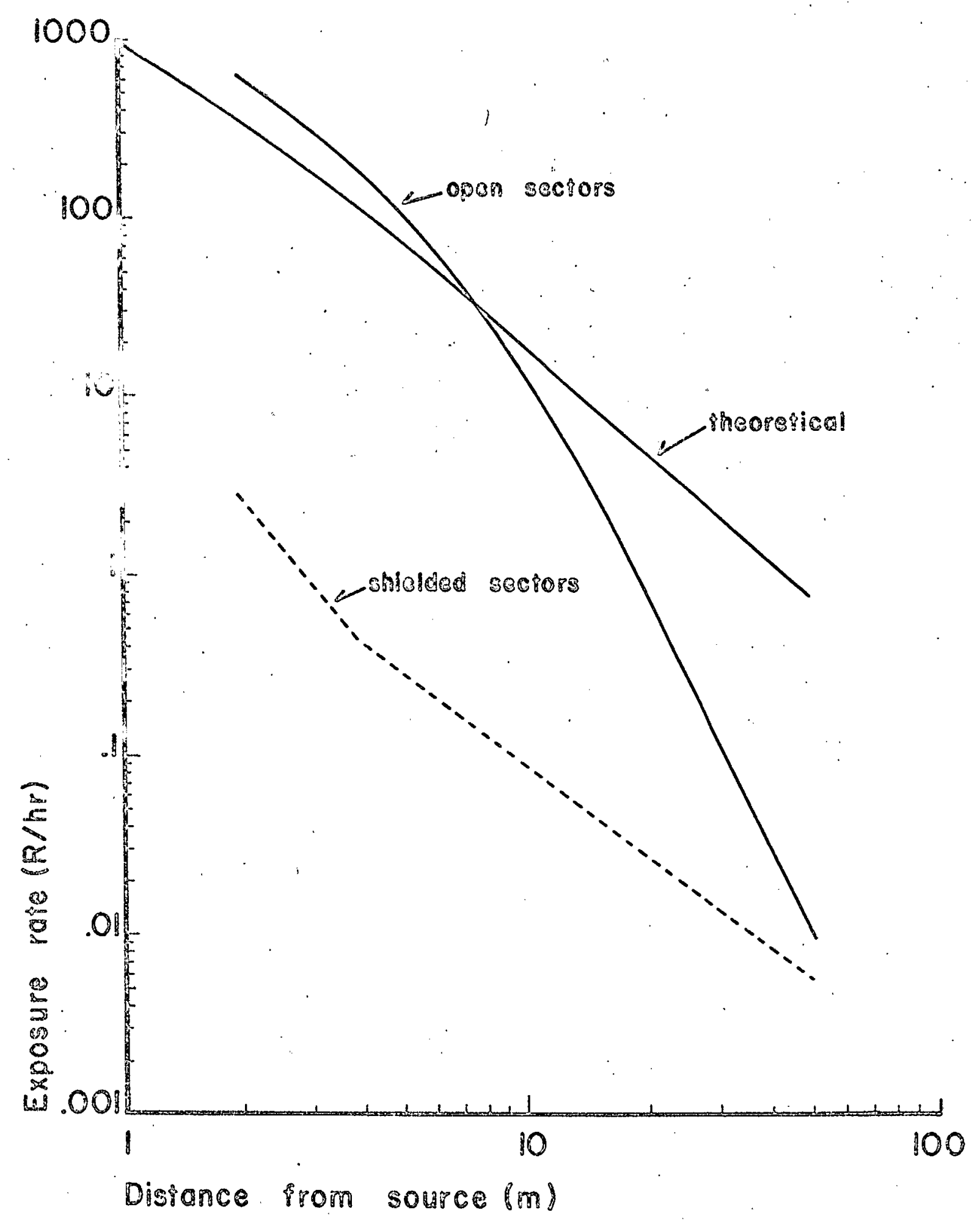

0

0

0 
The exposure rate did not vary with angle except for 5 to $7^{\circ}$ on either side of the sky-shine shield support plates. This eliminated the use of $15^{\circ}$ where each of the six support plates perturbed the radiation fleld. This left $45^{\circ}$ for each sector for use in the study.

During the summer of 1969, Car1 R. Throckmorton, a participant in the Summer Institute of Radiation Biology, mapped the field vertically using the same TLDs. No variation in the field was found from the soil surface to $50 \mathrm{~cm}$ above the soil. There was an attenuation of the radiation with depth in the soil. His data were plotted as the ratio of exposure rate at a given depth to the exposure rate at the soil surface versus distance from the source (Fig. 4).

\section{Experimental Design}

The experimental design was determined by the objectives of the experiment and the limitations imposed by the radiation field. Point sources limit the overall pattern to a circle. The need to use 6 support plates for the sky-shine shield dictated the use of 6 sectors or treatment areas (Fig. 2). Space limitations for sampling prevented the use of more sub-divistons of the areas. Each sector was divided into 22 macroplots (Fig. 5), varying in distance from 2 to $50 \mathrm{~m}$ from the source, as measured along the soil surface from a ground level point directly beneath the center of the source to the back edge of the macroplot. The first 8 macroplots were 1 meter wide with the width of the rest adjusted to give an exposure rate decrease of approximately 50 per cent from one macroplot to the next. Two rows of 6 microplots were located in the center of each macroplot, along the back 
(1)

$\bigcirc$

○

0 
Fig. 4. Exposure rates at selected soil depths relative to surface value as a function of distance from the source. 


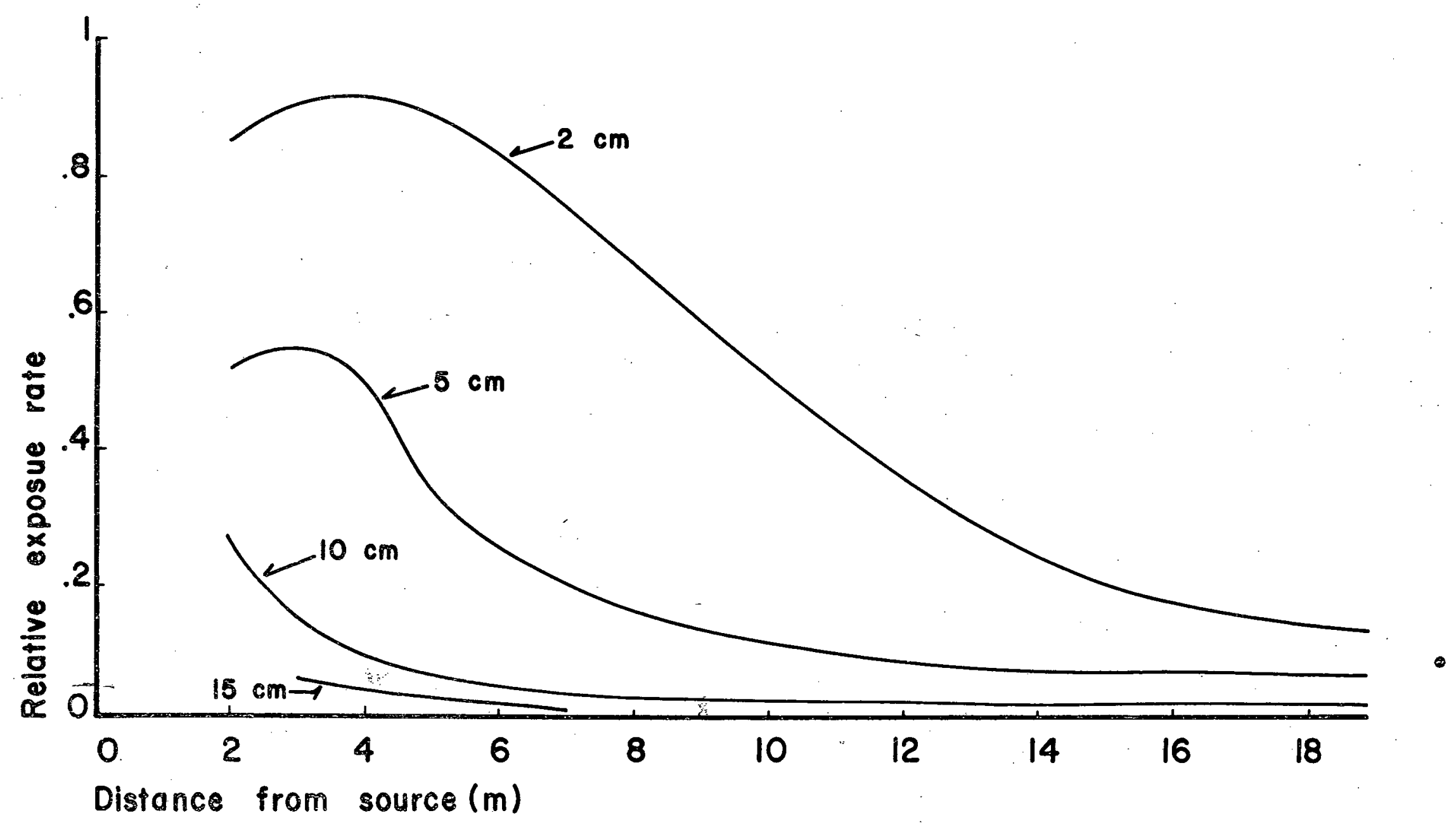


O

O

O

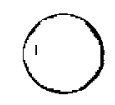


Fig. 5. Typical treatment sector plan showing location of macroplots within the sector. Exposure rate and distance measured at back edge of each macroplot are indicated. Macroplot 22 shows the arrangement of the microplots within each macroplot (not to scale) and the location of the walkway. 
(1)

(3)

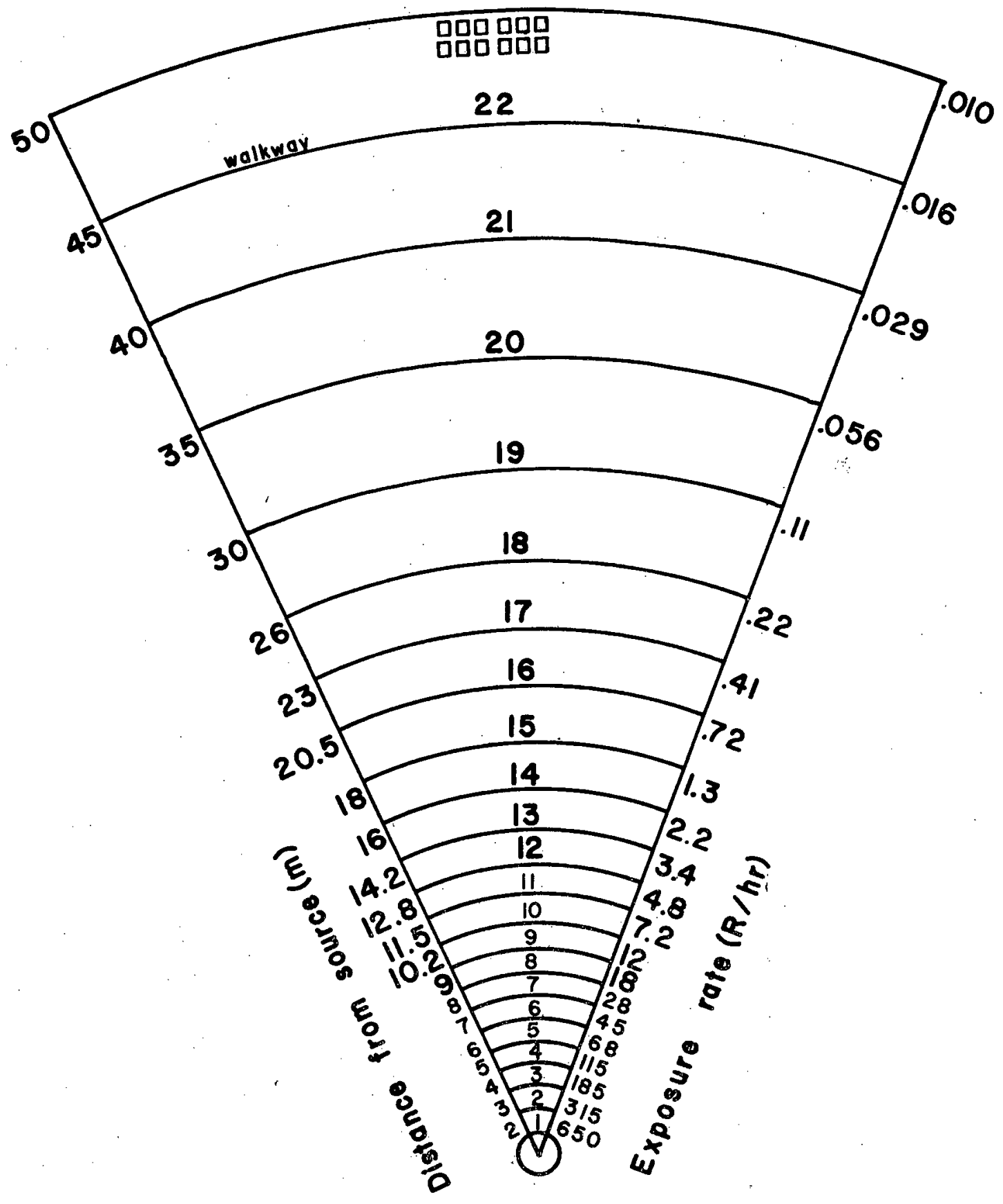

0 
edge. (Fig. 5). Each microplot was permanently located and was $25 \times 25 \mathrm{~cm}$. Each microplot was marked with two $\frac{1}{4} \times \frac{1}{2} \times 8$ inch plastic stakes which mated with locating rings on a portable quadrat frame.

The treatments were arbitrarily assigned to the 6 sectors with the restriction that the 2 sectors towards the control house would not be chronically exposed (Fig. 2). Sector 1, the control sector, was shielded during the entire experiment and was subject only to scattered radiation (Fig. 3). Sectors 2 and 3 were designated the chronic sectors and were exposed the entire time of the experiment. The results reported in this thesis include data through the fall of 1970 although the chronically exposed sectors will continue to be exposed for several years. Sectors $4,5 \& 6$ were designated the semiacute seasonal sectors and were exposed for approximately 30 days during spring, summer and late fall, respectively. At all other times, these 3 sectors were shielded with at least 8 inches of lead and recelved only scattered radiation. During the course of the experiment, the source was lowered into the shielding pig for up to 4 hours each day for work within the security fence area. The source was lowered only when necessary and no attempt was made to keep the number of hours per week with the source up uniform from one period of time to another. The spring treatment sector was exposed from 3 April 1969 to 6 May 1969, the summer treatment sector from 2 July 1969 to 5 August 1969 and the late fall treatment sector from 3 December 1969 to 7 January 1970 giving an average exposure of 796 hours for each sector (corrected for source down time). 


\section{Methods}

Sampling of each microplot to measure community structure and spectes sensitivity was accomplished by the use of a $25 \times 25 \mathrm{~cm}$. quadrat placed over permanent1y positioned locating stakes so that successive sampling data were obtained from the same areas. Sampling was done 3 times each year for the control (sector 1) and chronic exposure sectors (sectors $2 \& 3$ ); early April (4-60 and 4-70), mid to late June (6-69 and 6-70) and late September (9-69 and 9-70) except for September 1970 when only sector 2 (chronic) was sampled. For the seasonally exposed sectors, pre-irradiation data were taken in early April (4-69) for the spring exposed sector, early July (7-69) for the summer exposed sector and late September (9-69) for the late fall exposed sector. After the pre-irradiation data were taken, data were taken in the seasonally exposed sectors at the same time data were taken In the chronically exposed sectors including September 1970. The density. In stems per quadrat was recorded for each species except blue grama and pricklypear (Opuntia polyacantha). For blue grama, a $5 \times 5 \mathrm{~cm}$ nested quadrat was used and the basal ground area (per cent cover) was estimated. For pricklypear the number of lobes in each $25 \times 25 \mathrm{~cm}$ quadrat was recorded with at least $\frac{1}{2}$ lobe in the quadrat being necessary before counting that lobe.

The density data were converted to stems per square meter, cover (1n per cent) for blue grama and lobes per square meter for pricklypear. From the density data, a species list was tabulated for each group of microplots. From this, a coefficient of community (CC) was calculated using the relationship

$$
C C=2 C /(A+B)
$$


where A equals the number of spectes in a control macroplot, B equals the number of species in an exposed macroplot and $C$ equals the number of species common to each area (Greig-Smith, 1964). The coefficient of community value reported for each macroplot was the result of calculating 19 separate values and taking the average. These 19 values were obtained by calculating a CC value using control plot 4, then control plot 5, and so on, to control plot 22. This was done because there was no inherent reason to match any one control plot with any one particular treated plot. Control sector macroplots 1 through 3 were not used because they were in an exposure rate area (due to scattered radiation) that might result in radiation damage.

From the density data, frequency of occurrence in the 12 microplots was calculated. From the frequency data, a diversity index (D) was calculated for each macroplot using the relationship

$$
D=-1.433 \sum_{i=1}^{n} P_{i} \ln \left(P_{i}\right)
$$

where $P_{1}$ was the frequency of occurrence of the ith species (Patten, 1962).

Also, the density data were used to determine survival for selected species and the LD50 and/or LD100 for these species were estimated.

The stage of development was recorded for selected species at approximately weekly intervals. These data were used to determine a phenological index.

In late August 1969 and in September 1970 a visual estimate, patterned after the method described by Pechanec and Pickford (1937), was made of the grass-sedge component of the standing crop. This 
estimate was determined for each microplot. Calibration was accomplished by clipping plots outside the radiation zone. After the 1970 visual estimate was made, all microplots were clipped and the standing crop was divided into grass-sedge, forb and shrub components. Aliquots were dried at $95^{\circ} \mathrm{C}$ unt 11 the mass stabilized to calculate dry weight. Photographs were taken of approximately 1 square meter where the mfcroplots were located. These were taken with a Canon FTQL $35 \mathrm{~mm}$ SLR camera mounted on a tripod and a Canon FL $28 \mathrm{~mm}$ wide-angle lens. and repeated at intervals throughout the 1969 and 1970 growing seasons. The tripod was placed at the same location each time so that comparIsons could be made through time. During the early part of the 1969 season, Kodak Plus-X film was used. Since then, Kodak Panatomic-X film was used. Approximately 1100 black and white photographs were taken. 
CHAPTER 3

RESULTS

The major purpose of this study was to determine the effects of radiation on the structure of the vegetation under study. Therefore, most of the effort was applied to the community characteristics such as coefficient of community and diversity. This was done partly to determine the sensitivity of the shortgrass plains vegetation to radiation and partly to compare these results to other studies on natural plant systems which were reported in this manner. It was understood that the sensitivity of the species present determined the sensitivity of the vegetation in total. The sensitivity of a few spectes was reported to give an indication of the range of sensitivities encountered and to indicate a possible relationship between species sensitivity and growth form.

\section{Zonation}

The overall result of the irradiation was the formation of 3 zones which. seemed to occur regardless of types of effects examined. The zone nearest the source was a region of complete lethality in which all individuals of all species were apparently killed. The width of this "lethal" zone varied with time and the season of exposure. In the second zone, the radiation eliminated some species and killed individuals of some species and/or reduced growth. The effect of the radiation was proportional to $\mathrm{dx} / \mathrm{x}(\log \mathrm{x})$ where $\mathrm{x}$ represents the exposure rate. This "effects" zone varied in width, in the actual ratio of $\mathrm{dx} / \mathrm{x}$ and with time and season of exposure. The third zone was the "no effects" zone where methods used did not detect any effect of the radiation on the parameters under study. In order to analyse 
the effects of the radiation and to determine the boundaries of the zones, 2 methods were used. The first was a linear regression using the model $\left(y=b_{0}+b_{1} \log x\right)$ to delineate the "effects" zone. The second method included the data from all the macroplots and fit the data to the model

$$
y=\pi / 2 k+1 / k \arctan (-x / A+B)
$$

using a non-linear, least-squares $f i t$, where $y$ was the parameter under consideration, $k$ was defined by $\pi / k$, where $\pi / k$ equaled the "no effects" average, $x$ was the $10 g$ (exposure rate), and $A$ and $B$ were constants to be determined.

For the linear regression the following method was used to find the boundary between the "effects" and the "no effects" zones. Starting in the sloping portion of the data, 5 consecutive ordered pairs of data were fit to the linear model

$$
y=b_{0}+b_{1} \log x
$$

where $\mathrm{y}$ was the parameter under consideration and $\mathrm{x}$ was the exposure rate. If the slope $\left(b_{1}\right)$ was significantly different from zero (Snedecor, 1956) the ordered pair from the macroplot. nearest the source (of the 5 pairs used) was dropped and the next one was picked up on the other end of the pairs and the linear regression repeated. For example, if the first 5 pairs included data from macroplots 4, 5, $6,7, \& 8$ and the slope was significantly different from zero, then the data from macroplot 4 was dropped and the data from macroplot 9 was added so that the next regression was run on data from macroplots $5,6,7,8 \& 9$. In every regression, 5 ordered pairs were used. This was continued until the slope did not differ significantly from zero. 
Then the center ordered pair from these 5 pairs was picked as the first pair in the "no effects" zone and those ordered pairs closer to the source were considered to be in the "effects" zone. The "effects" zone continued in the direction of higher exposure rates up to and Including the first totally lethal macroplot of the "lethal" zone. After establishing the boundaries of the 3. zones, the data from the "no effects" zone were used to establish a "no effects" average value of the parameter under consideration. Then the data in the "effects" zone were fit to the linear model. A 50 per cent exposure rate value was calculated to determine what exposure rate was necessary to give a response equal to 50 per cent of the "no effects" average. In order to give some idea of confidence limits about the 50 per cent value, a reverse regression was run on the data (i.e. $\log y=b_{0}+b_{1} x$ where $y$ was the rate and $x$ was the parameter under consideration) and exposure rates for \pm 2 standard errors of the 50 per cent value were calculated. A check on this method was made by drawing in confidence bands on the normal regression for some of the data and comparing the range in exposure rates from one confidence band to the next (at the 50 per cent value) to the range in exposure rates obtained by the reverse regression method. Agreement was very good and the reverse regression method was used in preference to the confidence band method because it involved only calculations and no hand plotting and interpolation were necessary. It is questionable whether the confidence limits obtained from the reverse regression could be used in any test of significance but I believe that the limits are useful for estimating the general significance of the 50 per cent values reported. 
The linear regression gave good results in the middle of the "effects" zone but failed to properly fit either end where a tapering effect seemed to exist. In nearly all cases the data had a reverse slgmoldal shape in the "effects" zone. The linear regression gave no prediction of such a shape. In order to fit this portion of the curve, 2 forms of reverse sigmoidal curves were tried. First, a form of the population curve was tried:

$$
y=k /\left(1+e^{a-r / x}\right)
$$

where $y$ was the parameter under consideration, $k$ was the "no effects" average, $r$ was a constant to be determined for best fit, a was the ratto $r / k$ and $x$ was the $\log$ (exposure rate). This fit some of the data very well but did not have enough flexibllity in shape and slope for a large fraction of the data. The arctan function was also tried and was found to fit the data very well except for the slope near the 50 per cent value which of ten had a larger absolute value than the data would indicate. However the 50 per cent effects values compared very well with those values calculated by the linear regression method.

\section{Coefficient of Community}

\section{Chronic Irradiation}

In the chronic sectors, the lethal zone for coefficient of community (CC) increased in size through 1969 but did not increase during 1970 (Table 2a). The effects zone receeded from the source and, after June 1969, the slope of the effects zone data remained approximately constant (Fig. 6). The exposure rate (in $\mathrm{R} / \mathrm{hr}$ ) to give a 50 per cent reduction of the "no effects" average CC value 
Table 2a. Coefficient of community as a function of exposure rate for chronic irradiation treatment at selected sampling dates. Irradiation was initiated 4-69.

\begin{tabular}{|c|c|c|c|c|c|}
\hline \multirow{2}{*}{$\begin{array}{l}\text { exposure } \\
\text { rate } \\
(\mathrm{R} / \mathrm{hr}) \\
\end{array}$} & \multicolumn{5}{|c|}{ sampling date } \\
\hline & $4-69$ & $6-69$ & $9-69$ & $4-70$ & $6-70$ \\
\hline 650 & .48 & .0 & & & \\
\hline 315 & .58 & .11 & & & \\
\hline 185 & .58 & .14 & & & \\
\hline 115 & .59 & .28 & .0 & .0 & .0 \\
\hline 68 & .52 & .37 & .06 & .04 & .01 \\
\hline 45 & .61 & .39 & .07 & .23 & .03 \\
\hline 28 & .63 & .47 & .36 & .46 & .11 \\
\hline 18 & .60 & .47 & .49 & .46 & .20 \\
\hline 12 & .70 & .60 & .50 & .53 & .46 \\
\hline 7.2 & .63 & .57 & .54 & .66 & .61 \\
\hline 4.8 & .54 & 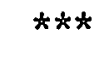 & .52 & .54 & .52 \\
\hline $\begin{array}{c}\text { "no effects" } \\
\text { mean }\end{array}$ & .60 & .57 & .61 & .59 & .59 \\
\hline
\end{tabular}

***These data were in the "no effects" zone and therefore not included in the table.

Table 2b. Parameters for fitted line $y=b_{0}+b_{1} \log x$ using data from Table $2 a$.

\begin{tabular}{|c|c|c|c|c|c|c|}
\hline sampling & & & standa & error & & \\
\hline date & $\mathrm{b}_{\mathrm{o}}$ & $\mathrm{b}_{1}$ & $b_{0}$ & $\mathrm{~b}_{1}$ & $\mathrm{R}^{2}$ & $\mathrm{LL} \leq \mathrm{CC} 50 \leq \mathrm{UL} *$ \\
\hline $6-69$ & .90 & -.31 & .04 & .02 & .97 & $73 \leq 88 \leq 107$ \\
\hline $9-69$ & .93 & -.45 & .10 & .07 & .87 & $18 \leq 24 \leq 33$ \\
\hline $4-70$ & 1.0 & -.47 & .11 & .08 & .86 & $22 \leq 31 \leq 42$ \\
\hline $6-70$ & .90 & -.49 & .11 & .08 & .87 & $14 \leq 18 \leq 25$ \\
\hline
\end{tabular}

*Lower limit (LL) and upper limit (UL) represent \pm 2 standard errors. See text for method of obtaining confidence limits on $\mathrm{CC} 50$. 
0

O

0

0 
F1g. 6. Coefficient of comunity as a function of exposure rate for the chronic irradiation treatment at selected

sampling dates. Irradiation was initiated 4-69. Tick marks at the top of each curve indicate the "no effects" mean. 


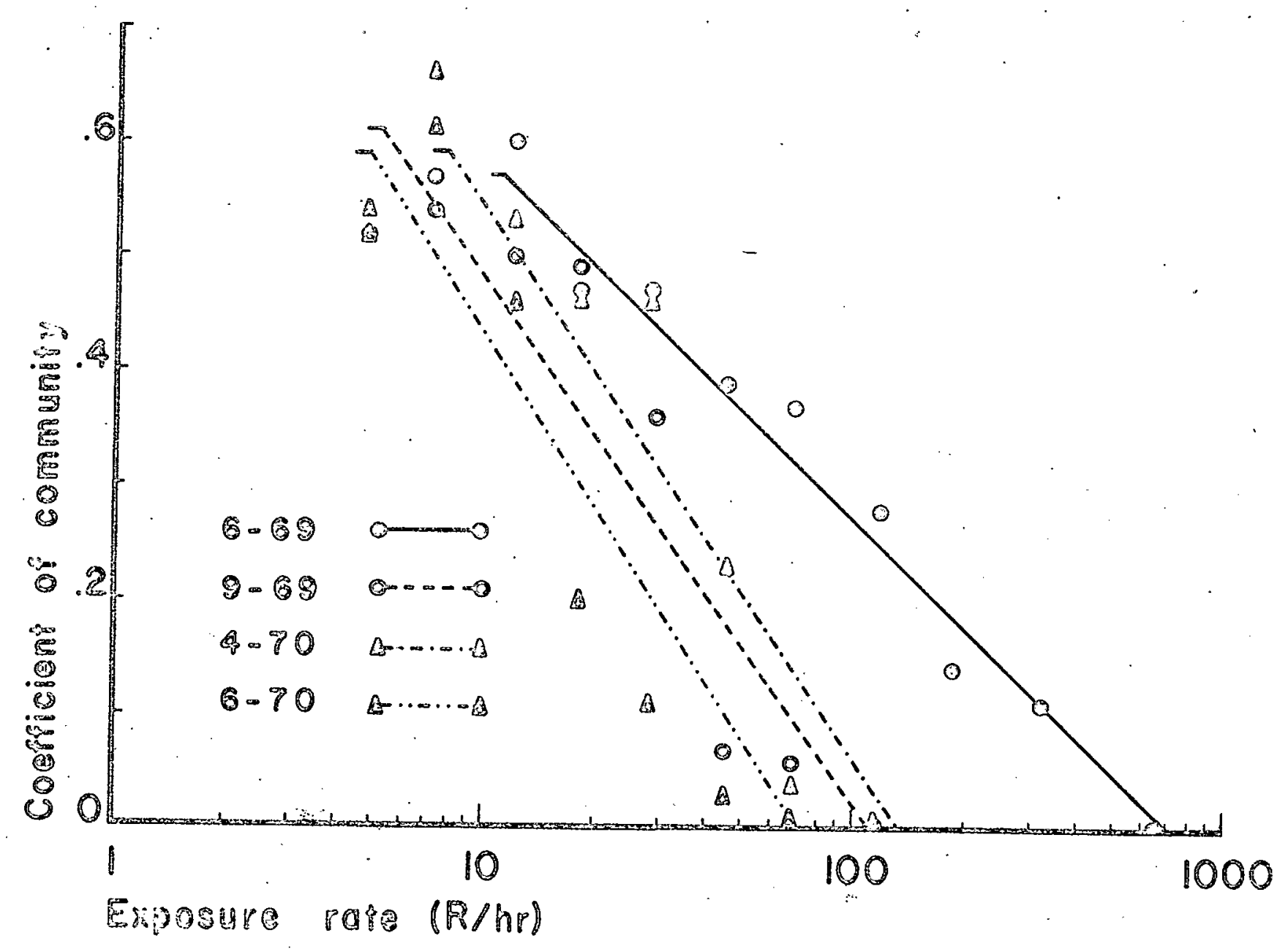


(CC50) decreased through 1969, with no further decrease by April 1970 and some decrease by June 1970 (Table 2b).

Using the results of the fit to the arctan function, the $\operatorname{cc} 50$ values were essentially the same as those from the linear regression nodel but the linear regression values averaged slightly lower (Table 3).

One major advantage of using the arctan model was that it provided curves that could be used to form a three-dimensional "picture" of the effect of the radiation on the CC (Fig. 7). For the chronically exposed sectors the $C C$ was at some average value $(0.6)$ prior to exposure ( 1 April 1969) and after exposure began there was a rapid decrease in CC to zero at the higher exposure rates. At somewhat lower exposure rates, the decrease in CC was slower during 1969, essentially constant from September 1969 to April 1970 and then decreased further by June 1970. At still lower exposure rates there was no change with time in the CC ("no effects" zone) except for slight seasonal variations.

\section{Seasonal Irradiation}

For the seasonally exposed sectors, the CC50 indicated that the shortgrass vegetation was most sensitive to gamma radiation in late fa11, least sensitive in summer and intermediate in spring (Tables $4 a$ and $\mathrm{b}$ and Fig. 8).

Examination of the three-dimensional diagrams indicated that for the spring exposure (Fig. 9) there was a sharp drop in CC by June 1969 at the higher and intermediate exposure rates and by september 1969 the CC values were increasing at all exposure rates where decreases 
Table 3. Fitted parameters for coefficient of community. as a function of exposure rate $(R / h r)$ for the equation $y=\pi / 2 k+1 / k a r c t a n(-x / A+B)$ for all irradiation treatments at selected sampling dates.

\begin{tabular}{c|c|c|c|c}
\hline \multirow{2}{*}{$\begin{array}{c}\text { Irradjation } \\
\text { treatment* }\end{array}$} & $\begin{array}{c}\text { sampling } \\
\text { date }\end{array}$ & \multicolumn{2}{|c|}{ parameter } & $\begin{array}{c}\text { CC50 } \\
\text { (R/hr) }\end{array}$ \\
\cline { 2 - 5 } chronic & $6-69$ & $.24 \pm .066$ & $8.2 \pm 2.3$ & 100 \\
& $9-69$ & $.082 \pm .021$ & $18 \pm 4.7$ & 29 \\
& $4-70$ & $.091 \pm .030$ & $17 \pm 5.5$ & 35 \\
& $6-70$ & $.065 \pm .017$ & $19 \pm 5.0$ & 17 \\
& $6-69$ & $.20 \pm .061$ & $11 \pm 3.5$ & 206 \\
spring & $9-69$ & $.17 \pm .079$ & $14 \pm 6.5$ & 260 \\
summer & $9-70$ & $.31 \pm .088$ & $6.7 \pm 1.9$ & 120 \\
late fall & $6-70$ &
\end{tabular}

*Chronic irradiation initiated 4-69; spring, summer and late fall treatments applied in April, July and December, respectively, in 1969. 
0

0

(1)

0 
Fig. 7. Coefficient of community as a function of exposure rate and time after inftiation of the chronic irradiation treatment. 


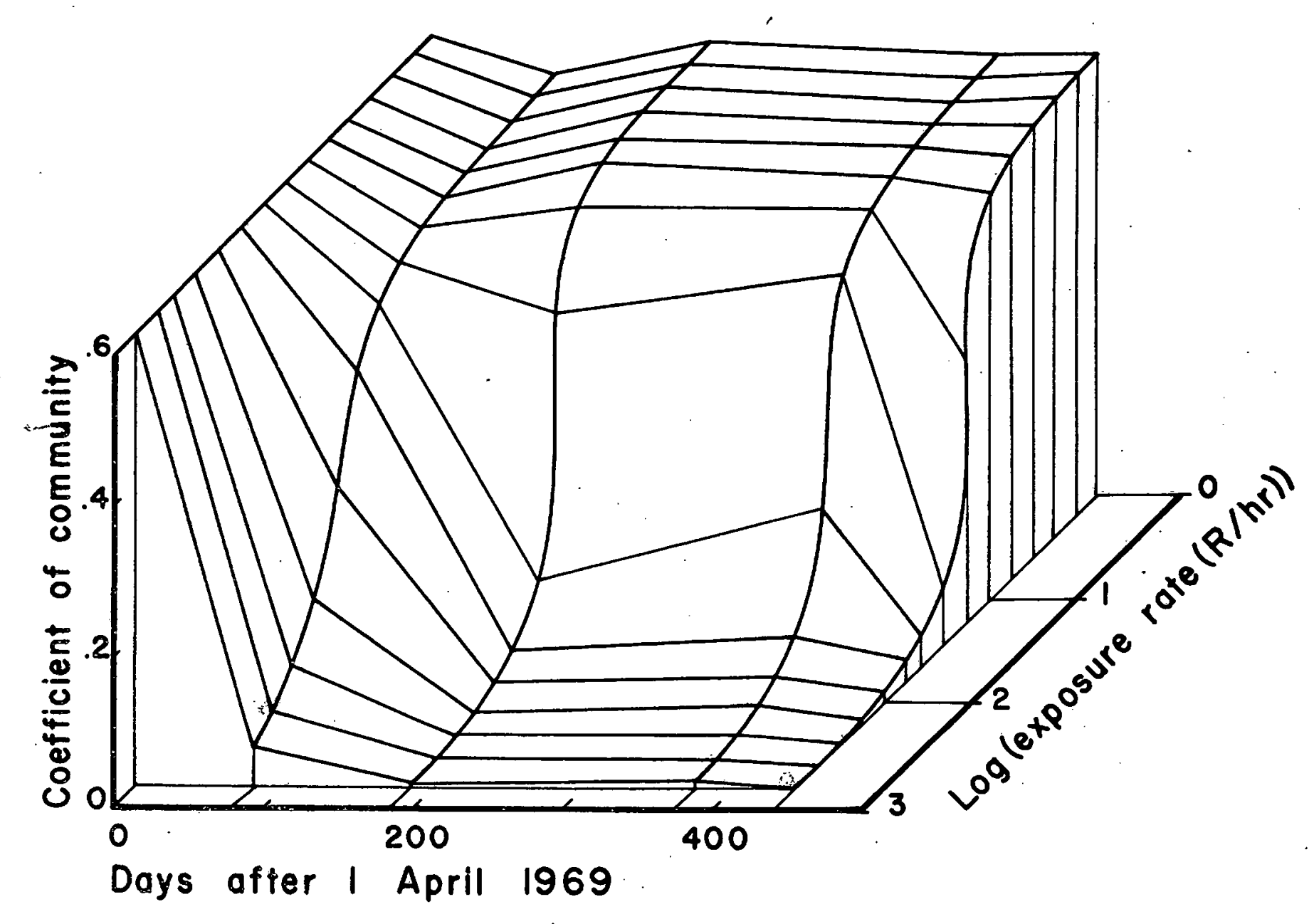


Table 4a. Pre and post irradiation coefficient of community as a function of exposure rate for seasonal irradiation treatments.

\begin{tabular}{|c|c|c|c|c|c|c|}
\hline \multirow{3}{*}{$\begin{array}{c}\text { exposure } \\
\text { rate } \\
\text { (R/hr) }\end{array}$} & \multicolumn{6}{|c|}{ season of exposure } \\
\hline & \multicolumn{2}{|c|}{ spring $(4-69)$} & \multicolumn{2}{|c|}{ summer $(7-69)$} & \multicolumn{2}{|c|}{ late fal1(12-69) } \\
\hline & $4-69 *$ & $6-69$ & $6-69$ & $9-69$ & $9-69$ & $6-70$ \\
\hline 650 & .66 & .0 & .59 & .0 & .38 & .0 \\
\hline 315 & .56 & .21 & .63 & .37 & .54 & .16 \\
\hline 185 & .66 & .36 & .67 & .34 & .54 & .32 \\
\hline 115 & .63 & .36 & .70 & .55 & .37 & .27 \\
\hline 68 & .66 & .51 & .62 & .62 & .54 & .29 \\
\hline 45 & $* * *$ & $\star \star \star * *$ & $\star * *$ & 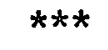 & .54 & .47 \\
\hline 28 & 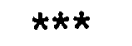 & $\star * *$ & 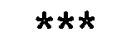 & $* * *$ & .59 & .51 \\
\hline 18 & *** & $\star \star \star *$ & *** & *** & .55 & .59 \\
\hline 12 & 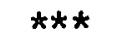 & $\star \star * \star$ & $\star \star \star *$ & $* * *$ & .59 & .64 \\
\hline $\begin{array}{l}\text { "no effects" } \\
\text { mean }\end{array}$ & .56 & .58 & .59 & .63 & .61 & .57 \\
\hline
\end{tabular}

*First column for each exposure gives pre irradiation values, the second column gives post irradiation values.

***These data were in the "no effects" zone and therefore not included in the table.

Table 4b. Parameters for fitted line $y=b_{0}+b_{1} \log x$ using data from Table $4 a$.

\begin{tabular}{|c|c|c|c|c|c|c|}
\hline season of & & & standar & error & & \\
\hline exposure & $\mathrm{b}_{\mathrm{o}}$ & $\mathrm{b}_{1}$ & $\mathrm{~b}_{\mathrm{o}}$ & $\mathrm{b}_{1}$ & $\mathrm{R}^{2}$ & $\mathrm{LL} \leq \mathrm{CC} 50 \leq \mathrm{UL} *$ \\
\hline spring & 1.4 & -.49 & .15 & .06 & .95 & $160 \leq 195 \leq 240$ \\
\hline summer & 1.6 & -.60 & .27 & .11 & .90 & $180 \leq 240 \leq 325$ \\
\hline late fall & 1.0 & -3.5 & .06 & .03 & .94 & $95 \leq 120 \leq 155$ \\
\hline
\end{tabular}

*Lower limit (LL) and upper limit (UL) represent \pm 2 standard errors. 
O

0

(1)

0 
Fig. 8. Coefficient of community as a function of exposure rate for seasonal irradiation treatment. Tick marks at the top of each curve indicate the "no effects" mean. Data were collected 10, 13, and 28 weeks after the initiation of irradiation of the spring, summer and late fall exposure treatments, respectively. 


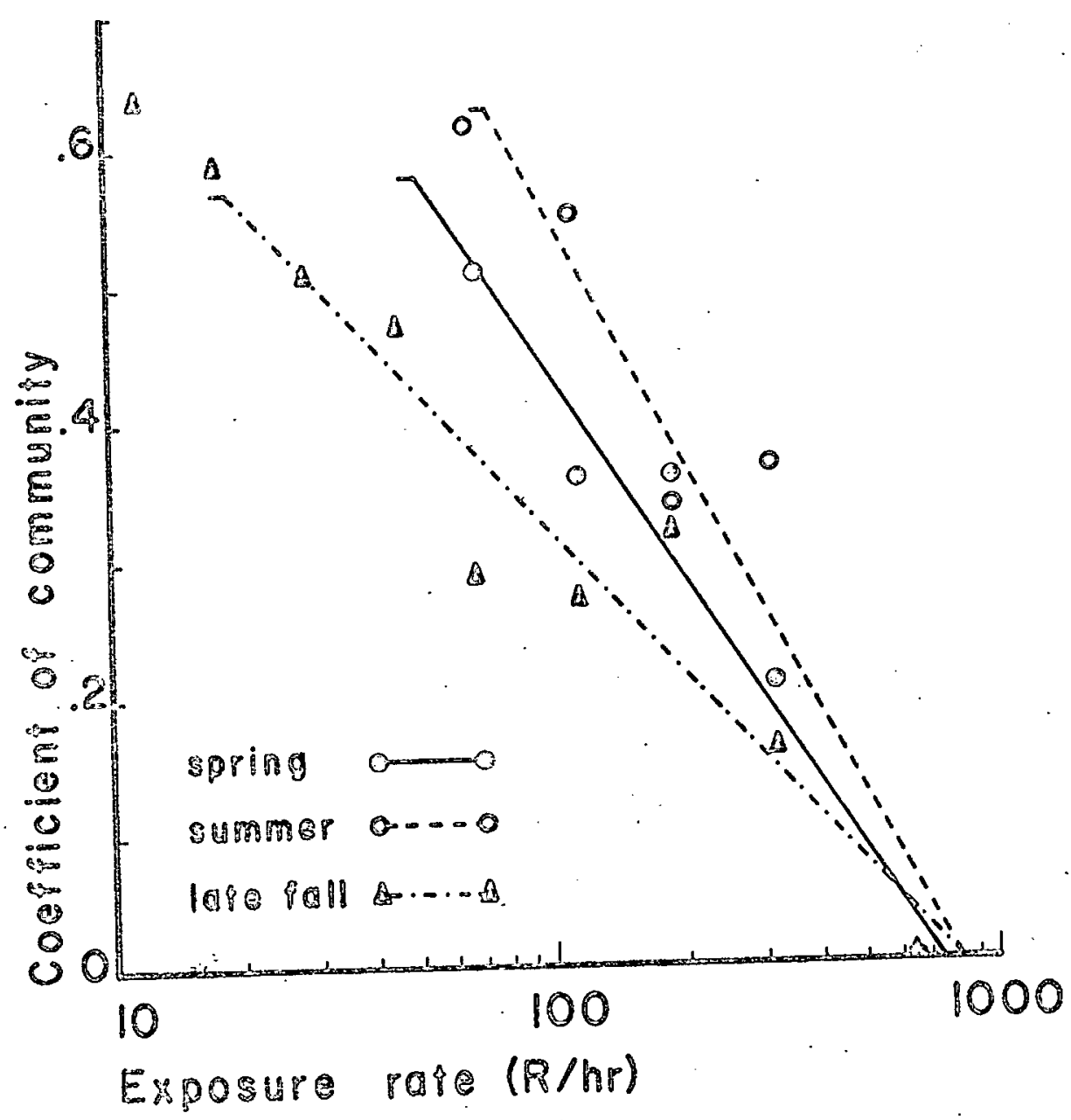


0

(1)

0

0 
F1g. 9. Coefficient of community as a function of exposure rate and time for the spring irradiation treatment. The dark parallelogram on the horizontal axis (time) represents the period of irradiation. 


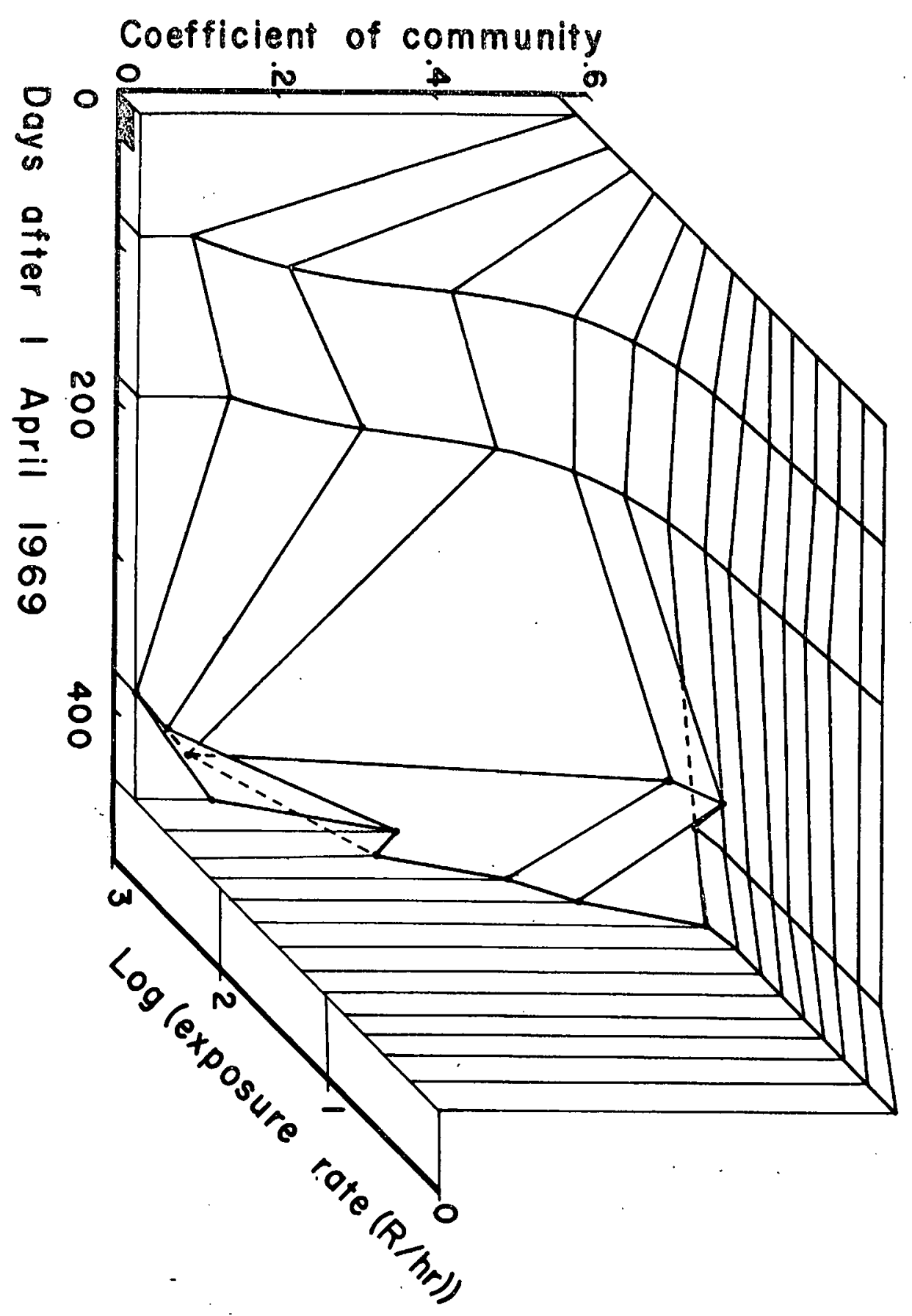

0

O 
had occurred. By April 1970 the data no longer fit the arctan function and the actual data were plotted in Fig. 9 for the first 6 exposure rates and the "no effects" average was plotted for the rest of the curve.

The summer exposure (Fig. 10) resulted in the same general pattern with the July 1970 data not fitting the arctan function.

There was no indication of radiation damage, as measured by the coeffictent of community, by Apri1 1970 for the December exposed sector (FIg. 11). By June 1970, damage was apparent and the arctan function adequately described the vegetation response.

\section{Diversity Index}

In general, the response of the shortgrass plant community to radiation, as measured by diversity, closely paralled the response as measured by coefficient of community with diversity being a more sensitive measurement of radiation damage. The 50 per cent values

for the diversity index (DI50) averaged 70 per cent of the CC50 values.

\section{Chronic irradiation}

For the chronically exposed sectors, the diversity decreased through June 1970 without any further decrease being evident by September 1970. The slight increase of the 50 per cent value for Apri1 1970 over September 1969 that was apparent in the coefficient of community data could not be seen in the diversity data (Tables $5 a$ and $b$ and Fig. 12). The DI50 results, as determined by the fit to the arctan function were essentially the same as the DI50 values obtained by the fit to the linear regression model (Table 6). 
0

0

(1)

0 
Fig. 10. Coefficient of community as a function of exposure rate and time for the summer irradiation treatment. The dark parallelogram on the horizontal axis (time) represents the period of Irradiation. 


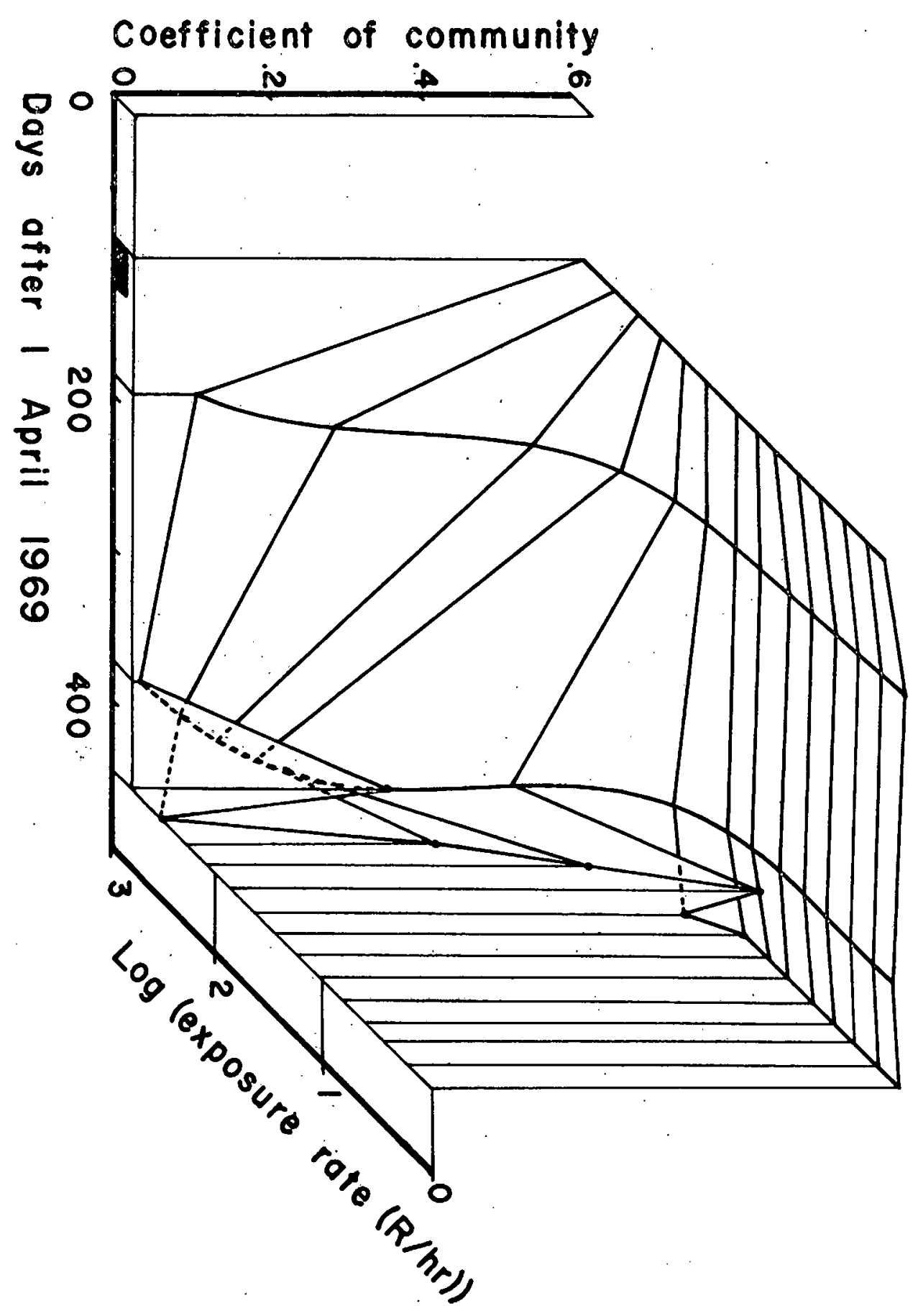

0

0 
O

0

O

0 
Fig. 11. Coefficient of community as a function of exposure rate and time for the late fall irradiation treatment. The dark parallelogram on the horizontal axis (time) represents the period of irradiation. 


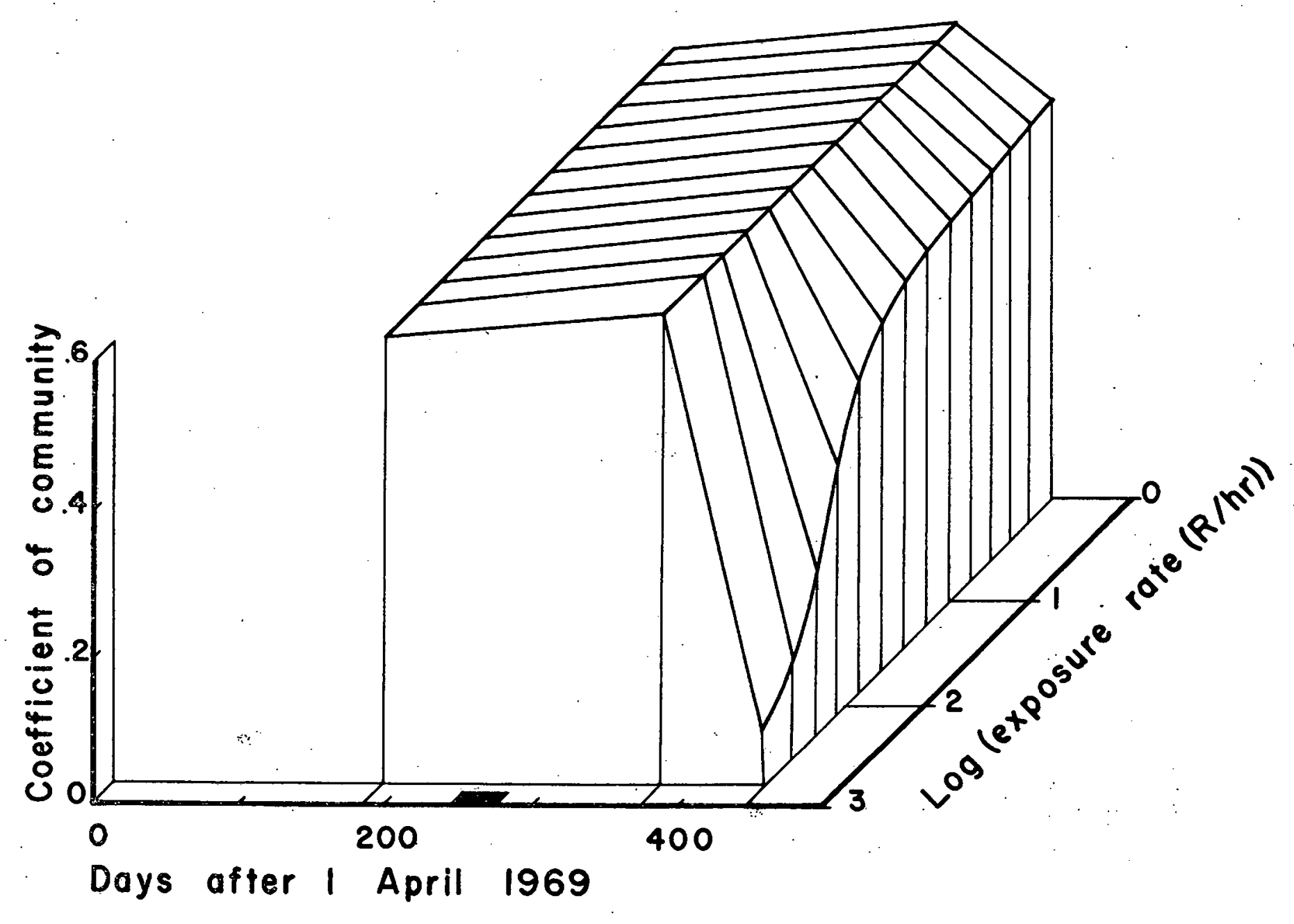


Table 5a. Diversity index as a function of exposure rate for chronic irradiation treatment at selected sampling dates. Normalized for seasonal fluctuations to the June 1970 control sector mean of 4.4. Irradiation was inftiated 4-69.

\begin{tabular}{|c|c|c|c|c|c|c|}
\hline \multirow{2}{*}{$\begin{array}{c}\text { exposure } \\
\text { rate } \\
\text { (R/hr) }\end{array}$} & \multicolumn{6}{|c|}{ sampling date } \\
\hline & $4-69$ & $6-69$ & $9-69$ & $4-70$ & $6-70$ & $9-70$ \\
\hline 650 & 1.22 & 0 & & & & \\
\hline 315 & 2.92 & .30 & & & & \\
\hline 185 & 4.69 & .52 & & & & \\
\hline 115 & 3.92 & 1.24 & 0 & 0 & 0 & 0 \\
\hline 68 & 2.87 & 1.46 & 1.25 & .48 & .13 & .73 \\
\hline 45 & 4.87 & 2.70 & 1.28 & 1.17 & .13 & 0 \\
\hline 28 & 2.13 & 3.10 & 2.86 & 3.15 & .72 & 2.12 \\
\hline 18 & 6.12 & 2.83 & 2.72 & 2.19 & .74 & 1.35 \\
\hline 12 & 4.78 & $* \star \star \star$ & 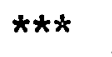 & $* * *$ & 2.27 & 2.55 \\
\hline $7: 2$ & 6.16 & $* * *$ & $* \star \star \star$ & $\star * *$ & 3.47 & 1.79 \\
\hline 4.8 & 4.61 & $* * *$ & $* * *$ & $\star * *$ & 3.23 & 4.75 \\
\hline
\end{tabular}

Table 5b. Parameters for fitted line $y=b_{o}+b_{1} \log x$ using data from Table $5 a$.

\begin{tabular}{c|c|c|c|c|c|c}
\hline \multirow{2}{*}{$\begin{array}{c}\text { sampling } \\
\text { date }\end{array}$} & $\mathrm{b}_{\mathrm{O}}$ & $\mathrm{b}_{1}$ & \multicolumn{2}{|c|}{ standard error } & \multirow{2}{*}{$\mathrm{R}^{2}$} & $\mathrm{LL} \leq \mathrm{DI} 50 \leq \mathrm{UL} *$ \\
\cline { 3 - 6 } $6-69$ & 5.9 & -2.2 & .5 & .3 & .92 & $34 \leq 47 \leq 64$ \\
$9-69$ & 7.5 & -3.6 & 1.2 & .7 & .90 & $23 \leq 31 \leq 40$ \\
$4-70$ & 7.2 & -3.5 & 1.9 & 1.1 & .76 & $17 \leq 27 \leq 42$ \\
$6-70$ & 5.1 & -2.8 & .7 & .5 & .86 & $8 \leq 11 \leq 16$ \\
$9-70$ & 5.4 & -2.7 & 1.0 & .7 & .71 & $9 \leq 14 \leq 24$ \\
\hline
\end{tabular}

*Lower limit (LL) and upper limit (UL) represent \pm 2 standard errors. 
O

O

O

(1) 
Fig. 12. Diversity index as a function of exposure rate for chronic irradiation treatment at selected sampling dates. Normalized for seasonal fluctuations to the June 1970 control sector mean of 4.4. Irradiation was inftiated 4-69. 


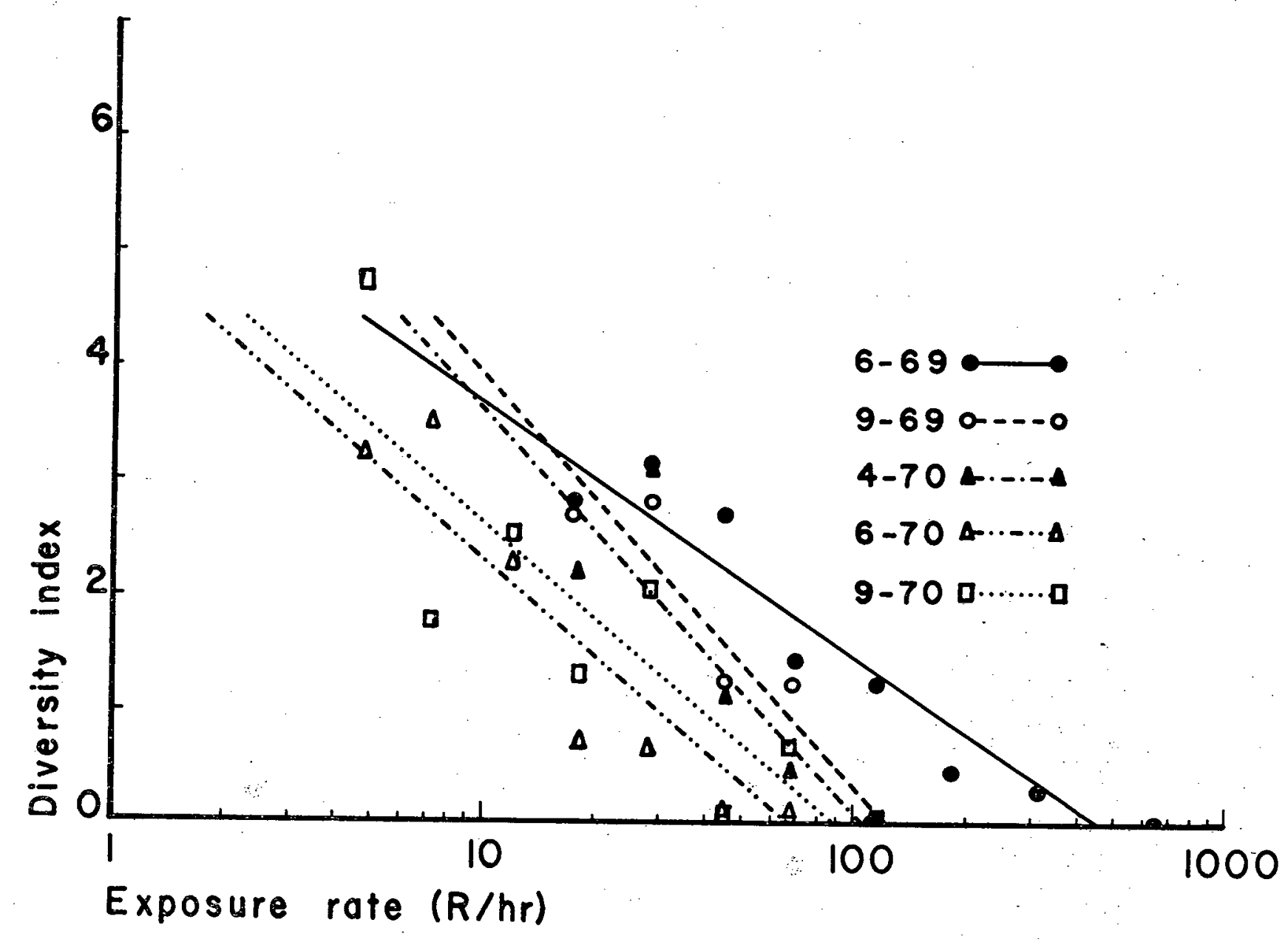


Table 6. Fitted parameters for diversity index as a function of exposure rate $(R / h r)$ for the equation $y=\pi / 2 k+1 / k \arctan (-x / A+B)$ for all irradiation treatments at selected sampling dates.

\begin{tabular}{c|c|c|c|c}
\hline $\begin{array}{c}\text { Irradiation } \\
\text { treatment* }\end{array}$ & $\begin{array}{c}\text { sampling } \\
\text { date }\end{array}$ & \multicolumn{2}{|c|}{ parameter } & $\begin{array}{c}\text { DI50 } \\
\text { (R/hr) }\end{array}$ \\
\cline { 2 - 5 } chronic & $6-69$ & $.21 \pm .049$ & $8.0 \pm 1.9$ & 50 \\
& $9-69$ & $.11 \pm .051$ & $14 \pm 6.4$ & 33 \\
& $4-70$ & $.20 \pm .085$ & $6.5 \pm 2.9$ & 21 \\
& $6-70$ & $.078 \pm .019$ & $14 \pm 3.4$ & 12 \\
& $9-70$ & $.18 \pm .072$ & $5.2 \pm 2.2$ & 8 \\
spring & $6-69$ & $.17 \pm .081$ & $11 \pm 5.2$ & 72 \\
summer & $9-69$ & $.096 \pm .10$ & $24 \pm 26$ & 180 \\
late fal1 & $6-70$ & $.18 \pm .078$ & $9.9 \pm 4.4$ & 58 \\
\hline
\end{tabular}

*Chronlc irradiation initiated $4-69$; spring, summer and late fall treatments applied in April, July and December, respectively, in 1969 . 
When analysing the diversity data using the three-dimensional plot (F1g. 13) an added variable, the change in diversity with season, becomes readily apparent. In order to reduce the effect of this added variable as much as possible, the data were normalized to the June 1970 control sector average (average value of 4.4) and plotted (Fig. 14). This allowed the effect of the radiation to become more apparent.

In the chronically exposed sectors, the diversity dropped sharply to zero at the higher exposure rates (Fig. 14). At somewhat lower exposure rates, the diversity decreased more slowly during 1969 and then dropped more sharply during 1970. There was still evidence of decreasing diversity by September 1970 .

\section{Seasonal irradiation}

For the seasonal exposures, the plant stand irradiated during summer was the most resistant and the spring and late fall irradiated plant stands showing approximately the same sensitivity with the DI50 slightly lower for the late fall irradiated plant stand (Tables 7a and $\mathrm{b}$ and Fig. 15).

There was a sharp decrease in diversity for the spring exposed sector by June 1969 followed by increasing diversity by September (Fig. 16). During 1970, the data no longer fit the arctan model and the first 5 points plotted for each sampling data were the actual data and the rest of each line was the "no effects" average. The diversity in the first 5 macroplots was erratic but tended to increase through 19.70 . 
O

O

0

(1) 
Fig. 13. Diversity index (not normalized for seasonal fluctuations) as a function of exposure rate and time after

inttiation of the chronic irradiation treatment. 
0

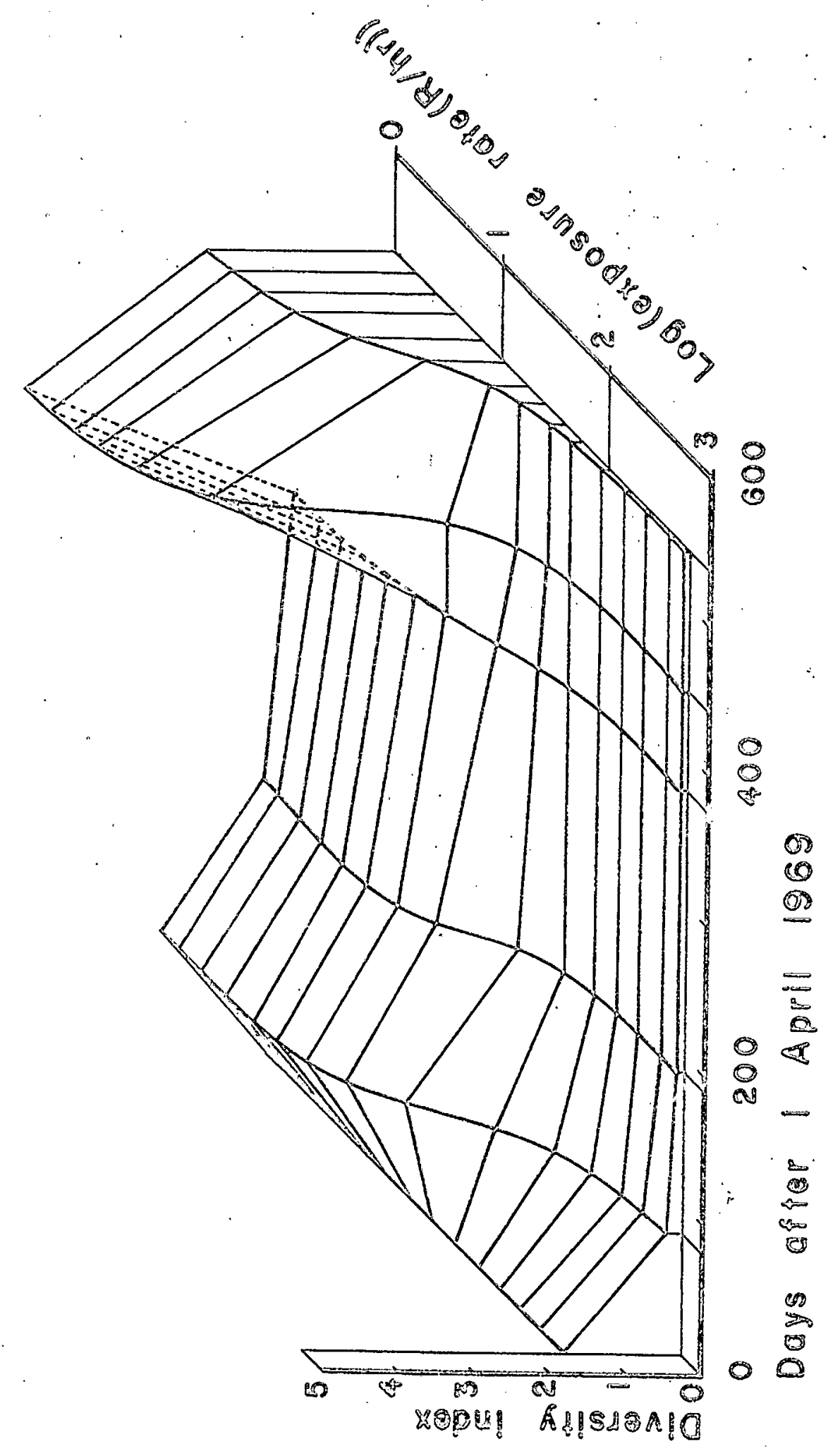


0

O

(1)

O 
F1g. 14. Diversity index as a function of exposure rate and time after initiation of the chronic irradiation treatment. Normalized for seasonal fluctuations to the June 1970 control sector mean of 4.4 . 


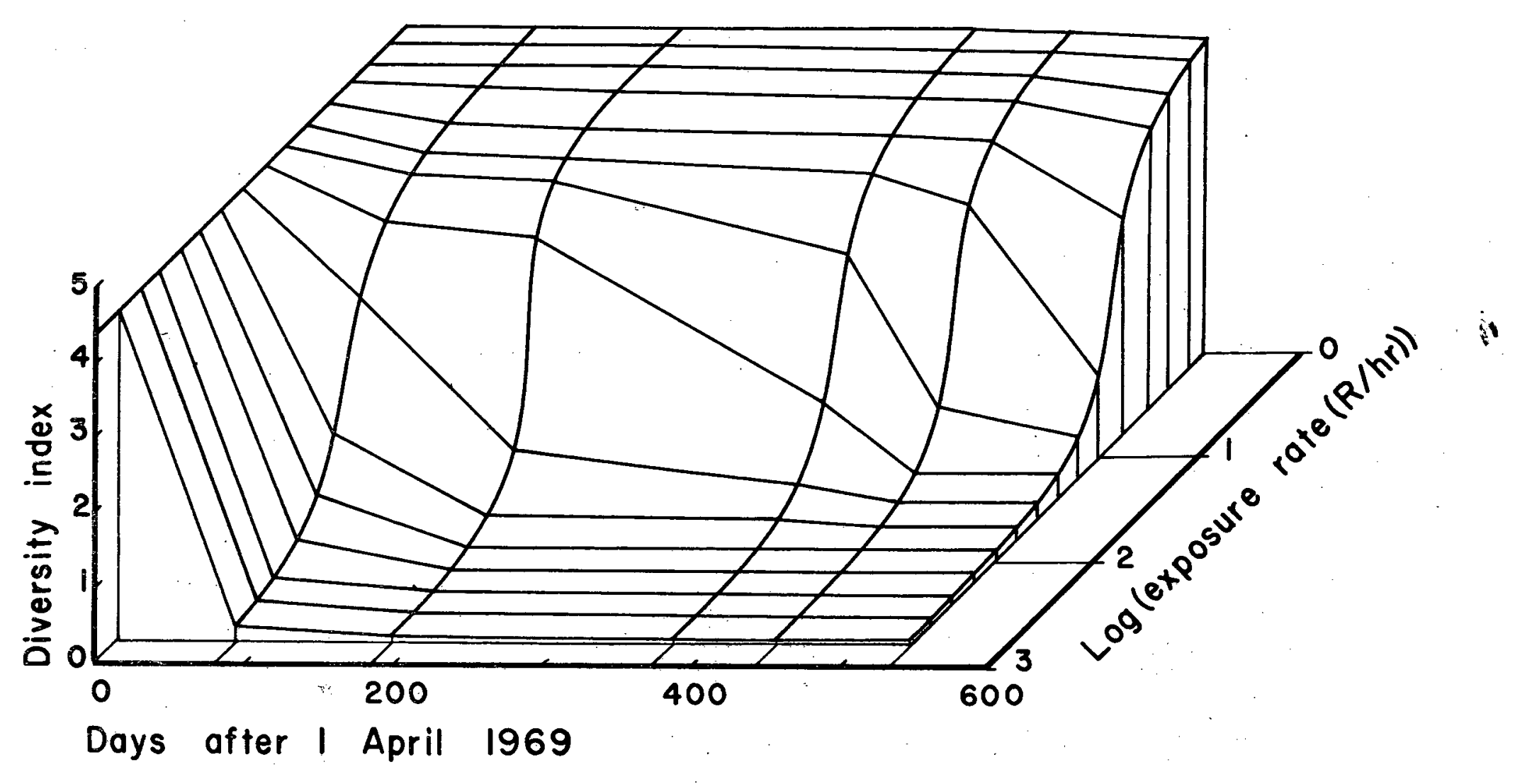


Table 7a. Pre and post irradiation diversity index as a function of exposure rate for seasonal irradiation treatments. Normalized for seasonal fluctuations to the June 1970 control sector mean of 4.4 .

\begin{tabular}{c|c|c|c|c|c|c}
\hline \multirow{2}{*}{$\begin{array}{c}\text { exposure } \\
\text { rate } \\
(\mathrm{R} / \mathrm{hr})\end{array}$} & \multicolumn{6}{|c|}{ season of exposure } \\
\cline { 2 - 7 } & \multicolumn{6}{|c|}{ spring(4-69) } \\
\cline { 2 - 7 } 650 & 1.81 & 0 & 6.03 & 0 & 3.62 & 0 \\
315 & 3.12 & .67 & 6.28 & .71 & 4.67 & .43 \\
185 & 6.02 & 1.13 & 5.89 & 1.90 & 7.14 & 1.25 \\
115 & 2.83 & 1.06 & 5.72 & 4.51 & 3.18 & 1.98 \\
68 & 4.82 & 2.16 & 4.45 & 4.91 & 6.09 & 1.28 \\
45 & 5.61 & 4.05 & 5.20 & 7.03 & 5.99 & 3.89 \\
28 & $* * *$ & $* * *$ & $* * *$ & $* * *$ & 3.97 & 2.85 \\
\hline
\end{tabular}

*First column for each exposure gives pre irradiation values, the second column gives post irradiation values.

***These data were in the "no effects" zone and therefore not included in the table.

Table 7b. Parameters for fitted line $y=b_{0}+b_{1} \log x$ using data from Table $7 a$.

\begin{tabular}{|c|c|c|c|c|c|c|}
\hline \multirow{2}{*}{$\begin{array}{l}\text { season of } \\
\text { exposure }\end{array}$} & \multirow[b]{2}{*}{$b_{0}$} & \multirow[b]{2}{*}{$\mathrm{b}_{1}$} & \multicolumn{2}{|c|}{ standard error } & \multirow[b]{2}{*}{$\mathrm{R}^{2}$} & \multirow[b]{2}{*}{$\mathrm{LL} \leq \mathrm{DI} 50 \leq \mathrm{UL} *$} \\
\hline & & & $b_{0}$ & $\mathrm{~b}_{1}$ & & \\
\hline spring & 8.1 & -3.0 & 1.6 & .7 & .81 & $55 \leq 90 \leq 140$ \\
\hline summer & 17 & -6.2 & 2 & .8 & .94 & $175 \leq 222 \leq 280$ \\
\hline late fall & 6.8 & -2.5 & 1.3 & .6 & .76 & $45 \leq 74 \leq 120$ \\
\hline
\end{tabular}

* Lower limit (LL) and upper limit (UL) represent \pm 2 standard errors. 
13

0

0

0

() 
Fig. 15. Diversity index as a function of exposure rate for spring, summer and late fall exposure to radiation. Data were collected 10,13 and 28 weeks after initiation of irradlation of the spring, summer and late fall exposure treatments, respectively. Normalized for seasonal fluctuations to the June 1970 control sector mean of 4.4 . 


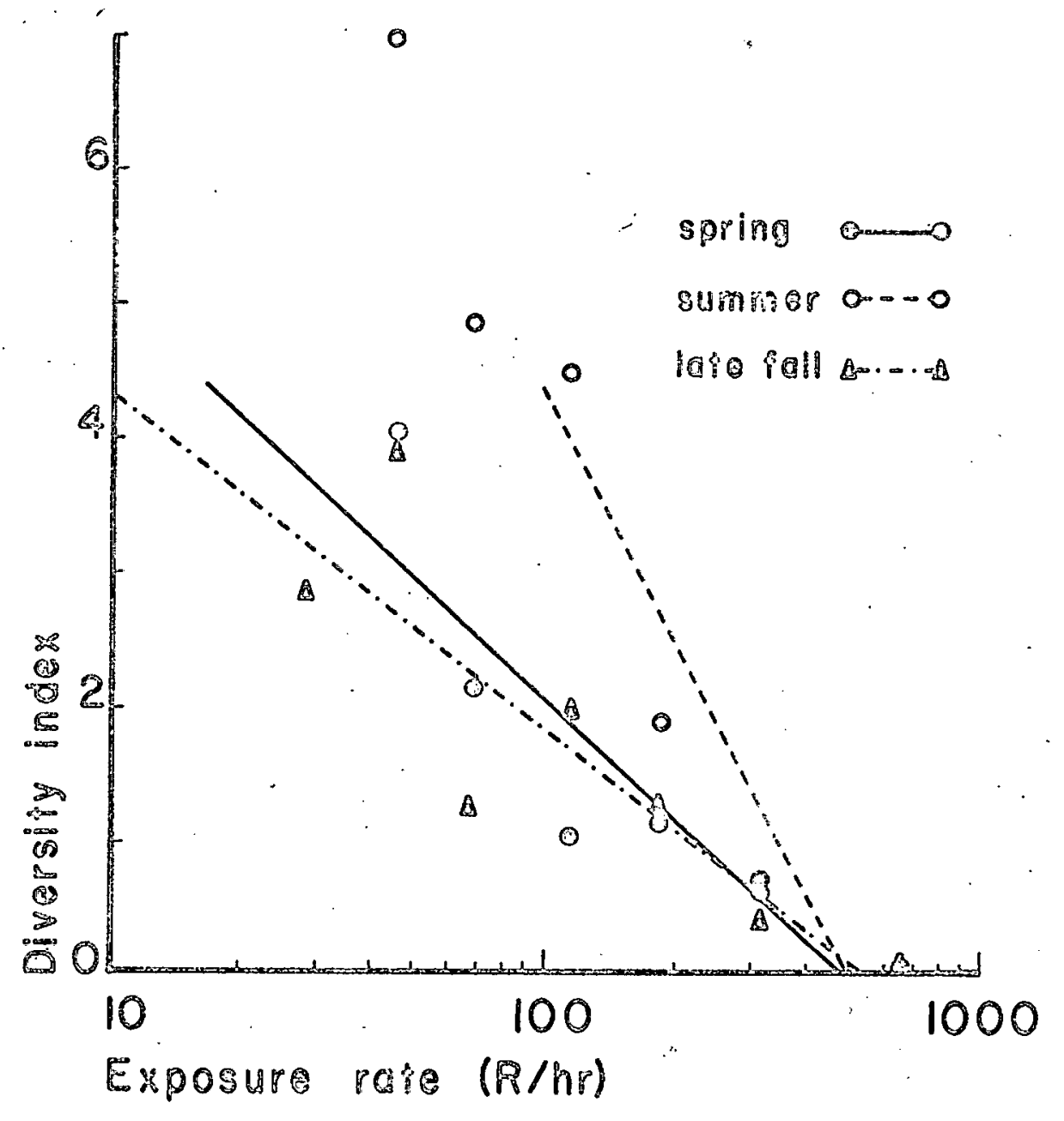


0

0

0

0 
FIg. 16. Diversity index as a function of exposure rate and time for the spring irradiation treatment. Normalized for seasonal fluctuations to the June 1970 control sector mean of 4.4. The dark parallelogram on the horizontal axis (time) represents the period of irradiation. 


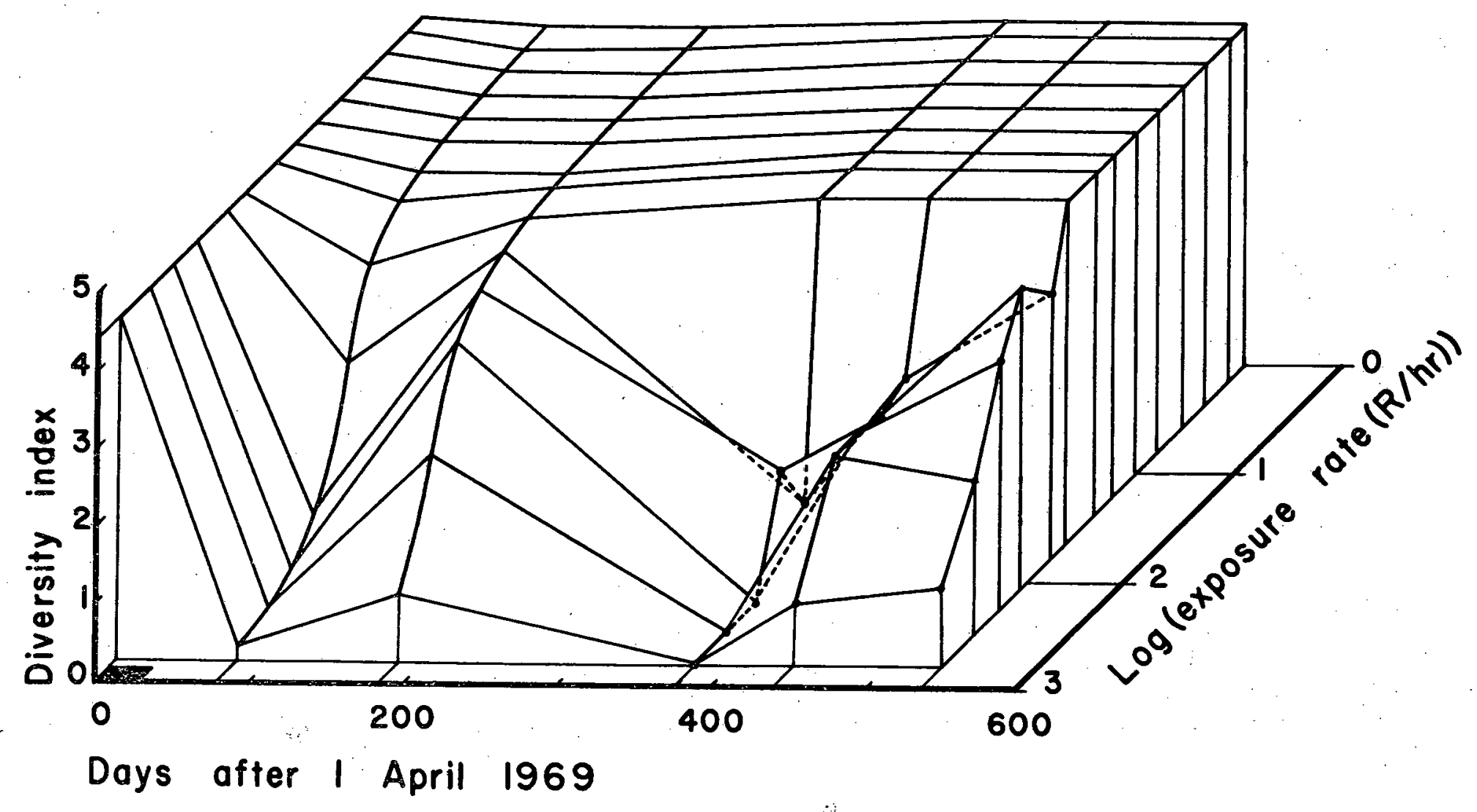


For the plant stand irradiated during summer there was a decrease in diversity at the higher exposure rates by September 1969 and a further decrease was apparent by April 1970 (FIg. 17). However, diversity had increased by the June and September 1970 sampling dates and the data no longer fit the arctan model. For these 2 sampling dates, the actual data points were plotted for the first 5 macroplots and the rest of the line was represented by the "no effects" average. The diversity in these first 5 macroplots was erratic but seemed to be increasing with time and decreasing exposure rates.

For the late fall exposed sector, the diversity did not show any effect of the radiation by April 1970, the first sampling date after Irradiation (F1g. 18): By June 1970, there was a sharp reduction in diversity at higher exposure rates with little change by September 1970 .

\section{Yield}

The total vegetative yield $\left(\mathrm{g} / \mathrm{m}^{2}\right.$ - dry weight) as of September 1970 as a function of exposure rate is shown in Fig. 19. In the chronically exposed sectors the yield in all macroplots which received an exposure rate greater than $1.3 \mathrm{R} / \mathrm{hr}$ was significantly lower than the overall "no effects" average yield $\left(130 \mathrm{~g} / \mathrm{m}^{2}\right)$. For the spring exposed sector, the $650 \mathrm{R} / \mathrm{hr}$ macroplot yield was significantly lower than the "no effects" average yield. The yield in the $315 \mathrm{R} / \mathrm{hr}$ macroplot was considerably larger than the "no effects" average but was not significantly different from the average because of a large variance. The yleld from all other macroplots was not significantly different 
O

o

0

0 
F1g. 17. Diversity index as a function of exposure rate and time for the summer irradiation treatment. Normalized for seasonal fluctuations to the June 1970 control sector mean of 4.4 . The dark parallelogram on the horizontal axis (time) represents the period of irradiation. 


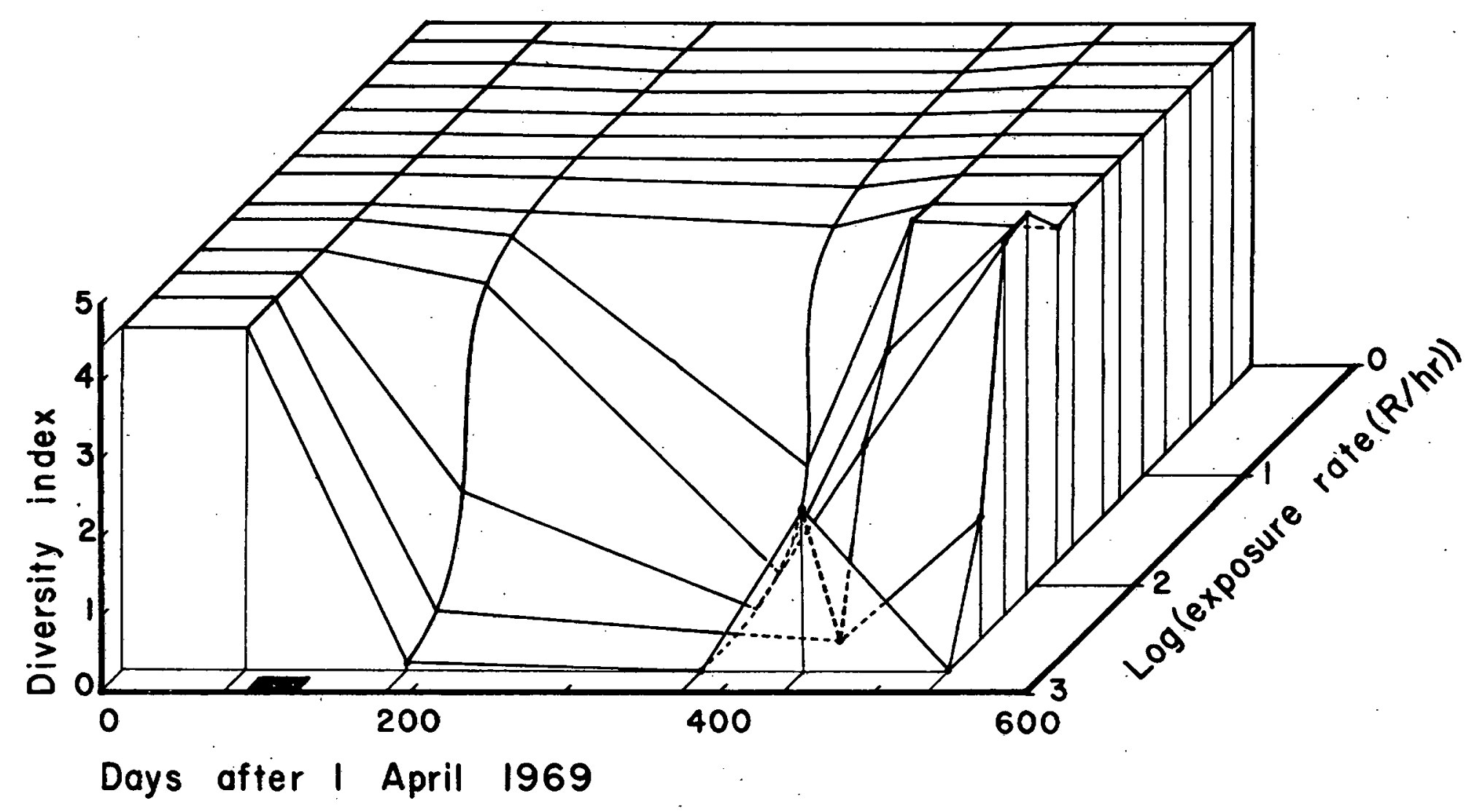


0

O

0

O 
Fig. 18. Diversity index as a function of exposure rate and time for the late fall irradiation treatment. Normalized for seasonal fluctuations to the June 1970 control sector mean of 4.4. The dark parallelogram on the horizontal axis (time) represents the period of irradiation. 


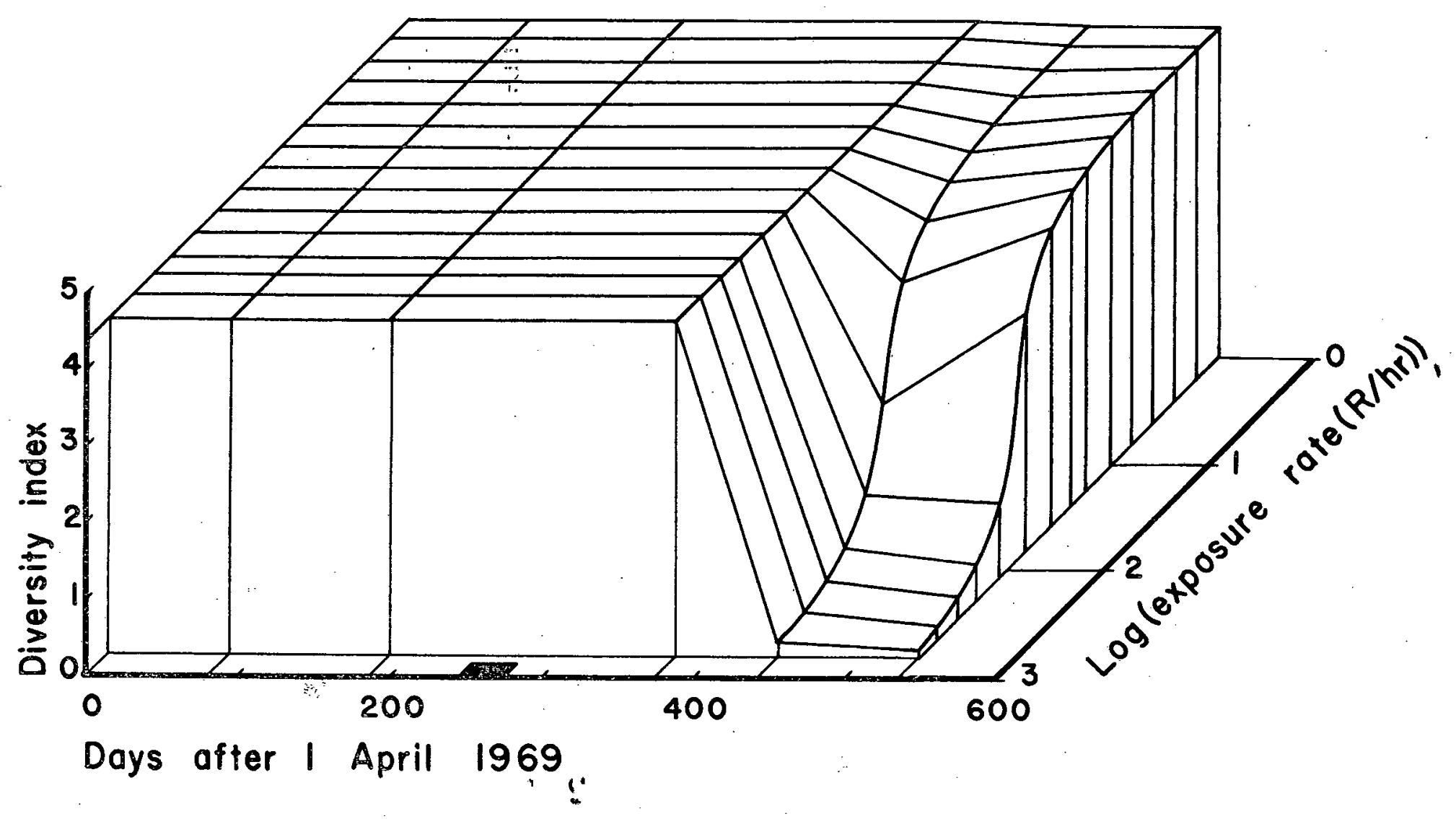


72

0

0

0

O 
F1g. 19. Total vegetative yield $\left(\mathrm{g} / \mathrm{m}^{2}\right.$ - dry weight) as a function of exposure rate for the chronic and seasonal irradiation treatments, September 1970. 


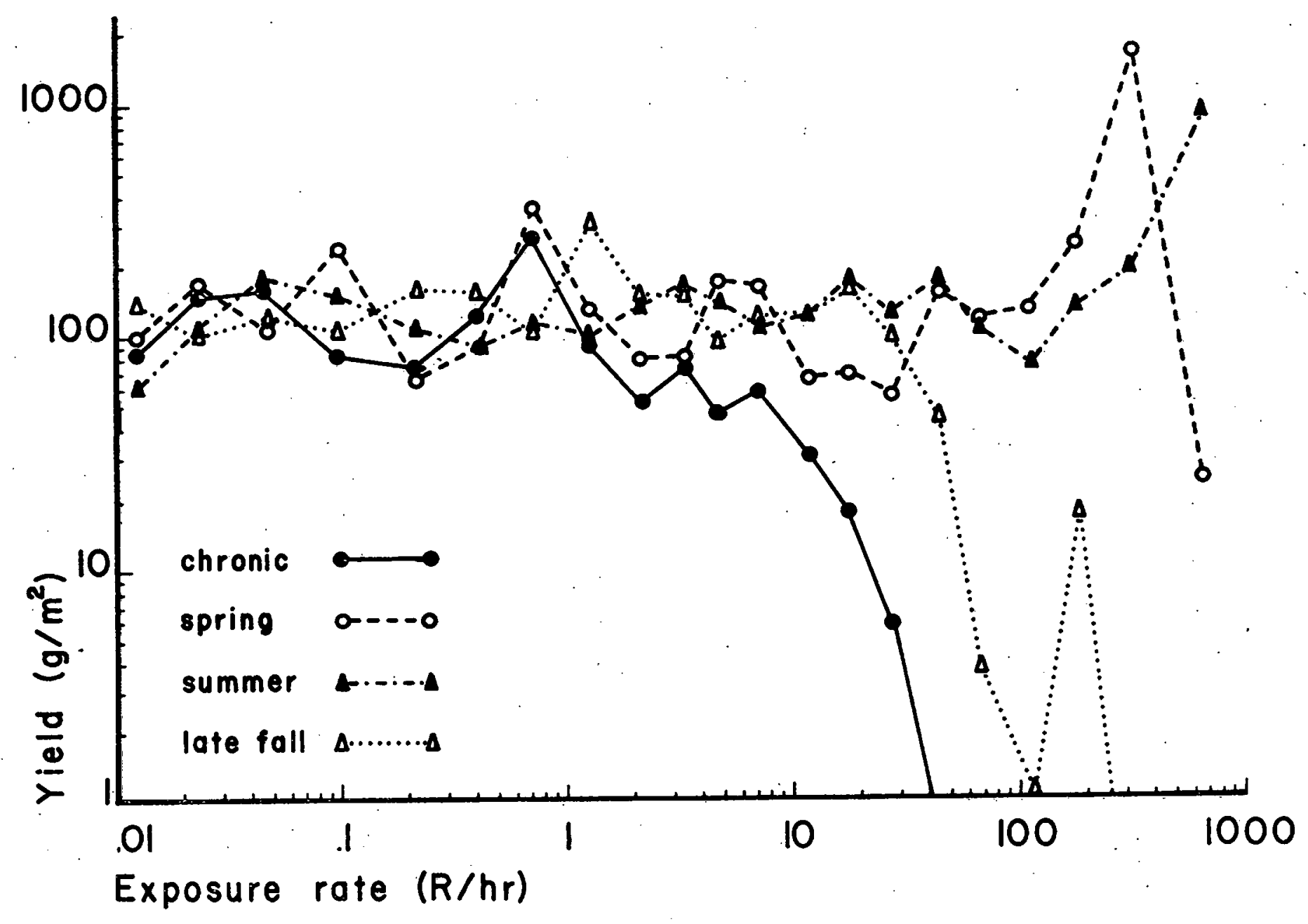


from the average. For the summer exposed sector, the $650 \mathrm{R} / \mathrm{hr}$ macroplot had a yield that was significantly larger than the "no effects" average yield. For the late fall exposed sector, all macroplots that had an exposure rate of $45 \mathrm{R} / \mathrm{hr}$ or more produced a yield that was significantly lower than the "no effects" average. The grass-sedge component of the yield displayed zonation similar to the coefficient of community and diversity index data. The "effects" zone data were subjected to analysis by fitting it to the same linear regression model (Tables $8 \mathrm{a}$ and $\mathrm{b}$ and $\mathrm{Fig} .20$ ). The 50 per cent value (YLD50) for the chronically irradiated sectors was $7 \mathrm{R} / \mathrm{hr}$. The data from the seasonally exposed sectors indicated that the grass-sedge component of the plant community was most sensitive to radiation in late fall, least sensitive in summer and intermediate in spring.

The September 1969 visual yield estimates of the grass-sedge component of the vegetation (Tables $9 a$ and $b$ and Fig. 21) indicated a YLD 50 of $16 \mathrm{R} / \mathrm{hr}$ for the chronically exposed sectors and $67 \mathrm{R} / \mathrm{hr}$ for the spring exposed sector. By September 1970, the visual yield estimate YLD50 had decreased to $9 \mathrm{R} / \mathrm{hr}$ for the chronically exposed sectors (Tables $10 a$ and $b$ and Fig. 22). The spring exposed sector YLD50 was essentially unchanged. The YLD50 for the summer exposed sector $(113 \mathrm{R} / \mathrm{hr})$ indicated the grass-sedge component of the shortgrass vegetation was more resistant to radiation during summer. It was most sensitive in late fall with a YLD50 of $27 \mathrm{R} / \mathrm{hr}$. 
Table 8a. September 1970 yield $\left(\mathrm{g} / \mathrm{m}^{2}\right.$ - dry weight) for the grasssedge component of the vegetation following chronic and seasonally administered irradiation. Chronic 1rradiation initiated 4-69.

\begin{tabular}{|c|c|c|c|c|}
\hline \multirow{2}{*}{$\begin{array}{c}\text { exposure } \\
\text { rate } \\
(\mathrm{R} / \mathrm{hr}) \\
\end{array}$} & \multicolumn{4}{|c|}{ exposure period } \\
\hline & chronic & spring (4-69) & summer $(7-69)$ & late fal1 (12-69) \\
\hline 315 & & 0 & 0 & \\
\hline 185 & & .89 & 21 & 0 . \\
\hline 68 & . & 34 & 26 & 1.6 \\
\hline 45 & & 48 & 59 & 5.6 \\
\hline 28 & 0 & 46 & 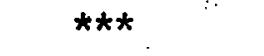 & 30 \\
\hline 18 & 17 & 51 & $\star \star \star$ & 46 \\
\hline 12 & 12 & $\star \star \star$ & *** & 71 \\
\hline 7.2 & 30 & $* * *$ & $\star * \star$ & $* * *$ \\
\hline 4.8 & 29 & 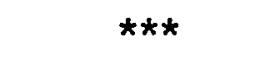 & $* * *$ & $* * *$ \\
\hline 3.4 & 41 & $* * *$ & $\star \star *$ & $* * *$ \\
\hline 2.2 & 43 & $\star \star \star$ & *** & $\star * *$ \\
\hline 1.3 & 48 & $\star \star *$ & $* \star *$ & $* * *$ \\
\hline $\begin{array}{c}\text { "no effects" } \\
\text { mean }\end{array}$ & 52 & 56 & 58 & 60 \\
\hline
\end{tabular}

Table 8b. Parameters for model $y=b_{0}+b_{1} \log x$ using data from Table $8 a$.

\begin{tabular}{|c|c|c|c|c|c|c|}
\hline \multirow{2}{*}{$\begin{array}{l}\text { exposure } \\
\text { period }\end{array}$} & \multirow[b]{2}{*}{$\mathrm{b}_{0}$} & \multirow[b]{2}{*}{$\mathrm{b}_{1}$} & \multicolumn{2}{|c|}{ standard error } & \multirow{2}{*}{$\mathrm{R}^{2}$} & \multirow[b]{2}{*}{$\mathrm{LL} \leq \mathrm{YLD} 50 \leq \mathrm{UL} *$} \\
\hline & & & $b_{0}$ & $b_{1}$ & & \\
\hline chronic & 55 & -35 & 4 & 4 & .93 & $5 \leq 7 \leq 8$ \\
\hline spring & 117 & -48 & 12 & 6 & .92 & $57 \leq 72 \leq 91$ \\
\hline summer & 146 & -57 & 35 & 17 & .80 & $79 \leq 113 \leq 163$ \\
\hline late fall & 141 & -74 & 20 & 13 & .90 & $24 \leq 31 \leq 40$ \\
\hline
\end{tabular}


0

0

0

0 
F1g. 20. September 1970 yield ( $g / \mathrm{m}^{2}$ - dry weight) for the grass-sedge component of the vegetation following chronic and seasonally admintstered irradiation. Chronic irradiation Initlated 4-69. Spring, summer and late fall irradiation administered Apr11, July and December, respectively, in 1969. Tick marks at the top of each curve indicates the "no effects" mean. 


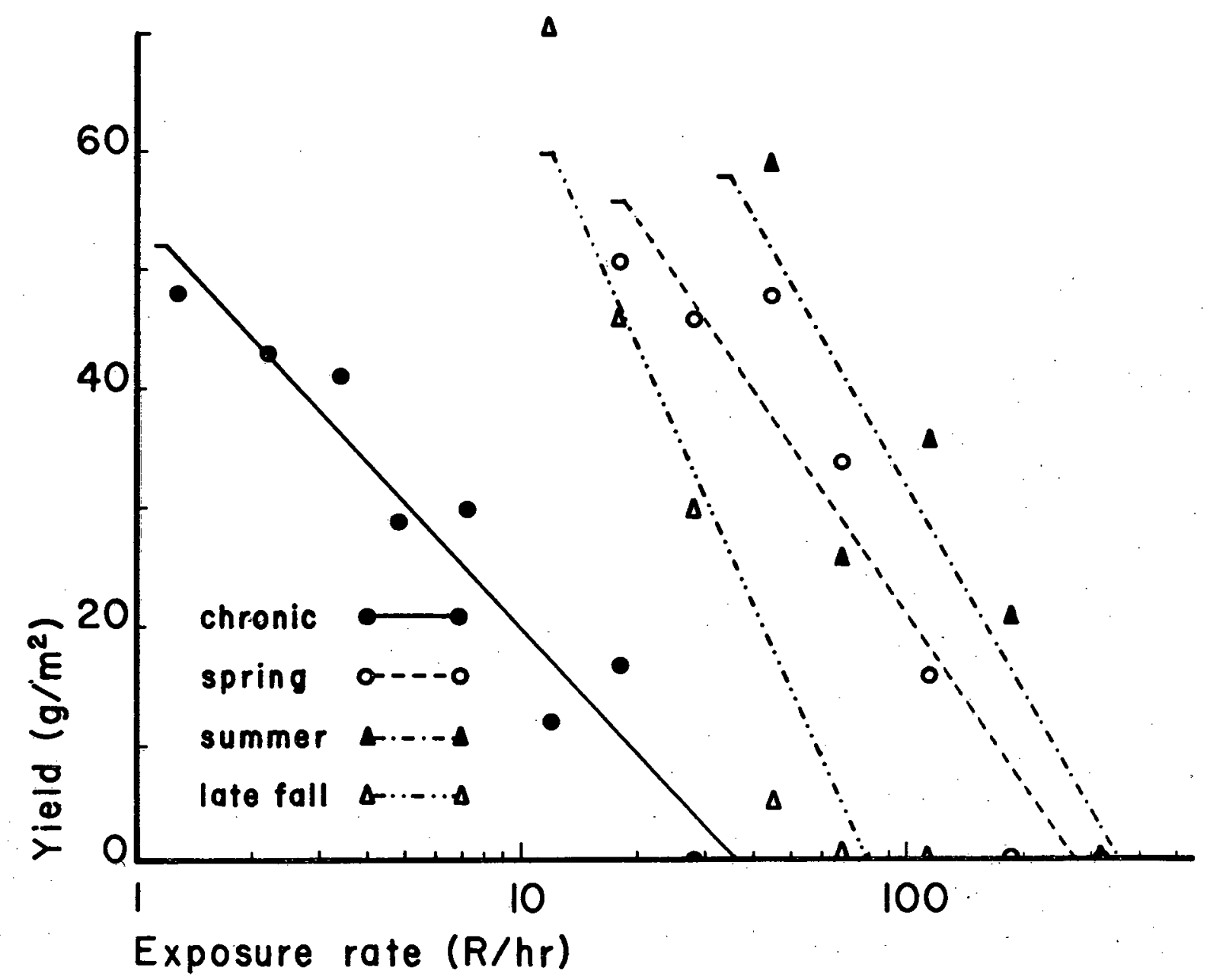


Tab1e 9a. Septémber 1969 visual yield estimates $\left(\mathrm{g} / \mathrm{m}^{2}\right.$ - dry weight) of the grass-sedge component of the vegetation following chronic and spring administered irradiation. Chronic irradiation initiated 4-69.

\begin{tabular}{|c|c|c|}
\hline \multirow{2}{*}{$\begin{array}{c}\text { exposure } \\
\text { rate } \\
(\mathrm{R} / \mathrm{hr})\end{array}$} & \multicolumn{2}{|c|}{ exposure period } \\
\hline & chrontc & spring (4-69) \\
\hline 185 & & 0 \\
\hline 115 & . & 6.2 \\
\hline 68 & 0 & 13 \\
\hline 45 & .29 & 37 \\
\hline 28 & 6.8 & $* * *$. \\
\hline 18 & 24 & 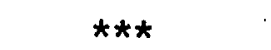 \\
\hline 12 & 27 & *** \\
\hline 7.2 & 31 & 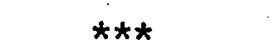 \\
\hline $\begin{array}{l}\text { "no effects" } \\
\text { mean }\end{array}$ & 42 & 42 \\
\hline
\end{tabular}

Table 9b. Parameters for model $y=b_{0}+b_{i} \log x$ using data from Table 9a.

\begin{tabular}{|c|c|c|c|c|c|c|}
\hline \multirow{2}{*}{$\begin{array}{l}\text { exposure } \\
\text { treatment }\end{array}$} & \multirow[b]{2}{*}{$\mathrm{b}_{\mathrm{o}}$} & \multirow[b]{2}{*}{$\mathrm{b}_{1}$} & \multicolumn{2}{|c|}{ standard error } & \multirow[b]{2}{*}{$\mathrm{R}^{2}$} & \multirow[b]{2}{*}{$\mathrm{LL} \leq \mathrm{YLD} 50 \leq \mathrm{UL}$} \\
\hline & & & $\mathrm{b}_{0}$ & $\mathrm{~b}_{1}$ & & \\
\hline chronic & 65 & -37 & 8 & 6 & .92 & $12 \leq 16 \leq 20$ \\
\hline spring & 124 & -56 & 31 & 16 & .86 & $49 \leq 67 \leq 92$ \\
\hline
\end{tabular}


79

0

0

o

(1) 
F1g. 21. September 1969 visual yield estimates $\left(\mathrm{g} / \mathrm{m}^{2}-\mathrm{dry}\right.$ welght) of the grass-sedge component of the vegetation following chronic and spring administered irradiation. Chronic irradiation inftiated 4-69. Tick marks at the top of each curve indicates the "no effects" mean. 


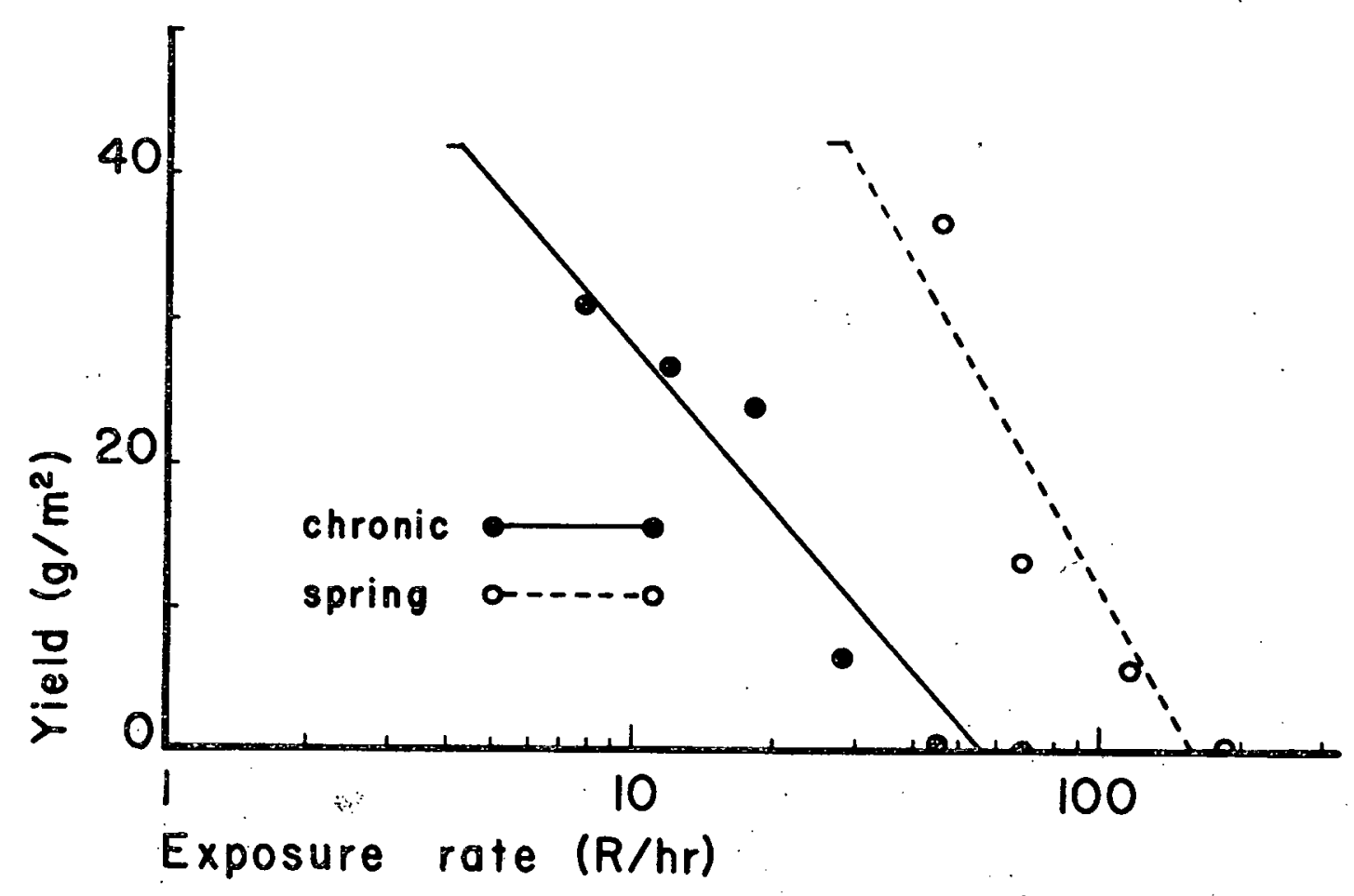


Table 10a. September 1970 visual yleld estimates $\left(\mathrm{g} / \mathrm{m}^{2}\right.$ - dry weight) of the grass-sedge component of the vegetation following chronic and seasonally administered Irradiation. Chronic 1rradiation initiated $4-69$.

\begin{tabular}{|c|c|c|c|c|c|}
\hline \multirow{2}{*}{$\begin{array}{c}\text { exposure } \\
\text { rate } \\
\text { (R/hr) } \\
\end{array}$} & \multicolumn{5}{|c|}{ exposure period } \\
\hline & chronic & spring (4-69 & summer $(7-69)$ & late & fa11(12-69) \\
\hline 315 & & 0 & 0 & & \\
\hline 185 & & 1.4 & 18 & & 0 \\
\hline 115 & & 9.6 & 39 & & 2.6 \\
\hline 68 & 0 & 24 & 30 & & 6.7 \\
\hline 45 & .96 & 50 & 50 & & 7.5 \\
\hline 28 & 1.8 & 62 & $\star * *$ & & 26 \\
\hline 18 & 4.5 & $* * *$ & $\star \star \star *$ & & 35 \\
\hline 12 & 10 & $\star * *$ & $* * *$ & & 57 \\
\hline 7.2 & 32 & $* \star *$ & $\star \star *$ & & $* * *$ \\
\hline 4.8 & 35 & $* * *$ & $\star \star \star *$ & & $* * *$ \\
\hline 3.4 & 63 & $* * *$ & $* \star *$ & & $* * *$ \\
\hline $\begin{array}{l}\text { "no effects" } \\
\text { mean }\end{array}$ & 57 & 67 & 56 & & 59 \\
\hline
\end{tabular}

Table 10b. Parameters for model $y=b_{0}+b_{1} \log x$ using data from Table $10 \mathrm{a}$.

\begin{tabular}{|c|c|c|c|c|c|c|}
\hline \multirow{2}{*}{$\begin{array}{l}\text { exposure } \\
\text { period }\end{array}$} & \multirow[b]{2}{*}{$b_{0}$} & \multirow[b]{2}{*}{$\mathrm{b}_{1}$} & \multicolumn{2}{|c|}{ standard error } & \multirow[b]{2}{*}{$\mathrm{R}^{2}$} & \multirow[b]{2}{*}{$\mathrm{LL} \leq \mathrm{YLD} 50 \leq \mathrm{UL} *$} \\
\hline & & & $b_{0}$ & $\mathrm{~b}_{1}$ & & \\
\hline chronic & 70 & -44 & 11 & 9 & .81 & $6 \leq 9 \leq 13$ \\
\hline spring & 149 & -63 & 20 & 10 & .91 & $51 \leq 66 \leq 86$ \\
\hline summer & 136 & -53 & 28 & 14 & .84 & $82 \leq 113 \leq 157$ \\
\hline late fall & 94 & -45 & 14 & 8 & .86 & $19 \leq 27 \leq 38$ \\
\hline
\end{tabular}

*Lower limit (LL) and upper limit (UL) represent \pm 2 standard errors. 
0

0

(1)

O 
F1g. 22. September 1970 visual yield estimates $\left(g / \mathrm{m}^{2}-\mathrm{dry}\right.$ welght) of the grass-sedge component of the vegetation following chronic and seasonally administered irradiation. Chronic irradiation initiated 4-69. Tick marks at the top of each curve Indicates the "no effects" mean. 


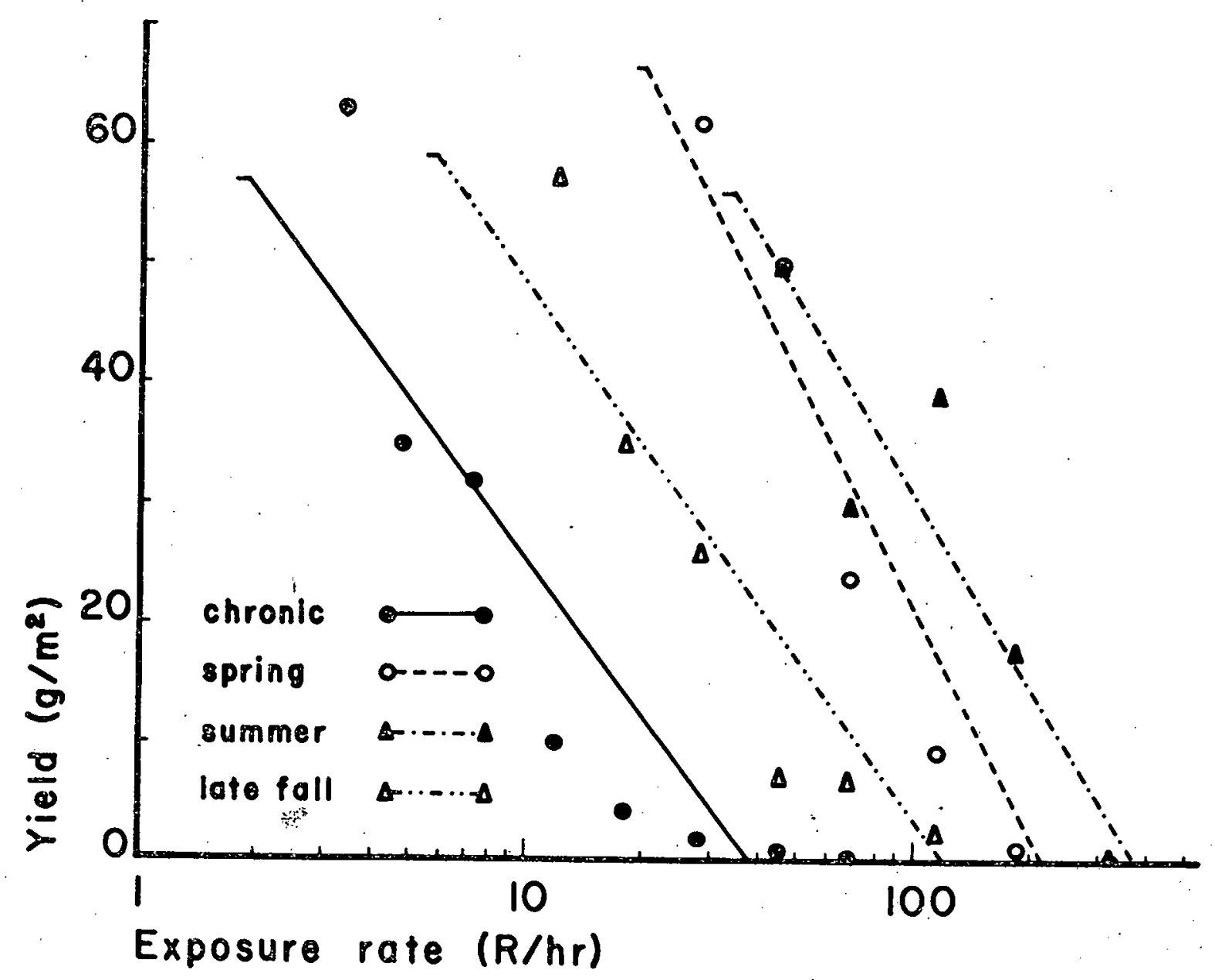




\section{Phenology}

The phenological index, reported only for 4 species in the chronically exposed sectors, indicated the general sensitivity of the species. For Bouteloua gracilis (Bogr), $100 \mathrm{R} / \mathrm{hr}$ or more resulted in death through the summer of 1969 although it took approximately 5 months to kill the plants (Figs. 23 and 24). Thirty $\mathrm{R} / \mathrm{hr}$ delayed the development of the plants with only some reaching anthesis during 1969. During the summer of 1970 more of the plants exposed to $30 \mathrm{R} / \mathrm{hr}$ reached anthesis. There was only a slight difference in the development of the control plants and those exposed to $10 \mathrm{R} / \mathrm{hr}$ and this difference was present during 1969 and 1970.

For Opuntia polyacantha (Oppo), $100 \mathrm{R} / \mathrm{hr}$ and $30 \mathrm{R} / \mathrm{hr}$ resulted in total lethality by the end of 5 months of exposure (Fig. 23 and 24). Plants exposed to $10 \mathrm{R} / \mathrm{hr}$ remained in the vegetative state during 1969 and during 1970 most, but not a11, of $\underline{0}$. polyacantha individuals died. At $3 \mathrm{R} / \mathrm{hr}$, most of the plants remalned vegetative throughout 1969 and 1970 with a few developing flower buds, none of which were observed to open. At $1 \mathrm{R} / \mathrm{hr}$, flower development was delayed but otherwise normal during 1969 and 1970 .

All plants of Gutierrezia sarothrae (Gusa) exposed to $30 \mathrm{R} / \mathrm{hr}$ died within 2 months after exposure started in 1969 (Figs. 23 and 24). At $10 \mathrm{R} / \mathrm{hr}$, Individuals lived through 1969 with most plants developing flower buds. In 1970 some plants exposed to $10 \mathrm{R} / \mathrm{hr}$ died and some remained vegetative. At $3 \mathrm{R} / \mathrm{hr}$ the plants developed the same as plants in the control sector.

Tradescantia occidentalis (Troc) plants exposed to $100 \mathrm{R} / \mathrm{hr}$ or $30 \mathrm{R} / \mathrm{hr}$ were killed during 1969 (Figs. 23 and 24). The development of 
0

0

0

0 
F1g. 23. 1969 Phenological index as a function of time for selected spectes and selected chronic exposure rates. Irradlation infitiated 4-69. Index 1s: 0, dormant or dead; 1 , vegetative; 2, flower bud (head emergence for Bogr); 3, flower (anthesis for Bogr); and 4, seed. 


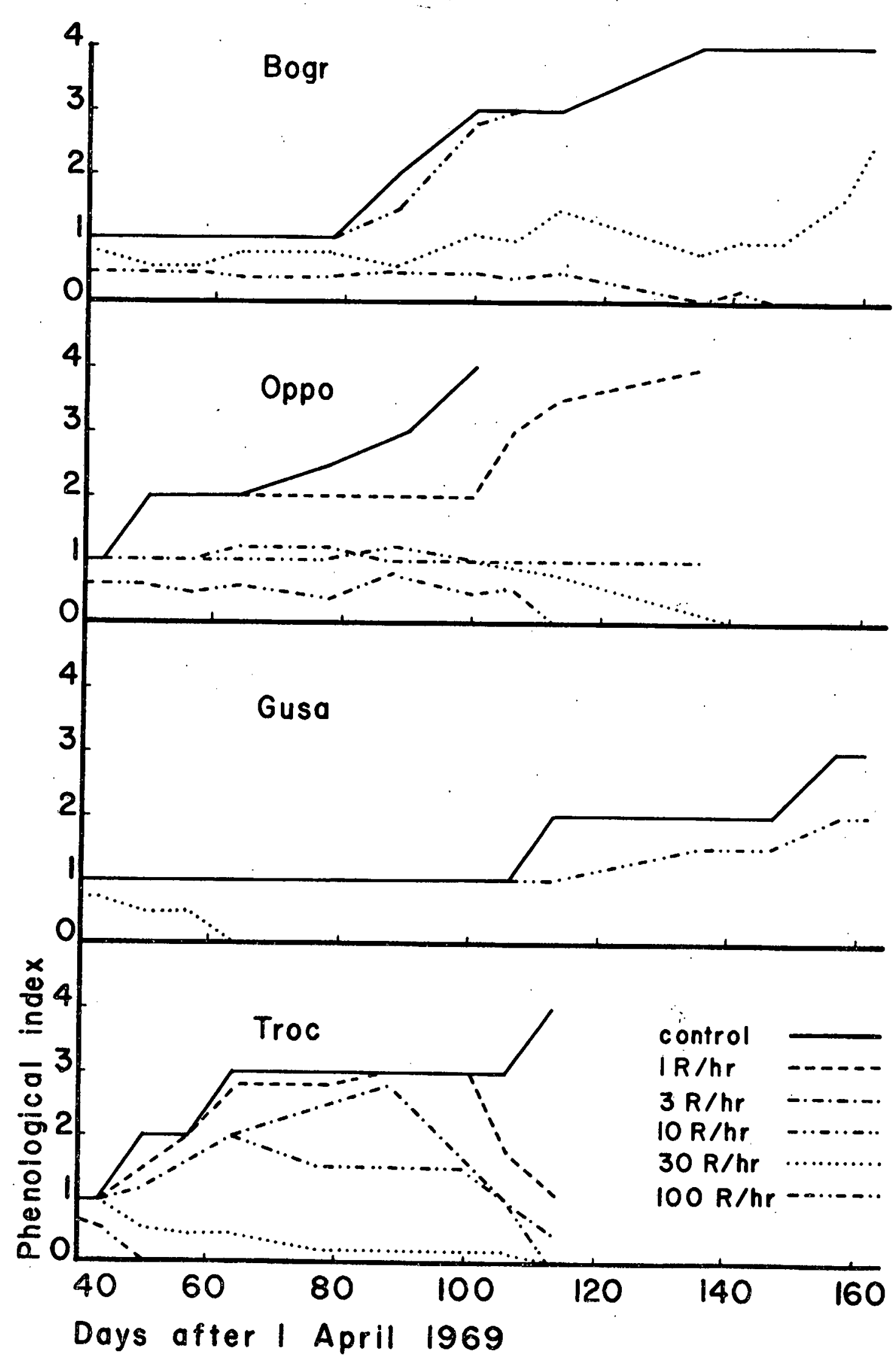

O

0 
87

0

0

O

O 
Fig. 24. 1970 Phenological 1ndex as a function of time for selected species and selected chronic exposure rates. Irradiation Inftiated 4-69. Index is: 0 , dormant or dead; 1 , vegetative; 2, flower bud (head emergence for Bogr); 3 , flower (anthesis for Bogr), and 4, seed. 
$\bigcirc$

$\bigcirc$

0

0

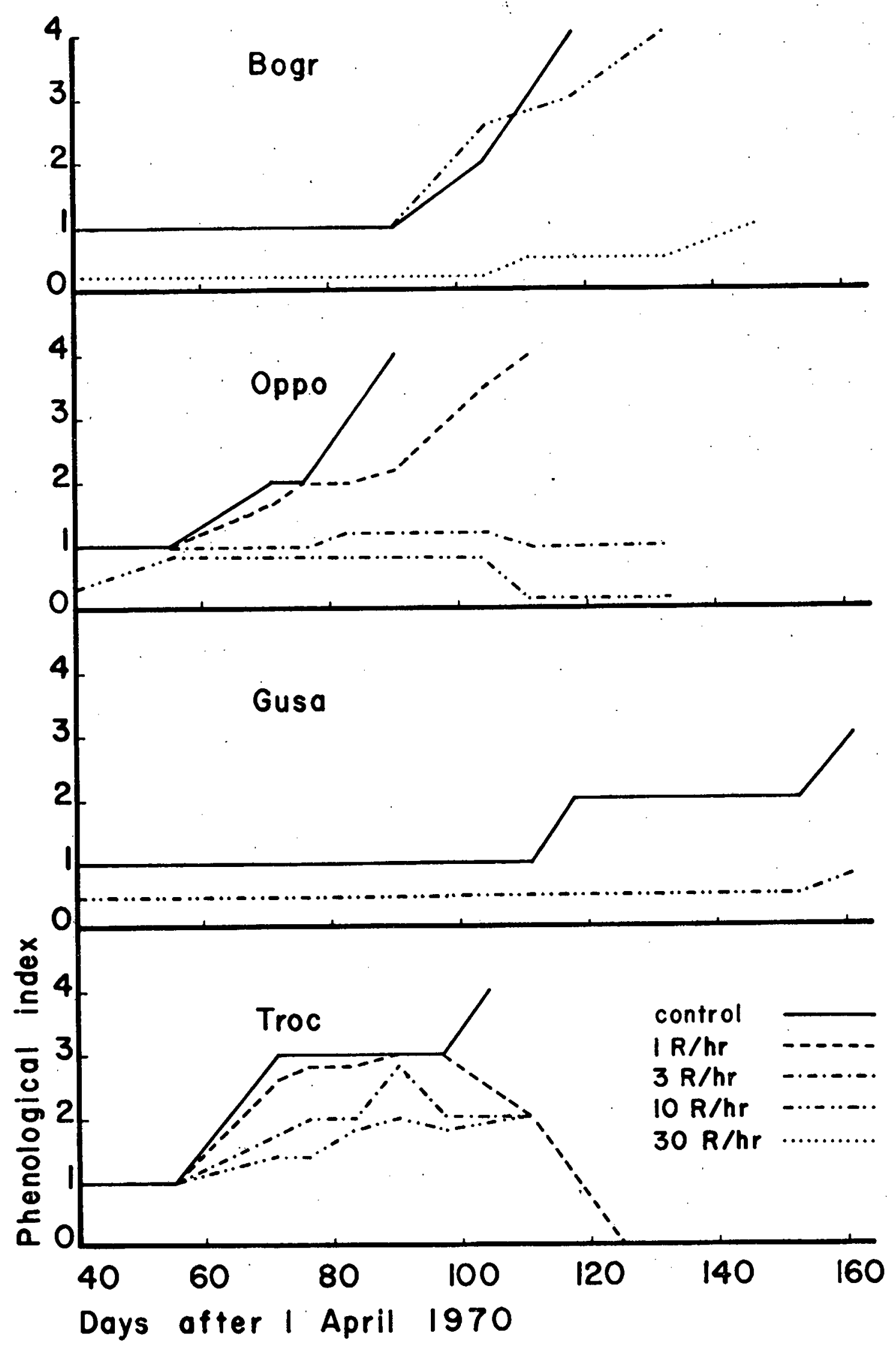


plants exposed to $10 \mathrm{R} / \mathrm{hr}$.was essentially the same during 1969 and 1970 with plants reaching the flower bud stage but not flowering. At exposure rates of $3 \mathrm{R} / \mathrm{hr}$ some plants flowered but no seeds developed. At $1 \mathrm{R} / \mathrm{hr}$ all the plants flowered but no seeds developed In efther 1969 or 1970; At lower exposure rates, development was the same as plants in the control sector.

\section{Density}

The density data gave some indication of the sensitivity of the Individual species in addition to the community characteristics already presented. These data, which are presented for 4 species, varied with season but were not normalized for seasonal fluctuations. Since the data are reported as per cent of the pre-irradiation values, many values are greater than 100 but this should not be interpreted as a stimulatory effect.

For Bouteloua gracilis, cover generally decreased with time in the chronfcally exposed sectors. The exposure rate that resulted in a cover of 50 per cent of the "no effects" mean (LD50) decreased with time except for the September 1969 sampling date (see Discussion, Chapter 4 for comments on this data) and by September 1970 the LD50 was $5 \mathrm{R} / \mathrm{hr}$ (Tables $11 \mathrm{a}$ and $\mathrm{b}$ ).

For the seasonally exposed sectors the LD50 dropped and then fluctuated with sampling date and tended to increase with time except for the late fall exposure (Tables 12a and b, 13a and b, and 14a and b). For the late fall exposed sector, no effect was detected by April 1970. However, the LD50 decreased throughout the 1970 growing season. 
Table 11a. Cover of Bouteloua gracilis, as per cent of pre-1rradiation cover, as a function of exposure rate for selected sampling dates for chronic 1rradlation treatment. Irradiation inftiated 4-69. PreIrradiation cover measured 1. Apr 111969.

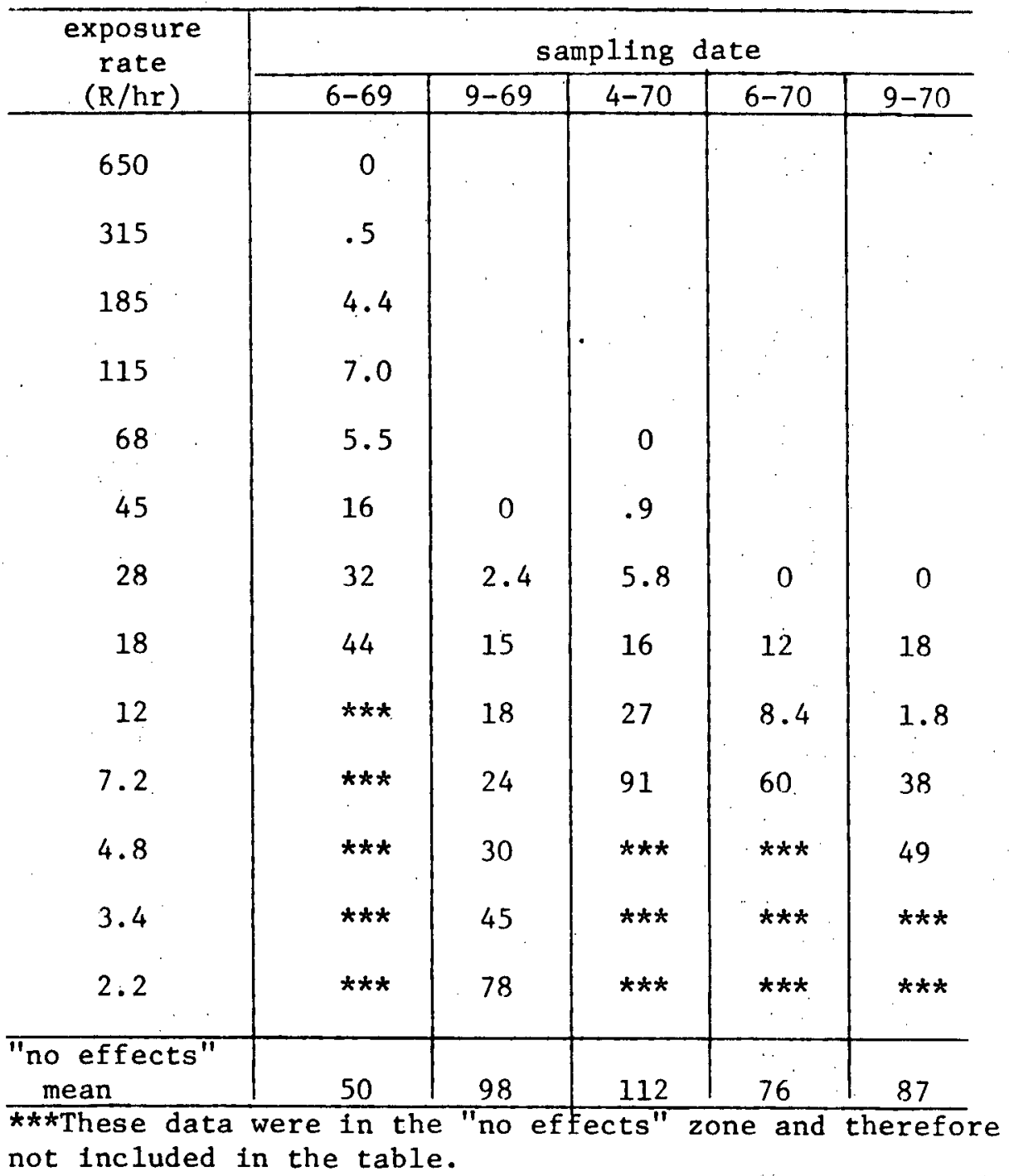


Table 11b. Parameters for model $y=b_{0}+b_{1} \log x$ using

O data from Table 11 .

\begin{tabular}{|c|c|c|c|c|c|c|}
\hline \multirow{2}{*}{$\begin{array}{c}\text { sampling } \\
\text { date }\end{array}$} & \multirow[b]{2}{*}{$b_{0}$} & \multirow[b]{2}{*}{$b_{1}$} & \multicolumn{2}{|c|}{ standard error } & \multirow[b]{2}{*}{$\mathrm{R}^{2}$} & \multirow[b]{2}{*}{$\mathrm{LL} \leq \mathrm{LD} 50 \leq \mathrm{UL} *$} \\
\hline & & & $b_{0}$ & $b_{1}$ & & \\
\hline $6-69$ & 66 & -27 & 12 & 6 & .77 & $22 \leq 35 \leq 62$ \\
\hline $9-69$ & 77 & -51 & 9 & 9 & .85 & $2 \leq 3 \leq 5$ \\
\hline $4-70$ & 133 & -81 & 35 & 25 & .72 & $5 \leq 9 \leq 16$ \\
\hline $6-70$ & 128 & -93 & 45 & 38 & .75 & $6 \leq 9 \leq 14$ \\
\hline $9-70$ & 87 & -62 & 22 & 20 & .76 & $3 \leq 5 \leq 9$ \\
\hline
\end{tabular}

*Lower limit (LL) and upper limit (UL) represent \pm 2 standard errors. 
Table 12a. Cover of Bouteloua gracilis, as per cent of pre-irradiation cover, as a function of exposure rate for selected sampling dates for spring irradlation (4-69) treatment. Pre-irradiation cover measured 1 April 1969.

\begin{tabular}{|c|c|c|c|c|c|}
\hline \multirow{2}{*}{$\begin{array}{c}\text { exposure } \\
\text { rate } \\
\text { (R/hr) } \\
\end{array}$} & \multicolumn{5}{|c|}{ sampling date } \\
\hline & $6-69$ & $9-69$ & $4-70$ & $6-70$ & $9-70$ \\
\hline 650 & 0 & & & & \\
\hline 215 & 3.4 & & & & \\
\hline 185 & 6.2 & 0 & 0 & 0 & 0 \\
\hline 115 & 6.5 & 3.2 & 15 & 22 & 38 \\
\hline 68 & 7.4 & 20 & 29 & 43 & 43 \\
\hline 45 & 59 & 94 & 52 & 71 & 129 \\
\hline 28 & $\star \star \star$ & $\star \star \star$ & 73 & 78 & $\star \star *$ \\
\hline 18 & *** & $* * *$ & 98 & 88 & $* * *$ \\
\hline $\begin{array}{l}\text { "no effects" } \\
\text { mean }\end{array}$ & 58 & 93 & 124 & 85 & 90 \\
\hline
\end{tabular}

Table 12b. Parameters for model $y=b_{0}+b_{1} \log x$ using data from Table $12 a$.

\begin{tabular}{|c|c|c|c|c|c|c|}
\hline \multirow{2}{*}{$\begin{array}{c}\text { sampling } \\
\text { date }\end{array}$} & \multirow[b]{2}{*}{$b_{0}$} & \multirow[b]{2}{*}{$\mathrm{b}_{1}$} & \multicolumn{2}{|c|}{ standard error } & \multirow[b]{2}{*}{$\mathrm{R}^{2}$} & \multirow[b]{2}{*}{$\mathrm{LL} \leq \mathrm{LD} 50 \leq \mathrm{UL}^{*}$} \\
\hline & & & $\mathrm{b}_{\mathrm{o}}$ & $\mathrm{b}_{1}$ & & \\
\hline $6-69$ & 93 & -36 & 41 & 19 & .49 & $26 \leq 59 \leq 131$ \\
\hline $9-69$ & 305 & -141 & 118 & 60 & .74 & $44 \leq 68 \leq 104$ \\
\hline $4-70$ & 214 & -97 & 12 & 6.5 & .98 & $33 \leq 37 \leq 42$ \\
\hline $6-70$ & 208 & -90 & 15 & 8.4 & .97 & $60 \leq 69 \leq 80$ \\
\hline $9-70$ & 415 & -186 & 117 & 59 & .83 & $72 \leq 100 \leq 136$ \\
\hline
\end{tabular}

*Lower limit (LL) and upper limit (UL) represent \pm 2 standard errors. 
Table 13a. Cover of Bouteloua gracilis, as per cent of pre-irradiation cover, as a function of exposure rate for selected sampling dates for summer Irradiation (7-69) treatment. Pre-irradiation cover measured 1 July 1969.

\begin{tabular}{|c|c|c|c|c|}
\hline $\begin{array}{c}\text { exposure } \\
\text { rate }\end{array}$ & & amplin & date & \\
\hline$(\mathrm{R} / \mathrm{hr})$ & $9-69$ & $4-70$ & $6-70$ & $9-70$ \\
\hline 650 & 0 & & & \\
\hline 315 & 9.1 & & 0 & 0 \\
\hline 185 & 53 & & 53 & 53 \\
\hline 115 & 45 & & 52 & 100 \\
\hline 68 & 121 & 0 & 136 & 179 \\
\hline 45 & $\star \star \star$ & 19 & 108 & 154 \\
\hline 28 & $\star * *$ & 147 & 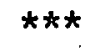 & $* * \star$ \\
\hline 18 & $\star \star *$ & 169 & $\star * *$ & $\star \star \star$ \\
\hline 12 & 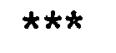 & 168 & 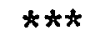 & $\star \star \star *$ \\
\hline 7.2 & 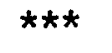 & 121 & $\star \star \star$ & 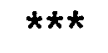 \\
\hline $\begin{array}{c}\text { "no effects" } \\
\text { mean }\end{array}$ & 212 & 275 & 192 & 190 \\
\hline
\end{tabular}

Table 13b. Parameters for model $y=b_{0}+b_{1} \log x$ using data from Table 13a.

\begin{tabular}{|c|c|c|c|c|c|c|}
\hline sampling & & & standa & error & & \\
\hline & $b_{0}$ & $\mathrm{~b}_{1}$ & $b_{0}$ & $\mathrm{~b}_{1}$ & $\mathrm{R}^{2}$ & $\mathrm{LL} \leq \mathrm{LD} 50 \leq \mathrm{UL}^{*}$ \\
\hline $9-69$ & 307 & -114 & 71 & 31 & .82 & $33 \leq 58 \leq 112$ \\
\hline $4-70$ & 424 & -225 & 60 & 43 & .87 & $14 \leq 19 \leq 25$ \\
\hline $6-70$ & 365 & -143 & 81 & 39 & .82 & $52 \leq 76 \leq 112$ \\
\hline $9-70$ & 524 & -207 & 80 & 38 & .91 & $92 \leq 118 \leq 151$ \\
\hline
\end{tabular}


Table 14a. Cover of Bouteloua gracilis, as per cent of preirradiation cover, as a function of exposure rate for selected sampling dates for late fall irradiation (12-69) treatment. Pre-irradiation cover measured 30 September 1969.

\begin{tabular}{l|c|c|c}
\hline \multirow{2}{*}{$\begin{array}{c}\text { exposure } \\
\text { rate } \\
(\mathrm{R} / \mathrm{hr})\end{array}$} & \multicolumn{3}{|c}{ sampling date } \\
\cline { 2 - 4 } 650 & $4-70$ & $6-70$ & $9-70$ \\
315 & 139 & 0 & \\
185 & 156 & 8.8 & \\
115 & 233 & 5.6 & \\
68 & 180 & 100 & \\
45 & 158 & 15 & 0 \\
28 & 150 & 29 & 10 \\
18 & 161 & 143 & 64 \\
\hline $\begin{array}{c}\text { no effects" } \\
\text { mean }\end{array}$ & 260 & 220 & 207 \\
\hline
\end{tabular}

Table 14b. Parameters for model $y=b_{0}+b_{1} \log x$ using data from Table $14 \mathrm{a}$.

\begin{tabular}{|c|c|c|c|c|c|c|}
\hline \multirow{2}{*}{$\begin{array}{c}\text { sampling } \\
\text { date }\end{array}$} & \multirow[b]{2}{*}{$b_{0}$} & \multirow[b]{2}{*}{$\mathrm{b}_{1}$} & \multicolumn{2}{|c|}{ standard error } & \multirow[b]{2}{*}{$\mathrm{R}^{2}$} & \multirow[b]{2}{*}{$\mathrm{LL} \leq \mathrm{LD} 50 \leq \mathrm{UL} *$} \\
\hline & & & $b_{0}$ & $\mathrm{~b}_{1}$ & & \\
\hline $4-70$ & no $r$ & ressio & n** & & & \\
\hline $6-70$ & 296 & -117 & 81 & 40 & .59 & $72 \leq 134 \leq 248$ \\
\hline $9-70$ & 612 & -350 & 167 & 107 & .84 & $30 \leq 41 \leq 55$ \\
\hline
\end{tabular}

*Lower limit (LL) and upper limit (UL) represent \pm 2 standard errors.

**Slope of data for 4-70 sampling date not significantly different from zero. 
There was a rapid decrease in the LD50 values of Opuntia polyacantha in the chronically exposed sectors during 1969 (Tables 15a and b). During 1970, this decrease was slower but continued. For the September 1970 sampling data, no regression analysis of the data was possible since the data were collected only from sector 2 for this date and the 4.8 and $1.3 \mathrm{R} / \mathrm{hr}$ exposure rate macroplots did not have $\underline{0}$. polyacantha prior to inftiation of irradiation. The slope of the line for the data presented was not significantly different from zero.

For the spring exposed sector, the LD50 dropped through 1969 and reached a low value of $14 \mathrm{R} / \mathrm{hr}$ for the June 1970 sampling date and then Increased for the September 1970 sampling date (Tables 16a and b). For the summer exposed sector, the LD50 continued to decrease through all sampling dates (Tables $17 \mathrm{a}$ and $\mathrm{b}$ ) and reached a low of $29 \mathrm{R} / \mathrm{hr}$ at the September 1970 sampling date. For the late fall exposed sector, no o. polyacantha occurred in macroplots recelving more than $185 \mathrm{R} / \mathrm{hr}$ (macroplots 1 and 2) and then none existed in macroplots 4, $5 \& 6$ (115, 68 and $45 \mathrm{R} / \mathrm{hr}$ ) so that it was not possible to apply regression analysis to the data (Table 18). The plants which received $185 \mathrm{R} / \mathrm{hr}$ were st11l apparently alive by September 1970 .

The density data for Eriogonum effusum were also tabulated. In the chronically exposed sectors this species had an LD100 of approxImately $18 \mathrm{R} / \mathrm{hr}$ (Table 19). In the spring, summer and late fall exposed sectors the LD 100 was approximately 185, 315 and $68 \mathrm{R} / \mathrm{hr}$, respectively (Table 20). For both Tradescantia and Eriogonum the results indicated the greatest sensitivity during December, the least sensitivity during July and intermediate sensitivity during April. 
Table 15a. Opuntia polyacantha density, expressed as a per cent of pre-irradiation values, as a function of exposure rate for selected sampling dates for chronic irradiation treatment. Irradiation initiated 4-69. Pre-1rradiation density measured 1 Apr 111969.

\begin{tabular}{|c|c|c|c|c|c|}
\hline \multirow{2}{*}{$\begin{array}{c}\text { exposure } \\
\text { rate } \\
(\mathrm{R} / \mathrm{hr}) \\
\end{array}$} & \multicolumn{5}{|c|}{ sampling date } \\
\hline & $6-69$ & $9-69$ & $4-70$ & $6-70$ & $9-70$ \\
\hline 185 & 0 & & & & \\
\hline 115 & 70 & & & & \\
\hline 68 & 175 & & & & \\
\hline 45 & $\star \star \star$ & & & & \\
\hline 28 & *** & 0 & & & \\
\hline 18 & $\star * *$ & 12 & & & \\
\hline 12 & $\star * \star$ & 0 & 0 & 0 & \\
\hline 7.2 & $\star \star \star$ & 100 & 86 & 50 & 0 \\
\hline 4.8 & $\star * \star$ & 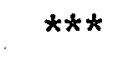 & 27 & 11 & ** \\
\hline 2.2 & $\star \star * *$ & $\star * *$ & 94 & 139 & 208 \\
\hline 1.3 & $\star * *$ & $\star \star \star$ & $* * *$ & 160 & $\star \star$ \\
\hline .72 & $\star \star \star *$ & $\star * *$ & $\star * *$ & $* * *$ & 87 \\
\hline .41 & $\star \star \star *$ & $\star \star \star$ & $* * *$ & $\star \star \star *$ & 208 \\
\hline $\begin{array}{l}\text { "no effects" } \\
\text { mean }\end{array}$ & 82 & 88 & 98 & 162 & 110 \\
\hline
\end{tabular}


Table 15b. Parameters for model $y=b_{0}+b_{1} \log x$ using data from Table 15a.

\begin{tabular}{c|c|c|c|c|c|c}
\hline $\begin{array}{c}\text { samp1ing } \\
\text { date }\end{array}$ & $\mathrm{b}_{\mathrm{o}}$ & $\mathrm{b}_{1}$ & $\mathrm{~b}_{\mathrm{o}}$ & $\mathrm{b}_{1}$ & $\mathrm{R}^{2}$ & $\mathrm{LL} \leq \mathrm{L}$ D $50 \leq \mathrm{UL} *$ \\
\hline $6-69$ & 910 & -404 & 72 & 35 & .99 & $132 \leq 143 \leq 155$ \\
$9-69$ & 206 & -153 & 97 & 82 & .64 & $7.2 \leq 11 \leq 18$ \\
$4-70$ & 124 & -99 & 60 & 76 & .46 & $3 \leq 6 \leq 11$ \\
$6-70$ & 179 & -174 & 30 & 43 & .85 & $3 \leq 4 \leq 5$ \\
$9-70$ & no & regression** & &. &
\end{tabular}

*Lower limit (LL) and upper limit (UL) represent \pm 2 standard errors.

**Slope of data for 9-70 sampling date not significantly different from zero. 
Table 16a. Opuntia polyacantha density for spring irradiation (4-69) treatment, expressed as a per cent of pre-irradiation values, as a function of exposure rate for selected sampling dates. Pre-irradiation density measured 1 April 1969.

\begin{tabular}{|c|c|c|c|c|c|}
\hline \multirow{2}{*}{$\begin{array}{c}\text { exposure } \\
\text { rate } \\
(\mathrm{R} / \mathrm{hr})\end{array}$} & \multicolumn{5}{|c|}{ sampling date } \\
\hline & $6-69$ & $9-69$ & $4-70$ & $6-70$ & $9-70$ \\
\hline 315 & 0 & & & & \\
\hline 185 & 54 & 0 & 0 & & \\
\hline 115 & 92 & 4.2 & 2.0 & & \\
\hline 68 & $\star \star \star *$ & 0 & 4.8 & 0 & 0 \\
\hline 45 & $* * *$ & 49 & 28 & 42 & 21 \\
\hline 28 & $\star * *$ & 100 & 100 & 100 & 0 \\
\hline 7.2 & $* * *$ & $* * *$ & $* * *$ & 109 & 109 \\
\hline $\begin{array}{l}\text { "no effects" } \\
\text { mean }\end{array}$ & 74 & 120 & 94 & 188 & 80 \\
\hline
\end{tabular}

Table 16b. Parameters for model $y=b_{0}+b_{1} \log x$ using data from Table $16 a$.

\begin{tabular}{|c|c|c|c|c|c|c|}
\hline \multirow{2}{*}{$\begin{array}{c}\text { sampling } \\
\text { date }\end{array}$} & \multirow[b]{2}{*}{$\mathrm{b}_{0}$} & \multirow[b]{2}{*}{$\mathrm{b}_{1}$} & \multicolumn{2}{|c|}{ standard error } & \multirow[b]{2}{*}{$\mathrm{R}^{2}$} & \multirow[b]{2}{*}{$\mathrm{LL} \leq \mathrm{LD} 50 \leq \mathrm{UL}$ * } \\
\hline & & & $\mathrm{b}_{\mathrm{o}}$ & $\mathrm{b}_{1}$ & & \\
\hline $6-69$ & 528 & -211 & 33 & 14 & .99 & $202 \leq 214 \leq 227$ \\
\hline $9-69$ & 248 & -118 & 73 & 39 & .75 & $25 \leq 40 \leq 65$ \\
\hline $4-70$ & 229 & -109 & 78 & 42 & .69 & $29 \leq 46 \leq 75$ \\
\hline $6-70$ & 212 & -103 & 66 & 44 & .73 & $6 \leq 14 \leq 30$ \\
\hline $9-70$ & 194 & -111 & 54 & 36 & .83 & $14 \leq 24 \leq 40$ \\
\hline
\end{tabular}

*Lower limit (LL) and upper limit (UL) represent \pm 2 standard errors. 
Table 17a. Opunt1a polyacantha denstty for summer irradiation (7-69) treatment expressed as a per cent of pre-irradiation values, as a function of exposure rate for selected sampling dates. Pre-1rradiation density measured $1 \mathrm{July}$ 1969.

\begin{tabular}{|c|c|c|c|c|}
\hline \multirow{2}{*}{$\begin{array}{c}\text { exposure } \\
\text { rate } \\
(\mathrm{R} / \mathrm{hr}) \\
\end{array}$} & \multicolumn{4}{|c|}{ sampling dates } \\
\hline & $9-69$ & $4-70$ & $6-70$ & $9-70$ \\
\hline 185 & 0 & : & 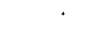 & \\
\hline 115 & 25 & 0 & 0 & 0 \\
\hline 68 & 54 & 37 & 15 & 3.0 \\
\hline 45 & $* * *$ & 43 & 32 & 32 \\
\hline 28 & 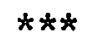 & 62 & 80 & 44 \\
\hline 18 & $\star \star \star *$ & 55 & 105 & 60 \\
\hline 12 & $\star \star \star *$ & 69 & 81 & 58 \\
\hline 7.2 & $\star \star * \star$ & 92 & $\star \star \star \star$ & $* \star *$ \\
\hline $\begin{array}{c}\text { "no effects" } \\
\text { mean }\end{array}$ & 69 & 72 & 115 & 79 \\
\hline
\end{tabular}

Table 17b. Parameters for model $y=b_{0}+b_{1} 10 g \times$ using data - from Table 17a.

\begin{tabular}{l|c|c|c|c|c|c}
\hline $\begin{array}{c}\text { sampling } \\
\text { date }\end{array}$ & $\mathrm{b}_{\mathrm{o}}$ & $\mathrm{b}_{1}$ & $\mathrm{~b}_{\mathrm{o}}$ & $\mathrm{b}_{1}$ & $\mathrm{R}^{2}$ & $\mathrm{LL} \leq \mathrm{LD} 50 \leq \mathrm{UL} *$ \\
\hline $9-69$ & 282 & -124 & 4 & 2 & .99 & $96 \leq 97 \leq 98$ \\
$4-70$ & 145 & -64 & 15 & 10 & .90 & $36 \leq 49 \leq 66$ \\
$6-70$ & 217 & -106 & 36 & 22 & .85 & $24 \leq 32 \leq 43$ \\
$9-70$ & 140 & -69 & 16 & 10 & .92 & $23 \leq 29 \leq 36$ \\
$\begin{array}{l}\text { *Lower 1imit (LL) and upper 1imit (UL) represent } \pm 2 \text { standard } \\
\text { errors }\end{array}$
\end{tabular}


Table 18. Density of Opuntia polyacantha for late fall Irradiation (12-69) treatment, expressed as per cent of pre-irradiation density, as a function of exposure rate for selected sampling dates. Pre-irradiation density measured 30 September 1969.

\begin{tabular}{c|r|r|r}
\hline \multirow{2}{*}{$\begin{array}{c}\text { exposure } \\
\text { rate } \\
(\mathrm{R} / \mathrm{hr})\end{array}$} & \multicolumn{3}{|c}{ sampling date } \\
\cline { 2 - 4 } $185 *$ & $4-70$ & $6-70$ & $9-70$ \\
\hline 28 & 100 & 92 & 72 \\
18 & 89 & 71 & 54 \\
12 & 80 & 96 & 76 \\
7.2 & 55 & 120 & 80 \\
4.8 & 16 & 50 & 16 \\
3.4 & 138 & 162 & 138 \\
2.2 & 74 & 139 & 104 \\
1.3 & 125 & 158 & 100 \\
\hline mean & 109 & 173 & 123 \\
\hline
\end{tabular}

*No 0. polyacantha occurred in plots with an exposure rate greater than $185 \mathrm{R} / \mathrm{hr}$ nor in plots with exposure rates between 28 and $185 \mathrm{R} / \mathrm{hr}$.

No regression analyses were possible with these data. 
Table 19. Density (plants/m $\mathrm{m}^{2}$ ) of Eriogonum effusum for chronic irradlation treatment (sectors two and three) as a function of exposure rate for June 1969 and 1970 sampling dates. Irradiation initiated 4-69.

\begin{tabular}{|c|c|c|c|c|}
\hline $\begin{array}{c}\text { exposure } \\
\text { rate }\end{array}$ & sect & two & sect & three \\
\hline$(\mathrm{R} / \mathrm{hr})$ & $6-69$ & $6-70$ & $6-69$ & $6-70$ \\
\hline 315 & 0 & 0 & $0 *$ & $0 *$ \\
\hline 185 & $0 *$ & $0 *$ & 0 * & $0 *$ \\
\hline 115 & $0 *$ & $0 *$ & $0 *$ & $0 *$ \\
\hline 68 & $0 *$ & 0 * & $0 *$ & $0 *$ \\
\hline 45 & 0 * & $0 *$ & $0 *$ & $0 *$ \\
\hline 28 & $0 *$ & 0 * & $0 *$ & $0 *$ \\
\hline 18 & $0 *$ & $0 *$ & 1.3 & $0 *$ \\
\hline 12 & 1.3 & 1.3 & 4.0 & 1.3 \\
\hline 7.2 . & 4.0 & 4.0 & 2.7 & 2.7 \\
\hline 4.8 & 4.0 & 4.0 & 0 & 0 \\
\hline
\end{tabular}


Table 20. Density (plants $/ \mathrm{m}^{2}$ ) of Eriogonum effusum for seasonal irradiation treatments as a function of exposure rate for June 1969 and 1970 sampling dates except for late fall. exposed sector which was first sampled 9-69.

\begin{tabular}{|c|c|c|c|c|c|c|}
\hline \multirow{3}{*}{$\begin{array}{c}\text { exposure } \\
\text { rate } \\
\text { (R/hr) }\end{array}$} & \multicolumn{6}{|c|}{ season of exposure } \\
\hline & \multicolumn{2}{|c|}{ spring $(4-69)$} & \multicolumn{2}{|c|}{ summer $(7-69)$} & \multicolumn{2}{|c|}{ late fall (12-69) } \\
\hline & $6-69$ & $6-70$ & $6-69$ & $6-70$ & $9-69$ & $6-70$ \\
\hline 650 & 0 & 0 & 8.0 & $0 *$ & 0 & 0 \\
\hline 315 & 0 & 0 & 2.7 & 0 * & 1.3 & $0 *$ \\
\hline 185 & 0 * & 0 * & 2.7 & 1.3 & 0 & 0 \\
\hline 115 & 0 & 0 & 2.7 & 0 * & 0 & 0 \\
\hline 68 & 0 * & 5.3 & 1.3 & 1.3 & 4.0 & $0 *$ \\
\hline 45 & 1.3 & 1.3 & 4.0 & 5.3 & 4.0 & 2.7 \\
\hline 28 & 0 & 0 & 0 & 0 & 0 & 0 \\
\hline 18 & 2.7 & 2.7 & 4.0 & 4.0 & 6.7 & 6.7 \\
\hline 12 & 1.3 & 1.3 & 4.0 & 4.0 & 2.7 & 1.3 \\
\hline
\end{tabular}

*These plots had one $\mathrm{plant} / \mathrm{m}^{2}$ or more prior to irradiation; other zero density plots had no $\underline{E}$. effusum prior to irradiation. 
The results of the density measurements of Tradescantia occidentalis could not be subjected to regression analysis because of the low density of the plants. The results in the chronically. exposed sectors (Table 21) Indicated an LD100 (total lethality) of approximately $28 \mathrm{R} / \mathrm{hr}$ for sector 2 and greater than $12 \mathrm{R} / \mathrm{hr}$ for sector 3. The LD100 was approximately 45, 115 and $18 \mathrm{R} / \mathrm{hr}$ in the spring, summer and late fall exposed sectors, respectively (Table 22). 
Table 21. Density (plants $/ \mathrm{m}^{2}$ ) of Tradescantia occidentalis for chronic irradiation treatment. (sectors two and three) as a function of exposure rate for June 1969 and 1970 sampling dates. Irradiation initiated 4-69.

\begin{tabular}{|c|c|c|c|c|}
\hline \multirow{2}{*}{$\begin{array}{c}\text { exposure } \\
\text { rate } \\
(\mathrm{R} / \mathrm{hr})\end{array}$} & \multicolumn{2}{|c|}{ sector two } & \multicolumn{2}{|c|}{ sector three } \\
\hline & $6-69$ & $6-70$ & $6-69$ & $6-70$ \\
\hline 650 & $0 *$ & $0 *$ & 0 & 0 \\
\hline 185 & $0 *$ & $0 *$ & 0 & 0 \\
\hline 68 & $0 *$ & $0 *$ & 0 & 0 \\
\hline 45 & 1.3 & $0 *$ & 0 & 0 \\
\hline 28 & 4.0 & 0 * & 0 & 0 \\
\hline 18 & 4.0 & 1.3 & 0 & 0 \\
\hline 12 & 2.7 & $0 *$ & 1.3 & 1.3 \\
\hline 7.2 & 5.3 & 2.7 & 9.3 & 8.0 \\
\hline 4.8 & 0 & 0 & 16 & 1.3 \\
\hline 3.4 & 0 & 0 & 16 & 6.7 \\
\hline 2.2 & 0 & 0 & 6.7 & 8.0 \\
\hline 1.3 & 1.3 & 1.3 & 1.3 & 1.3 \\
\hline .72 & 12 & 13 & 4.0 & 2.7 \\
\hline .41 & 17 & 20 & 5.3 & 5.3 \\
\hline
\end{tabular}


Table 22. Density ( 1 lants $/ \mathrm{m}^{2}$ ) of Tradescantia occidentalis for seasonal irradiation treatment as a function of exposure rate for June 1969 and 1970 sampling dates except for the late fall exposed sector which was first sampled 4-70.

\begin{tabular}{|c|c|c|c|c|c|c|}
\hline \multirow{3}{*}{$\begin{array}{c}\text { exposure } \\
\text { rate } \\
(\mathrm{R} / \mathrm{hr}) \\
\end{array}$} & \multicolumn{6}{|c|}{ season of exposure } \\
\hline & \multicolumn{2}{|c|}{ spring $(4-69)$} & \multicolumn{2}{|c|}{ summer $(7-69)$} & \multicolumn{2}{|c|}{ late fall(12-69) } \\
\hline & $6-69$ & $6-70$ & $6-69$ & $6-70$ & $4-70$ & $6-70$ \\
\hline 315 & 0 & 0 & 5.3 & $0 *$ & 4.0 & $0 *$ \\
\hline 185 & 0 & 0 & 2.7 & $0 *$ & 4.0 & $0 *$ \\
\hline 115 & 0 & 0 & 4.0 & $0 *$ & 2.7 & $0 *$ \\
\hline 68 & 0 & 0 & 9.3 & 1.3 & 1.3 & 0 * \\
\hline 45 & 1.3 & $0 *$ & 13 & 0 * & 1.3 & $0 *$ \\
\hline 28 & 0 & 0 & 2.7 & 4.0 & 2.7 & $0 *$ \\
\hline 18 & 1.3 & 1.3 & 2.7 & 4.0 & 8.0 & $0 *$ \\
\hline 12 & 5.3 & 4.0 & 0 & 0 & 0 & 0 \\
\hline 7.2 & 1.3 & $0 *$ & 0 & 1.3 & 0 & 0 \\
\hline 4.8 & 2.7 & 2.7 & 0 & 1.3 & 9.3 & 8.0 \\
\hline 3.4 & 20 & 1.3 & 1.3 & 1.3 & 1.3 & \\
\hline 2.2 & 4.0 & 4.0 & 2.7 & 2.7 & 11 & 9.3 \\
\hline 1.3 & 8.0 & 6.7 & 5.3 & 5.3 & 2.7 & 2.7 \\
\hline .72 & 5.3 & 1.3 & 5.3 & 6.7 & 15 & 13 \\
\hline
\end{tabular}

*These plots had $1 \mathrm{plant} / \mathrm{m}^{2}$ or more prior to irradiation; other zero density plots had no $\underline{T}$. occidentalis prior to Irradiation. 


\section{Chapter 4}

\section{DISCUSSION}

The net effect measured at any one time as a result of exposure to radiation is a combination of the effect of the radiation plus recovery and the two can never be completely separated in a field study. However, it seemed prudent to present the two separately in the discussion.

\section{Effects}

\section{Zonation}

The zonation described earlier was apparent in all parameters measured. The 3 zones reported are somewhat different than the 5 zones reported by Woodwell and Rebuck (1967). They reported the formation of 5 zones with the 3 middle zones being specific for the particular plant stand in question. The first and fifth zones (lethal and no effects) were the same as the first and third zones reported here. These zones are of interest primarily to set the boundaries of the center or "effects" zone. It is the "effects" zone that is of primary interest. Although a major portion of the "effects" zone decreased linearly with increasing logarithm of the exposure rates (indicating a $\mathrm{dx} / \mathrm{x}$ response) there was a tapering effect at each end of the "effects" zone. At the higher exposure rate end this seemed to be due to the "hanging on" of a few apparently more radioresistant plants, sometimes including more than one species. At the lower exposure rate end, the reason for the tapering off was less apparent. It may have been due to meristematic damage followed by complete or partial repair or the initiation of new meristems that allowed most individuals to survive and/or production to remain nearly normal 
(Iqbal, 1970). A tapering effect was shown in diagrams reported by Woodivell and Sparrow (1963) although no specific attempt was made to fit a line to the data.

\section{Coefficient of community}

The coefficient of community comparing pre-irradiated to postirradiated or control to irradiated communities has been used by several authors (Mi1ler, 1968; Woodwel1 and Rebuck, 1967; Monk, 1966; and Woodwell and Oosting, 1965). In these cases, the coefficient of community was calculated from the relationship

$$
C C=C /(A+B-C)
$$

where $A$ was the number of species in the control plot, B was the number of specles in the treated plot and $C$ was the number of species shared by the two plots. This relationship has two drawbacks, however.

Firstly, the rate of change of $\mathrm{CC}$ is inversely related to $\mathrm{CC}$ i.e., $\mathrm{dCC} / \mathrm{dC}=(\mathrm{A}+\mathrm{B}) /(\mathrm{A}+\mathrm{B}-\mathrm{C})^{2}$

which means that the slope of the $C C$ versus $C$ curve varies as $C$ varles for a given $A$ and $B$. Second $1 y$, when $A$ equals $B$ and $C$ equals A/2 (half of the species are shared), the $\mathrm{CC}$ is not 0.5 but 0.333 . Greig-Smith (1964) suggests that

$$
C C=2 C /(A+B)
$$

is a more desirable relationship. In this case,

$$
\mathrm{dCC} / \mathrm{dC}=2 /(\mathrm{A}+\mathrm{B})
$$

which is constant as $C$ changes for given values of $A$ and $B$. When $A$ equals $B$ and $C$ equals $A / 2, C C$ equals 0.5 . The latter relationship was used in this study. 
Chrontc 1rradiation - The decrease in the CC50 value, calculated from efther the linear regression or arctan model, was approximately what would be expected (Tables 2 and 3 ). The threshold appeared to be approxtmately $5 \mathrm{R} / \mathrm{hr}(120 \mathrm{R} / \mathrm{da})$ for $\mathrm{CC}$ effects after 15 months of irradiation. This was considerably greater than $50 \mathrm{R} / 20 \mathrm{hr}$ da reported by Woodwell and Oosting (1965) for an old field community or the approximate value of $20 \mathrm{R} / 20 \mathrm{hr}$ da reported by Woodwell and Rebuck (1967) for an oak-pine forest. The increase from the September 1969 to April 1970 sampling dates of 24 to $31 \mathrm{R} / \mathrm{hr}$ was probably not significant and due to sampling variability since there were differences in species present, both annuals and perennials, in the fall and spring with fewer species present in the spring. The $\mathrm{dx} / \mathrm{x}$ response of coefficient of community to radiation has been reported by Miller (1968), Woodwell and Rebuck (1967) and Woodwell and Oosting (19.65).

The very low but non-zero coefficient of community values in the 68 and $45 \mathrm{R} / \mathrm{hr}$ exposure rate macroplots were due to persistant plants of Gaura coccinea. These plants made little growth but remained alive through 1970 (they were still present in July 1971). It was not determined whether the plants were separate individuals or interconnected underground by rhizomes or rootstocks. It was possible that these plants were connected to roots of plants outside the exposed macroplots. There were also some individuals of Carex heliophila in these macroplots. All other species were eliminated.

The data presented do not indicate that the CC50 had stabilized as of June 1970 and it is expected to decrease in the future. 
Seasonal irradiation - The spring exposed sector appeared to be intermediate in sensitivity as determined by the CC50 whether calculated from the linear or the arctan model. The value of $206 \mathrm{R} / \mathrm{hr}$ was not significantly different (i.e. it is within \pm 2 s.e.) from the value of $195 \mathrm{R} / \mathrm{hr}$ (Tables 3 and $4 \mathrm{~b}$ ).

The summer exposed sector appeared to be the most resistant to radiation of the three seasonal exposures with a CC50 of $240 \mathrm{R} / \mathrm{hr}$.

The late fall exposed sector was the most sensitive to radiation with a CC50 of $120 \mathrm{R} / \mathrm{hr}$ with both the linear and arctan models. This exposure was during the dormant season when one would expect very little meristematic activity. In this situation, the cells present would receive the total insult of radiation and therefore might sustain more damage to DNA and other nuclear components of the cell, thereby giving maximum damage to the cell and therefore, the plant (Woodwell and Sparrow, 1963). Furthermore, sub-cellular recovery processes may be reduced under the conditions of cellular dormancy, cold temperatures and low. moisture content of the plant tissues. There was no indication that the air temperature was unusual at the time of irradiation of the late fall exposed sector but the total precipitation for December 1969, January and February 1970 was $0.4 \mathrm{~cm}$ wh1ch was somewhat less than the 1939 through 1953 average of $1.6 \mathrm{~cm}$ (Kipple and Costel1o, 1960). This may have resulted in many species being more sensitive than they would be under conditions of increased moisture.

For the spring exposed sector, the plants were in a rapid growth phase and meristematic activity was high. Although each cell may have been more sensitive, it was exposed to the radiation only a few hours 
until division, if possible, would take place. This seems to have increased the resistance of these plants.

During the summer exposed sector, the plants were in various stages of growth. Bouteloua gracilis was just starting the anthesis stage, Tradescantia occidentalis was nearing the end of its growth cycle and other species such as Gutierrezia sarothrae, were just inftiating floral buds. Many species are apparently semi-dormant during the summer season, depending on the moisture supply, and this may partially account for the increased resistance to radiation at this time of year.

The above results appear somewhat in conflict with those predicted for trees by Taylor (1966) based on seasonal changes in chromosome volume and those reported by Miller (1968) who found an old field to be more sensttive during the spring.

\section{Diversity: Index}

Diversity was defined by Patten (1962) as "...how individuals are distributed among the species." He developed an index of diversity using the Boltzmann equation from statistical mechanics which gives the entropy of an aggregation as:

$$
\mathrm{H}=\mathrm{k} \log \mathrm{P} \text {. }
$$

The total number of individuals (N) was $\sum_{i=1}^{m} n_{i}$ where $n_{i}$ equaled the number of individuals of type $i$ and $m$ was the number of species. The probabllity of sampling the $i$ th type $\left(p_{i}\right)$ was $n_{i} / N$ where $\sum_{i=1}^{m} p_{i}=1$. Using the above relationship and Stirling's equation for approximation of the $\Gamma$ function, Patten derived the following as a measure of the 
average entropy per individual $(\overline{\mathrm{H}})$ :

$$
H=-k \sum_{i=1}^{m} p_{i} \log _{2} p_{i} .
$$

The properties of this equation were such as to give maximum diversity when $m$ equaled $N$, that is, when each individual belonged to a different species. Minimum diversity (zero) resulted when all individuals belonged to the same species.

I modified the equation by defining $p_{i}$ as the frequency of occurrence $\left(f_{i}\right)$ in per cent divided by 100 , i.e.,

$$
\mathrm{p}_{1}=\mathrm{f}_{i} / 100 \text {. }
$$

This changed the validity of the equation in that it no longer was a true measure of entropy i.e.,

$$
\sum_{i=1}^{m} p_{i}=1
$$

no longer holds, but it still maintained the desirable properties mentloned above. The final form of the equation for the diversity Index (D) was

$$
D=-k, \sum_{i=1}^{m} p_{i} \log _{2} p_{i} .
$$

The greatest rate of change of $D$ (i.e. $d D / d p$ was when $p$ equaled zero. Therefore, when a new species appeared in the sample, even with a very small value for $p$, it made a significant contribution to the total diversity. For the largest values of $p$, i.e., $p$ equals 1 , the amount added to the diversity by that species is zero. The slope of the equation reaches zero at $\mathrm{p}$ equals $1 / \mathrm{e}$ equals 0.37 which is the maximum addition to the diversity that a species can contribute. Species with a value of $p_{i}$ of .1 to .75 would contribute .2 or more to the diversity. 
After all species contributions were summed, then the sum was multiplied by the constant $k$ where $|k|$ was 1.433 which is the ratio between base 2 and base e logarithms. In actual practice, this constant is not necessary since it only amplifies $D$ and would not change the analysis in any way.

Chronic Irradiation - The effect of the chronic radiation, as measured by diversity, followed the same general pattern as that measured by the coefficlent of community. The ratio of CC50/DI50 was approximately 1.6 for values calculated, including the linear and arctan models. This is reasonable since to affect the coefficient of community, all individuals of a species must be eliminated from the plot whereas to affect the diversity index, only the frequency need be changed.

There was a continual decrease in the DI50 thru time with the exception of the September 1970 sampling date when there was a small but not significant increase for the linear model. There was no indication that stabilization, as measured by diversity, had taken place since the DI50 calculated from the arctan model continued to decrease through September 1970 and was approximately $8 \mathrm{R} / \mathrm{hr}$ at that sampling date (Table 6).

There appeared to be a threshold of approximately $2 \mathrm{R} / \mathrm{hr}$ $(48 \mathrm{R} / \mathrm{da})$ as of September 1970,18 months after initiation of irradiation, to affect the diversity index, which is similar to the value reported by Woodwell and Oosting (1965) for an old field community.

Seasonal irradiation - The seasonal results indicated that the vegetation, as measured by diversity index, was most sensitive to 
Irradiation in late fall, least sensitive in summer and intermediate during the spring.

There was a great deal of vartation in the "no effects" average: of the diversity index from season to season and from year to year. At the April sampling date, only those perennials which started early growth could be counted. (To be counted, a plant had to appear green and exhibit some evidence of growth.) By the June sampling date, essentially all of the perennials were in some growth stage and could be counted. By the September sampling date, some of the perennials had completed their normal growth cycle and could not be counted. Also, many annuals were present only for the June sampling date. The seasonal and annual variations present in Figure 13 were eliminated by multiplying the data by the ratio $A / B$ where $A$ was the June 1970 control sector average and B was the "no effects" average for the sector in question. The $\mathrm{CC50}$ and DI50 values and the fitted parameters of the arctan function were not altered by this adjustment.

Y1e1d

The decrease in yield in the chronically exposed sector at exposure rates of 2.2 to $4.8 \mathrm{R} / \mathrm{hr}$ was evidently due to decreased growth and development of the plants in those macroplots since no effect on coefficient of community or diversity index was apparent. At exposure rates of $4.8 \mathrm{R} / \mathrm{hr}$ or greater, both the coefficient of communtty and the diversity index were affected (Fig. 19). In macroplots with exposure rates of 28 to $68 \mathrm{R} / \mathrm{hr}$ only scattered individuals, which made very little growth, occurred. At exposure rates greater than $68 \mathrm{R} / \mathrm{hr}$ no plants survived. Most of the yield from the plots in 
in the higher exposure rate end of the "effects" part of the curve came from the grass-sedge component of the plant community except for the yleld in the $28 \mathrm{R} / \mathrm{hr}$ exposure rate macroplot which was due to Gaura cocc1nea.

The grass-sedge component of the yfeld, whether measured by visual estimates or by clipping gave a YLD50 of approximately $9 \mathrm{R} / \mathrm{hr}$ by September 1970 for the chronic irradiation.

Phenology and density

A few specific specles were chosen for sensitivity study because of their abundance and/or growth habit. Bouteloua gracilis was the dominant species in the area before Irradiation. The meristematic region is at the soil surface and some shielding by the soil may have affected the results. Opuntia polyacantha was the third most abundant spectes and had meristems above ground. The meristem was not always well defined. Gutierrezla sarothrae was a small shrub with meristems exposed all growing seasons. Frequency was quite low for $G$. sarothrae. Eriogonum effusum was similar in growth habit to $\underline{G}$. sarothrae and was considerably more abundant. Tradescantia occidentalis was moderately abundant. It had a meristem that was apparently shielded by the soil most of the year but was exposed during the reproductive period of growth.

The phenological index indicated that, for the chronic exposure, Bouteloua gracilis was the least sensitive of the four species for which the phenological data were presented. Gutierrezia sarothrae was more sensitive than $\underline{B}$. gracilis. Opuntia polyacantha appeared to be the most sensitive but only slightly more than Tradescantia occidenta11s. 
Bouteloua gracilis - Except for the data from the September 1969 sampling date, the LD50 declined with time in the chronic sectors. A careful analysis of the raw data indicated that the plant crowns appeared dead in some macroplots in late September 1969 in the chronic sectors that were actually alive and produced some growth the next year. Also, there was a heavy snow and cold temperatures in late September. The data were taken after the cold and snow and this may have affected the appearance of the plant crowns. Therefore, the 3 R/hr LD50 calculated for September 1969 should not be considered a reliable value. Based on the 1970 data, it would appear that the LD50 reached a value of 5 to $9 \mathrm{R} / \mathrm{hr}$ during the second growing season for $\underline{B}$. gracilis. The phenological index indicated that those plants whtch did survive experienced very little delay in development. Most of the growth and development took place around the edge of the crown, with most of the center of the crown killed at exposure rates in the LD50 range.

For the spring exposed sector it appeared that the LD50 was in the range of 40 to $70 \mathrm{R} / \mathrm{hr}$. By comparing the cover data with time, it appears that growth of the $\underline{B}$. gracilis crowns was taking place in plots that had been exposed to $115 \mathrm{R} / \mathrm{hr}$ or 1ess. The LD100 appeared to be between 115 and $185 \mathrm{R} / \mathrm{hr}$.

For the summer exposed sector, there appeared to be one inconsistent set of data; that from the April 1970 sampling date. The apparent reason was the appearance of the plant crown at that time. For example, in the 185, 115, and $68 \mathrm{R} / \mathrm{hr}$ exposure rate macroplots, the crowns all appeared dead in April 1970 yet showed growth by June 1970. The data from this sampling date should not be considered valid and the LD50 
of $19 \mathrm{R} / \mathrm{hr}$ was not a true indication of the sensitivity of $\mathrm{B}$. gracilis exposed to radiation in July, 1969. It would appear that the LD50 was approximately 60 to $80 \mathrm{R} / \mathrm{hr}$. The LD100 was between 185 and $315 \mathrm{R} / \mathrm{hr}$. These data made the summer exposure appear to be less sensitive than the spring exposure. At the beginning of the exposure period, the B. gracilis in the July exposed sector had just started anthesis. Since most of the spring growth had taken place, this may have allowed the plants to recover from radiation damage better than in the April exposure, where growth did not take place.

For the late fall exposed sector, the $\underline{B}$. gracilis plants had completed their normal 1969 growth and were dormant at the time of exposure. By Apri1 1970 there was no evidence of radiation damage. The plant crowns appeared alive, even at the highest exposure rates. During the 1970 growing season, damage began to be expressed. By the June 1970 sampling date many crowns appeared dead although some still had green leaves showing. Very little growth was made at the higher exposure rates. By September 1970 the plants at the higher exposure rates showed more dead crowns. Based on the difficulty of interpreting the data from the other exposures $I$ do not believe that a rellable estimate of the LD50 or LD100 can be made for the late fall exposure until the 1971 data are available. From the yield data it would appear that the LD50 of $41 \mathrm{R} / \mathrm{hr}$ from the September 1970 data would be a closer approximation to the sensitivity of $\underline{B}$. gracilis in December than the June 1970 LD50 of $134 \mathrm{R} / \mathrm{hr}$.

The problems in analyzing the above data indicate some of the sampling problems which arise when determining seasonal sensitivity of plant species or communities. The delay in expressing damage 
appeared to be different for different seasons of exposure and the amount of damage that was experienced by plants appeared to be different. A very careful system of sampling through time must be employed to determine the true sensitivity.

Opuntia polyacantha - When determining the sensitivities of species that are somewhat less abundant than optimal, two problems are encountered. First, that particular species may not occur in every exposure rate plot, leaving gaps in the data. Also, in some exposure rate plots only one or a very few individuals exist and a small change in the number of plants gives a large fractional change. These problems existed in the data for Opuntia polyacantha, as well as for other species, and was accentuated by the necessarily smail quadrat size used in this study.

The LD50 for $\underline{0}$. polyacantha in the chronically exposed sectors decreased steadily through all sampling dates to the September 1970 sampling date. Due to the problems mentioned above, it was not possible to run a regression on the data for that date. The LD50 dropped from $143 \mathrm{R} / \mathrm{hr}$ for the Jure 1969 sampling date to $4 \mathrm{R} / \mathrm{hr}$ for the June 1970 sampling date. The LD100, by mid-1970 was approximately $10 \mathrm{R} / \mathrm{hr}$. Based on the data from the seasonal exposures, there was a considerable delay in the expresston of radiation damage and perhaps a part of the lethality was due to secondary causes which occurred because the radiation damaged the plants and they could not survive other environmental stresses.

For the spring exposed sector, it appeared that the LD50 was 15 to $40 \mathrm{R} / \mathrm{hr}$ and the $\mathrm{LD} 100$ between 45 and $68 \mathrm{R} / \mathrm{hr}$. For the summer 
exposed sector, the LD50 was 30 to $50 \mathrm{R} / \mathrm{hr}$ and the LD100 between 68 and $115 \mathrm{R} / \mathrm{hr}$ which indicated that the $\underline{0}$. polyacantha was more resistant in summer than in spring. The plants in the summer exposed sector were fust starting to flower when exposure started.

The data from the late fall exposed sector were inconclusive. Little or no damage was apparent by the September 1970 sampling date and most of the plants at the $185 \mathrm{R} / \mathrm{hr}$ exposure rate were still apparently alive by September 1970. The plants did not form flower or lobe buds during 1970 and did not appear healthy or vigorous by September 1970. A check was made In April of 1971 and the plants in the $185 \mathrm{R} / \mathrm{hr}$ exposure rate macroplot appeared dead so apparently the significant observation here was the delay in the expression of radiation damage.

Erlogonum effusum - Since it was difficult to determine in April whether or not spectfic plants of Eriogonum effusum were alive, only data from the June sampling dates were used. Also, the range between complete lethality and no effect on density was so small that it was not possible to apply a regression line to the data and only approxImations of LD100's were possible. For the chronically exposed sectors, the LD100 for E. effusum was between 12 and $18 \mathrm{R} / \mathrm{hr}$ and was approximately the same in 1969 and 1970.

For the spring exposed sector, the LD100 was between 68 and 185 $\mathrm{R} / \mathrm{hr}$. There were $\mathrm{E}$. effusum plants in the 185 and $68 \mathrm{R} / \mathrm{hr}$ exposure rate macroplots prior to irradiation but none in the $115 \mathrm{R} / \mathrm{hr}$ exposure rate macroplot. Those in the $185 \mathrm{R} / \mathrm{hr}$ macroplot were killed and those In the $68 \mathrm{R} / \mathrm{hr}$ macroplot appeared dead in June 1969 but had recovered and resumed growth by September 1969 and were near normal by the June 
1970 sampling date. The LD100 for the summer exposed sector was between 185 and $315 \mathrm{R} / \mathrm{hr}$. There was some reduction in the density of E. effusum exposed at. 185 and $115 \mathrm{R} / \mathrm{hr}$ (one of two and two of two plants died respectively). For the late fall exposed sector, the LD100 appeared to be between 45 and $68 \mathrm{R} / \mathrm{hr}$ although some recovery may take place that was not yet apparent in September 1970 .

Tradescantia occidentalis - The LD100 of Tradescantia occidentalis in the chronically exposed sectors decreased from between 45 to 68 $\mathrm{R} / \mathrm{hr}$ In June 1969 to between 18 and $28 \mathrm{R} / \mathrm{hr}$ in June 1970 based on data from sector 2. No $\underline{T}$. occidentalis occurred close enough to the source in sector 3 to determine the LD100 but it was greater than $12 \mathrm{R} / \mathrm{hr}$.

For the seasonally exposed sectors, the LDi00 was at least $45 \mathrm{R} / \mathrm{hr}$ for the spring sector, $115 \mathrm{R} / \mathrm{hr}$ for the summer sector and $18 \mathrm{R} / \mathrm{hr}$ for the late fall sector.

Based on LD50 and LD100 estimates from the density data, it appeared that Opuntia polyacantha was the most sensitive species, Erlogonum effusum slightly more resistant and Bouteloua gracilis and Tradescantia occidentalis still more resistant with very little difference between the 1atter two species. It also appeared that each spectes was the most sensitive. in late fall, less sensitive in spring and most resistant in summer except perhaps for Opuntia polyacantha.

As Indicated by the phenology data, it was expected that Tradescantia occidentalis would have been much more sensitive than either Bouteloua gracilis or Eriogonum effusum. The true sensitivity of Tradescantia occidentalis may have been masked by the growth habit 
of the plant which allowed the meristem to be shielded most of each year.

\section{Recovery}

There was no evidence of recovery in the chronically exposed sectors by September 1970 (chronic irradiation still continuing as of August 1971). The two species present in the high exposure rate macroplots ( 68 and $.45 \mathrm{R} / \mathrm{hr}$ ) were Gaura coccinea and Carex heliophila. These species were present prior to inftiation of irradiation. They remained allve but made little growth during 1970.

Recovery, when used in the sense of revegetation, was very rapid In the seasonally irradiated sectors except for the late fall exposed sector ( $1 \mathrm{t}$ is not to be implied that the recovery resulted in the same vegetation that existed prior to irradiation). The recovery seemed to result from two separate, simultaneous phenomena. One was the regrowth of perennials with underground perennating organs which were apparently not killed (or were attached to plants outside of the exposure area). In the high exposure macroplots near the source (1.e. $100 \mathrm{R} / \mathrm{hr}$ to $650 \mathrm{R} / \mathrm{hr}$ ) these species consisted primarily of Lygodesmia juncea (rush skeletonplant), Gaura coccinea (scarlet gaura) and Oenothera coronopifolia (evening primrose). Grasses and shrubs did not seem to recover in this manner.

The second method of recovery was the influx of invader species whose growth and development apparently resulted from release of interspecific competition with the perennials since the annuals present in the recovery area were also present in all other parts of the study area although smaller and with a lower frequency of occurrence. The 
species most common were Salsola kali tenuifolia (tumbling russian thistle), Lepidium densiflorum (prairie pepperweed) and Chenopodium leptophyllum (slimleaf goosefoot). Also present, but in smaller numbers, were Euphorbia glyptosperma (ridgeseed euphorbia) and Aster tanacetffollus (tansyleaf aster).

Recovery was detectable by the September 1969 sampling date in the spring exposed sector. During the 1970 growing season recovery took place in the spring and summer exposed sectors but very little In the late fall exposed sector and that limited to macroplots which had received exposure rates of less than $115 \mathrm{R} / \mathrm{hr}$ and consisted of the reappearance of perennials listed above. Apparently exposure rates of $68 \mathrm{R} / \mathrm{hr}$ or greater ( $54 \mathrm{kR}$ total) affected the germinability of the seed of the annuals since the seed was probably distributed before irradiation. (Visual observation in the early 1971 growing season indicated that there was an influx of invader specles with at least Salsola kali tenuifolia and Lepidium densiflorum seedlings present in large numbers.

Preliminary results of an associated study in which plots were disturbed by burning, scraping or rototilling indicated that recovery of the rototilled plots was most similar to recovery of the seasonally exposed macroplots which received high levels of radiation. The 1969 rototilled plots were invaded in 1970 by Salsola kali tenuifolia and Chenopodium leptophyllum with smaller numbers of Lepidium densiflorum, Aster tanacetifolius and Euphorbia glyptosperma. Plants of these species in the rototilled plots made vigorous growth during 1970 , especially Salsola kali tenuifolla and Chenopodium leptophyllum which 
paralleled the growth pattern of these species in the high exposure rate macroplots of the spring and summer exposed sectors.

\section{Coefficient of community}

The coefficient of community for the spring exposed sector Increased rapidly, although erratically, during the latter part of the 1969 growing season and during 1970 (Fig. 9). The apparent decrease in recovery for the April 1970 sampling date was due to the absence of early growing perennials and annuals and did not reflect a true lack of recovery. For the summer exposed sector, much the same pattern existed with very little recovery indicated by April 1970 but significant recovery was apparent by June 1970 (Fig. 10). For the late fall exposed sector, there was a much longer delay in detecting the effects of the radiation and no recovery was detectable by June 1970 (F1g. 11).

\section{Diversity index}

The recovery of the high exposure rate macroplots of the seasonally exposed sectors as measured by diversity was similar to that measured by the coefficient of community. The major difference was that the addition of a species added to diversity regardless of its occurrence elsewhere in the study area while the addition of a species added to the coefficient of community only if it also occurred in the control sector plots. This might allow the development of a highly diverse communtty in one of the recovering macroplots with a zero coefficient of community. In general, this was not a problem in this study since the control sector macroplots contained essentially all species that 
occurred in other sectors before, during or after irradiation. However, the recovery macroplots did not have the same vegetation as the stand prevtous to irradiation since major perennial grasses and shrubs had been eliminated (Figs. 16, 17 and 18).

\section{$\underline{\text { Yield }}$}

All yields, including total, the grass-sedge component and the visual estimates of the grass-sedge component, were recorded a' considerable time after cessation of irradiation and an opportunity for recovery had taken place.

The total yield and grass-sedge components of the total yield were determined by clipping the plots in September 1970. The visual estimates of the grass-sedge component were recorded in August 1969 for the spring exposed sector and in September 1970, just prior to clipping, for the spring, summer and late fall exposed sectors.

Total yleld - In the spring exposure sector, macroplot 1 (650 $\mathrm{R} / \mathrm{hr})$ had a significantly lower yield than the overali "no effects" mean of $132 \mathrm{~g} / \mathrm{m}^{2}$ although the reason is not apparent (Fig. 19). In macroplot $2\left(315 \mathrm{R} / \mathrm{hr}\right.$ ) the yield averaged approximately $1800 \mathrm{~g} / \mathrm{m}^{2}$. This was not significantly different from the overall average because of the high varlance which was primartly due to one large Salsola kali tenuifolia Individual in one microplot. The yield of the third macroplot (185 $\mathrm{R} / \mathrm{hr}$ ), had decreased to $260 \mathrm{~g} / \mathrm{m}^{2}$, not significantly different from the overall mean.

The yields in the high exposure rate macroplots of the summer exposed sector were similar. In macroplot 1 , the yield was just under 
$1000 \mathrm{~g} / \mathrm{m}^{2}$, again, due to large Salsola kali tenuifolia and also

Chenopodium leptophyllum plants. In macroplots further from the source, the yleld was not significantly different from the overail average. The high yield in the close in plots seemed to be due to Invasion by three species, the two mentioned above plus some Lepidium densiflorum. Other species were present but did not contribute significantly to the total yleld.

The late fall exposed sector showed a different pattern. No plants occurred in the close-in macroplots. Macroplot 3 did have some Opuntia polyacantha that were apparently still alive by September 1970 and this species contributed all of the $18 \mathrm{~g} / \mathrm{m}^{2}$ yield of that macroplot. In macroplots 4 and 5, some carex was still growing and that spectes made up the 1 and $4 \mathrm{~g} / \mathrm{m}^{2}$ average yield in those 2 macroplots. In macroplot 6 , several species, including Bouteloua gracilis, were present and the yield was $46 \mathrm{~g} / \mathrm{m}^{2}$, still significantly lower than the overall average. The annuals present in the recovery of the spring and summer exposed sectors were missing from the December exposure sector, apparently due to the effect of the radiation on the seed of the annuals. Lack of these annuals prevented the large yield in the close-in macroplots of the late fall exposed sector as was seen in the spring and summer exposed sectors.

Visual estimates of grass-sedge yleld - Visually estimating the grasssedge yield gave essentially the same results as the clipped yield and involved considerably less time. It took approximately 15 minutes per macroplot to clip the grass-sedge component. In addition, the clipped material had to be dried and weighed. Visual estimates took 
approximately two minutes per macroplot plus approximately one hour per day for calibration by clipping plots outside the radiation field. The September 1969 YLD50 from the visual estimates was $16 \mathrm{R} / \mathrm{hr}$ and the DI50 was $31 \mathrm{R} / \mathrm{hr}$ or a ratio of 1.9:1. For September 1970 the values were $9 \mathrm{R} / \mathrm{hr}$ for YLD50 and $14 \mathrm{R} / \mathrm{hr}$ for DI50 or a ratio of $1.6: 1$. If the grasses and sedges are the most resistant component of the plant comminity, then this ratio should approach 1 under long-term chronic irradiation.

Note that there was no change in the YLD50 for the spring irradiation treatment from 1969 to 1970 (67 compared to $66 \mathrm{R} / \mathrm{hr}$ ) indicating some growth of Bouteloua gracilis after the cessation of irradiation In 1969 but little, if any, recovery during 1970 by new growth or spreading of old plants.

\section{Density}

There was no clear pattern of recovery for Bouteloua gracilis in the seasonal Irradiation treatments by September 1970. The low LD50 of $19 \mathrm{R} / \mathrm{hr}$ for the sumer irradiation treatment, April 1970 sampling date was apparently due to a lack of early growth of the $\underline{B}$. gracilis crowns since the June 1970 data did not indicate similar results. For the late fall irradiation treatment, cover values in the "effects" zone decreased during 1970 and it was not clear by September 1970 if they had stabilized.

There was a time lag in the expression of radiation damage for Opuntia polyacantha as measured by density. It should be noted that the "no effects" mean was higher for all June 1969 and 1970 data than for other sampling dates due to the formation of new lobes. Apparently 
old lobes died during the growing season since the lobe density decreased by September each year. This change did not appear in the "effects" zone and probably reflects radiation damage to the meristem or due to a general reduction in the vigor of the plant. There was no indication of recovery for $\underline{0}$. polyacantha.

For the other two specles for which density was reported, Eriogonum effusum and Tradescantia occidentalis, there was no indication of recovery except for macroplot $5(68 \mathrm{R} / \mathrm{hr})$ of the spring irradiation treatment. E. effusum plants in this plot appeared to be dead at the June 1969 sampling date but had recovered by the September 1969 sampling date. They were st111 living in 1970 and appeared to have good vigor. 


\section{Chapter 5}

\section{CONCLUSIONS}

The shortgrass plains plant community appears to be very radioresistant. McCormick (1969) summarizes the sensitivities of plant communities studied to that date and lists the exposures necessary to cause severe effects from 2 to $3 \mathrm{kR}$ for a pine forest to $45 \mathrm{kR}$ for an abandoned crop land community. Based on the results of the present study the most sensitive period for the shortgrass vegetation, of the 3 pertods studied, was late fall with $120 \mathrm{R} / \mathrm{hr}(95 \mathrm{kR})$ necessary to cause a 50 per cent reduction in coefficient of community and 60 to $90 \mathrm{R} / \mathrm{hr}$ (48 to $56 \mathrm{kR}$ total) resulting in a 50 per cent reduction in diversity. Both coefficient of community and diversity can be considered as detecting severe effects since both involve the elimination of individual plants to cause changes.

Minor effects, such as a reduction in growth, was estimated as 0.1 to $1 \mathrm{kR}$ for the plne forest and 3 to $7 \mathrm{kR}$ for the abandoned crop land community. The exposure rate that resulted in a 50 per cent reduction in the yield of the grass-sedge component of the shortgrass vegetation was $31 \mathrm{R} / \mathrm{hr}$ ( $24 \mathrm{kR}$ total) for the most radiosensitive season, late fall.

The most senstive indication of radiation induced change appeared to be phenology. Tradescantia occidentalis and Opuntia polyacantha had similar radiation sensitivities and the lowest exposure rate affecting phenology in the chronically irradiated sectors during the second, growing season was $1 \mathrm{R} / \mathrm{hr}(24 \mathrm{R} / \mathrm{da})$. In contrast, Woodwell and Rebuck (1967) reported that, for the oak-pine forest, there was a 
measurable reduction in helght growth of stems and trees (both oak and pine) at a chronic exposure rate of $1 \mathrm{R} / \mathrm{da}$.

Miller (1968) reported that an old fleld plant community was most sensitive during the spring, least sensitive during winter and intermediate during summer and fall. The results of this study indicated that the shortgrass vegetation is most sensitive in late fal1, least sensitive in summer and intermediate in spring. The spring and summer irradiation treatments corresponded in time (April and July) to M11ler's study but the late fall irradiation treatment (December) was during the time between Miller's fall (October) and winter (January) treatments. In both studies, the period of irradiation was approximately 30 days. Had the same total exposure for each sector been delivered in a few hours (an acute exposure) instead of 30 days (semiacute or semi-chronic) the shortgrass plains vegetation would have probably been most radiosensitive during the spring period when meristematic activity was high.

The effects of the radiation (and early recovery for the seasonal irradiation treatments) are graphically displayed in photographs taken In August 1970 (Fig. 25 through 28). Fig. 25 shows the "lethal" zone in one chronic treatment sector with a portion of the "effects" zone near the left edge of the picture. Also, a portion of the other chronic zone can be seen in the foreground. The control sector can be seen in the background. Fig. 26 shows the spring exposed sector where large plants of Salsola kali tenuifolia can be seen near the source. The summer exposed sector is shown in Fig. 27 and the large $\underline{\text { s. }}$ kali tenuifolia plants can be seen near the source. Other species are present but cannot be recognized in the picture. Fig. 28 shows the 
129

0

O

O

0 
Fig. 25. Photo of chronically irradiated area (sector two). The arcs indicate approximate boundaries of macroplots starting with macroplot 1 nearest the source at the right. Portions of macroplots $8,9 \& 10$ can be seen at the left. Patches of dead Opuntia polyacantha can be seen in macroplots 4, 5, $6 \& 7$. Patches of living Bouteloua gracilis can be seen in macroplot 7 with more general growth noted in macroplot 8 . The control sector extends out from the source to the upper left and the other chronically exposed sector extends out to the lower left. Note the vegetation in the shadow area. Shadow areas were used as walkways to the source area and macroplots. The chain link security fence, gates and control house ( 500 feet away) can be seen in the background. Photo was taken with a Canon FTQL SLR $35 \mathrm{~mm}$ camera with a FL $28 \mathrm{~mm}$ wide angle lens on 12 August 1970,15 months after initiation of chronic irradiation. 


Fig. 26. Photo of the spring exposed sector showing the first 6 macroplots out from the source. Note the large Salsola kali tenuifolia plants near the source. Smaller plants in microplot 1 are mostly Lygodesmia juncea, a perennial. Stakes near the center of each macroplot mark the location of the 12 permanent microplots. Some of the $\underline{s}$. kali tenuifolia to the left are growing in the shadow area. Photo was taken with a Canon FTQL SLR $35 \mathrm{~mm}$ camera with a FL $28 \mathrm{~mm}$ wide angle lens from the rear of macroplot 8 ( $9 \mathrm{~m}$ from source) on 4 August 1970, 15 months after the irradiation treatment. 





Fig. 27. Photo of the summer exposed sector showing the first 6 macroplots out from the source. Note the vigorous recovery growth in macroplots 1 and 2 . This growth was comprised mostly of Salsola kali tenuifolia, Chenopodium leptophy1lum and Lepidium densiflorum. Average yield from macroplot 2 in September 1970 was $1800 \mathrm{~g} / \mathrm{m}^{2}$ while average yield from macroplot 6 was $180 \mathrm{~g} / \mathrm{m}^{2}$. Photo was taken with a Canon FTQL SLR $35 \mathrm{~mm}$ camera with a FL $28 \mathrm{~mm}$ wide angle lens from the rear of macroplot 8 (9 m from source) on 4 August 1970, 12 months after the irradiation treatment. 





Fig. 28. Photo of the late fall exposed sector showing the first 6 macroplots out from the source. Note the complete lack of recovery in the macroplots near the source (the Chenopodium sp. plant near the source was rooted in the walkway behind macroplot 1). Also note the persistence of Opuntia polyacantha in macroplot 3. Pitfall traps, used in an associated arthropod study, can be seen along the centerline of the sector. Photo was taken with a Canon FTQL SLR $35 \mathrm{~mm}$ camera with a FL $28 \mathrm{~mm}$ wide angle lens from the rear of macroplot 8 ( $9 \mathrm{~m}$ from the source) on 4 August 1970,8 months after the irradiation treatment. 


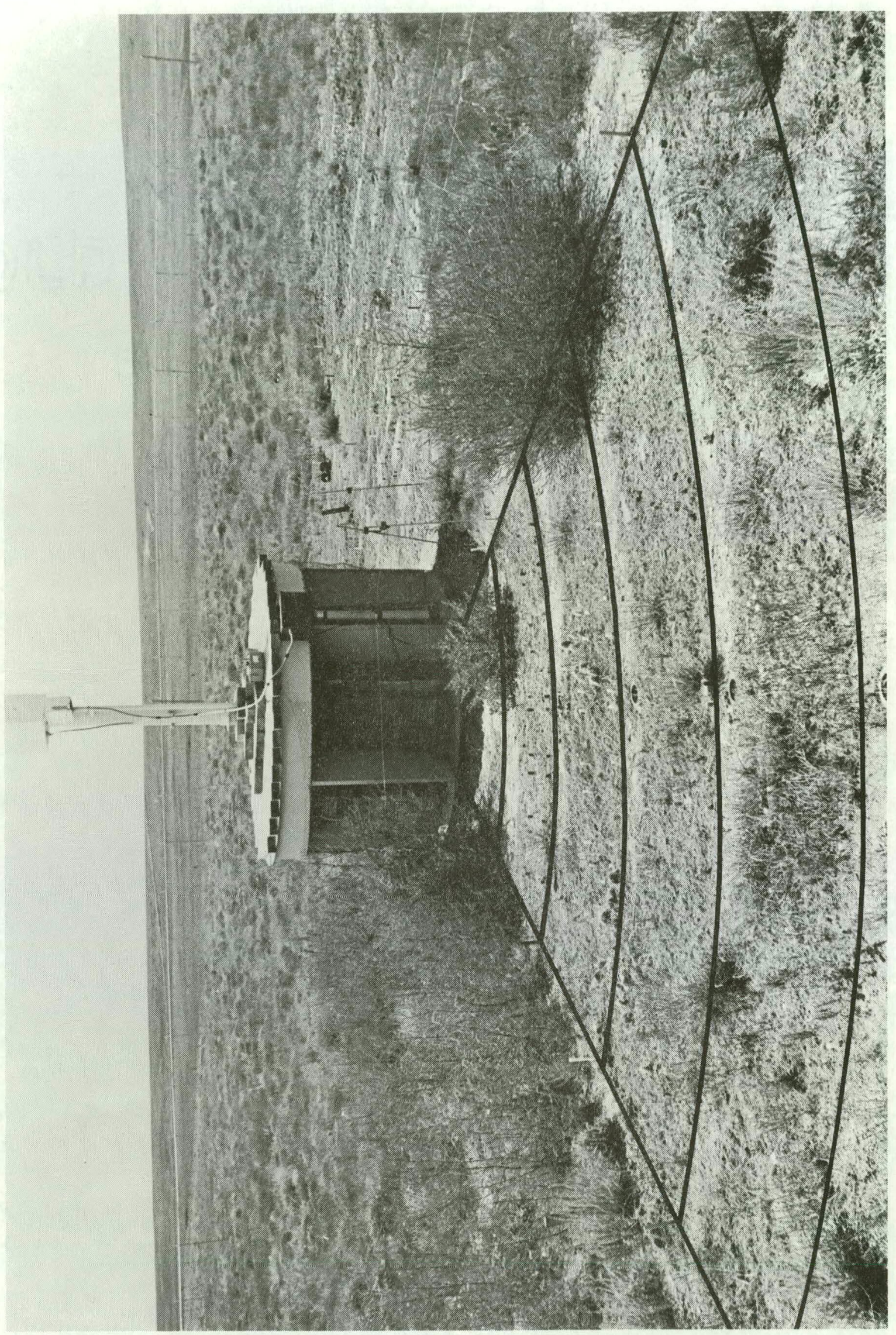


late fall exposed sector. Macroplots near the source are bare except for the Opuntia polyacantha in macroplot $3(185 \mathrm{R} / \mathrm{hr})$. Also, there is one plant, tentatively Identified as Chenopodium sp. that occurred in the walkway between macroplots 1 and 2 . This was the only plant of this specles seen in the study area.

In general, the results of this study seem to warrant these conclusions :

1. The structure of shortgrass plains vegetation is very radioresistant with exposure rates of 8 to $24 \mathrm{R} / \mathrm{hr}$ necessary to result in a 50 per cent reduction in the coefficient of communtty and/or diversity after 15 to 18 months of chronic exposure to gamma radiation.

2. Shortgrass plains vegetation is most sensitive to semiacute ( 30 day) gamma radiation in late fall, most resistant in summer and intermediate in spring.

3. Individual species of the shortgrass plains plant community are relatively radioresistant with the most sensitive species (Opuntia polyacantha and Tradescantia occidentalis) requiring a chronic exposure rate of $1 \mathrm{R} / \mathrm{hr}$ to produce detectable results as measured by changes in phenology.

4. Shortgrass plains vegetation showed rapid recovery from the effects of semi-acute radiation due to an influx of invader species (primarily Salsola kali tenuifolia and Chenopodium leptophyllum) and recovery of perennial species with underground perennating organs (primarily Lygodesmia juncea, Gaura coccinea and Denothera coronopifolia), although recovery rates varied with season of exposure. Recovery had not. taken place 
for the dominant spectes, Bouteloua gracilis, by the end of the 1970 growing season, and recovery for this spectes may be very slow. The plant community resulting from the early recovery phase appeared to have an entirely different structure (and probably function) than the pre-irradiation plant community. 


\section{LITERATURE CITED}

Cowan, J.J. and R.B. Platt. 1963. Radiation dosages in the vicinity of an unshielded nuclear reactor. p.311-318. in: V. Schultz and A.W. Klement, Jr. (Ed.) Radioecology. Reinhold, N.Y. 746 p.

Daniel, C.P. 1963. Study of successton in fields irradiated with fast neutron and gamma radiation. p.277-282. in: V. Schultz and A.W. Klement, Jr. (Ed.) Radioecology. Reinhold, N.Y. 746p.

Greig-Smith, P. 1964. Quantitative Plant Ecology. Butterworth \& Co., London, England. 256 p.

Harrington, H.D. 1954. Manual of the plants of Colorado. Sage Books, Denver, Colorado. $666 \mathrm{p}$.

Hyder, D.N., R.E. Bement, E.E. Remmenga, and C. Terwilliger, Jr. 1965. Frequency sampling of blue grama range. J. Range Manage. 18:90-93.

Hyder, D.N., R.E. Bement, E.E. Remmenga, and C. Terwilliger, Jr. 1966. Vegetation-soils and vegetation-grazing relations from frequency data. J. Range Manage. 19:11-17.

Iqbal, J. 1970. Recovery from cellular damage in vegetative shoot aptces of Capsicum annuum L. after acute gamma irradiation. Radiat. Bot. 10:337-343.

Klipple, G.E. and D.F. Coste11o. 1960. Vegetation and cattle responses to different intensities of grazing on short-grass ranges on the Central Great Plains. USDA Tech. Bul. No. 1216. $82 \mathrm{p}$.

Lyerly, R.L. and W. Mitchell, III. 1969. Nuclear power plants. U.S. Atomic Energy Commission, Division of Technical Information, Oak Ridge, Tennessee. $54 \mathrm{p}$.

McCormick, J.F. 1963. Changes in a herbaceous plant community following exposure to ionizing radiation gradients. p.271-276. in: V: Schultz and A.W. Klement, Jr. (Ed.) Radioecology. Reinhold, N.Y. 746 p.

McCormick, J.F. 1966. Effects of ionizing radiation on a southeastern pine forest. J. Elisha Mitchell Sci. Soc. 82(2):85.

McCormick, J.F. 1969. Effects of ionizing radiation on a pine forest. p. 78-87. in: D.J. Nelson and F.C. Evans (Ed.) Symposium on radioecology. CONF-670503. U.S. Atomic Energy Commission, Division of Technical Information Extension, Oak Ridge, Tennessee. $774 \mathrm{p}$. 
McCormick, J.F. and F.B. Golley. 1966. Irradlation of natural vegetation. An experimental facility, procedures and dosimetry. Hea1th Physics 12:1467-1474.

Miller, C.F. and P.D. LaRiviere. 1966. Introduction to long-term biological effects of nuclear war. SRI Project No. MU-5779. Stanford Research Institute, Menlo Park, California. 156 p.

Miller, G.L. 1968. The influence of season on the radiation sensitivity of an old field community. $\mathrm{Ph}$. D. Thesis. University of North Carolina, Chapel Hill, North Carolina. 250 p.

Monk, C.D. 1966. Effects of short-term gamma irradiation on an old field. Radiat. Bot. 6:329-335.

Morgan, K.2. and J.E. Turner. 1967. Principles of radiation protection: John Wiley and Sons, Inc. New York. 622 p.

Patten, B.C. 1962. Species diversity in net phytoplankton of Raritan Bay. J. Marine Res. 20:57-75.

Pechanec, J.F. and G.D. Pickford. 1937. A comparison of some methods used in determining percentage utilization of range grasses. J. Agr. Res. 54:753-765.

Platt, R.B. 1963. Ecological effects of ionizing radiation on organisms, communities and ecosystems. p. 243-255. in: V. Schultz and A.W. Klement, Jr. (Ed.) Radioecology. Reinhold, N.Y. 746 p.

Scoville, H., Jr. 1971. The limitation of offensive weapons. Sc1: Amer. 224:15-25.

Singleton, W.R., A. Caspar and W.S. Flory, Jr. 1961. A cobalt machine for semi-acute irradiation of growing plants. Int. J. Appl. Radiat. and Isotopes. 10:47-54.

Snedecor, G.W. 1956. Statistical methods. The Iowa State University Press, Ames, Iowa. $534 \mathrm{p}$.

Sparrow, A.H. and W.R. Singleton. 1953. The use of radiocobalt as a source of gamma rays and some effects of chronic irradiation on growing plants. Amer. Nat. 87:29-48.

Tamplin, A.R. 1970. The regulation of man-made radiation in the biosphere. p. 45-51. in: H. Foreman (Ed.) Nuclear power and the public. University of Minnesota Press, Minneapolis. 273 p.

Taylor, F.G. 1966. Predicted seasonal radiosensitivity of southeastern tree species. Radiat. Bot. 6:307-311. 
U.S. Department of Defense. 1969. Annual report of the Department of Defense for fiscal year 1967. U.S. Government Printing Office, Washington, D.C. 20402. 506 p.

U.S. Department of Health, Education, and Welfare. 1960. Radiological health handbook. U.S. Department of Health, Education and Welfare, Public Health Service, Bureau of State Services, Division of Radiological Health, Washington, D.C. 468 p.

Vaughn, T.A. 1967. Food habits of the northern pocket gopher on shortgrass prairie. Amer. Mid1. Natur. 77:176-189.

Whicker, F.W. and A.H. Dah1. 1968. Radioecology of some natural organisms and systems in Colorado. Sixth Annual Progress Rept. on Atomic Energy Commission Contract AT(11-1)-1156. Department of Radiology and Radiation Biology, Colorado State University, Fort Collins, Colorado. 32 p.

Witherspoon, J.P. 1965. Radiation damage to forest surrounding an unshielded fast reactor. Health Physics 11:1637-1642.

Witherspoon, J.P. 1969. Radiosensitivity of forest tree species to acute fast neutron radiation. p. 120-126. In: D.J. Nelson and F.C. Evans (Ed.) Symposium on radioecology. CONF-670503. U.S. Atomic Energy Commission, Division of Technical Information Extension, Oak Ridge, Tennessee. 774 p.

Woodwe11, G.M. 1963. Design of the Brookhaven experiment on the effects of ionizing radiation on a terrestrial ecosystem. Radiat. Bot. 3:125-133.

Woodwe11, G.M. and J.K. Oosting. 1965. Effects of chronic gamma Irradiation on the development of old field plant communities. Radiat. Bot. 5:205-222.

Woodwe11, G.M. and A.L. Rebuck. 1967. Effects of chronic gamma radiation on the structure and diversity of an oak-pine forest. Ecol. Monogr. 37:53-69.

Woodwell, G.M. and A.H. Sparrow. 1963. Predicted and observed effects of chronic gamma radiation on a near-climax forest ecosystem. Radiat. Bot. 3:231-237. 
0

○

APPENDIX 1.

O

O 
Checklist of plant species identified in the study area.*

\section{GRASSES}

\section{Sclentific Name}

Agropyron smithif

Aristida longiseta

Bouteloua gracilis

Buchlóe dactyloides

Festuca octoflora

Muhlenbergia torreyi

Oryzopsis hymenoides

Schedonnardus paniculatus

Sitanton hystrix

Sporobolus cryptandrus

Stipa comata

Carex fllifolia

Carex hellophila

Abronia fragrans

Allum textile

Argemone intermedia

Aster tanacetifolius

Astragalus bisulcatus

Astragalus gracilis

Astragalus mollissimus

Chenopodium album

\section{Common Name}

bluestem wheatgrass

red threeawn

blue grama

buffalograss

sixweeks fescue

ring muhly

indian ricegrass

tumblegrass

bottlebrush squirreltail

sand dropseed

needleand thread

SEDGES

threadleaf sedge

sun sedge

FORBS

snowbal1 sandverbena

textile onion

prickle poppy

tansyleaf aster

twogrooved loco

woolly loco

lambsquarters goosefoot

*Most scientific names follow Harrington (1954). 
Checklist (continued)

FORBS

Scientific Name

Common Name

Chenopodium leptophy 11 um

slimleaf goosefoot

Chrysopsis villosa

hairy goldaster

Cirsium undulatum

wavyleaf thistle

Cleome serrulata

bee spiderflower

Cryptantha jamesi $i$

james cryptantha

Cryptantha minima

Erigeron pumilis

low fleabane

Erlogonum effusum

bucl wheat

Euphorbia glyptosperma

ridgeseed euphorbia

Gaura coccinea

scaylet gaura

Gilia laxiflora

Grindelia squarrosa

curjycup gumweed

Haplopappus spinulosis

irouplant goldenweed

Helianthus annuus

common sunflower

Helianthus petiolaris

prairie sunflower

Lappula redowski

stickseed

Lepidium densiflorum

prairie pepperweed

Leucocrinum montanum

common starlily

Liatris punctata

dotted gayfeather

Lithospermum incisum

gromwe11

Lupinus pusillus

rusty lupine

Lygodesmla juncea

rush skeletonplant

Mentzelia stricta

stickleaf 
Checklist.. (continued)

\section{FORBS}

Scientific Name

Mirabilia linearis

Oenothera coronopifolia

Oxytropis lambert11

Penstemon albidus

Penstemon angustifollus

Physalis lanceolata

Plantago purshii

Psoralea tenuiflora

Ratibida columnaris

Salsola kali tenuiflora

Scutellaria brittonif

Senecio multicapitatus

Senecio tridenticulatus

Sphaeralcea coccinea

Stephanomeria pauciflora

Taraxacum

Talinum parvifiorum

Thelesperma megapotamicum

Thelesperma trifidum

Tradescantia occidentalis

Tragopogon porrifolius

Verbena bracteata

\section{Common Name}

four o'clock

evening : primrose

lambert crazyweed

white penstemon

narrowleaf penstemon

ground cherry

woolly indianwheat

common breadroot scurfpea

upright prairieconeflower.

russianthistle

brittons. skullcap

scarlet globemallow

wirelettuce

dandelion

prairie flameflower

spiderwort

vegetable-oyster salsify

bigbract verbena 
Checklist (continued)

\begin{tabular}{lc}
\hline \multicolumn{1}{c}{ Scientific Name } & SHRUBS \\
Artemisia frigida & Common Name \\
Chrysothamnus nauseosus & fringed sagebrush \\
Gutierrezia sarothrae & broom snakeweed \\
Mamillaria vivipara & common pricklypear \\
Opuntia polyacantha & small soapweed \\
Yucca glauca & OTHERS
\end{tabular}


0

O

APPENDIX 2

O

O 


\section{PROCEDURES}

(1)

Department of Radiology and Radiation Biology

Colorado State University

May 15, 1969 
OPERATION OF GRASSLAND RADIATION FACILITY

A. Authorized Users

Operation of the radiation source is 1 imited to individuals specifically authorized by Colorado State University's Radiation Safety. Committee and by the project's principal investigator. At present, the following individuals are authorized to utilize the facility: F. Ward Whicker, Leslie Fraley, Jr., and Larry L. Cadwell.

B. Custody of Keys to Facility

The University's Radiation Control Officer, Keith $\mathrm{J}$. Schiager and the project leaders, Leslie Fraley and F. Ward Whicker each have custody of a set of the keys necessary to operate the radiation facility. These persons are responsible for the security of all keys to the facility.

C. Records of Facility Usage

Each time the facility is occupied, a log sheet (see next page) will be completed. Complated log sheets $w$ ill be duplicated. The original copies will be kept by the project leader and the duplicate copies $w$ ill be submitted to the Radiation Control Officer.

D. Personnel Monitoring and Protection

All personnel associated with the grassland radiation study shall wear film badges and direct reading pocket dosimeters while at the facility. Visitors shall wear direct reading pocket dosimeters while at the facility. The initial, final, and net radiation exposure readings shall be recorded daily on the log sheet by each person at the facility.

A calibrated portable GM survey meter shall be maintained permanently in the control house. Upon arrival at the facility, the user shall immediately ascertain that the survey meter is functioning properly. A "test" reading is made with a calibration source. If the "test" reading indicates that the GM survey meter is not functioning properly, access to the facility shall not be granted until a survey meter that is operating properly can be brought to the facility. The dose rate at the control panel with the radiation source in the up position is measured. Another reading is taken after the source has been lowered before entry into the radiation field. All readings are recorded on the 
To be completed lor each visitation.

I. Diate:

II. Personnel Exposure Data (1 ist all persons entering the irradiation ficld and the monitoring device worn by each):

Chamber

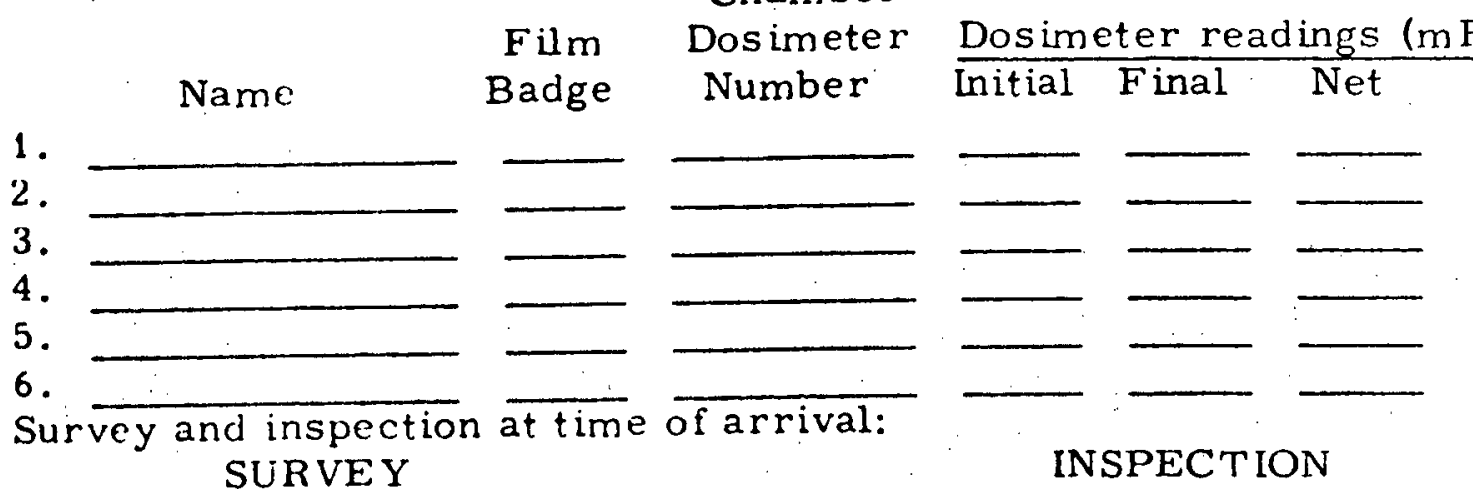

III. Survey and inspection at time of arrival: SURVEY

1. Meter used

2. Calibration date

3. "Test" reading $\mathrm{mR} / \mathrm{Hr}$

1. Wa rning lights

INSPECTION

4. Control Panel

Source up $\mathrm{mR} / \mathrm{Hr}$

Source down

2. Winch

3. Cables

IV. Utilization record:

Purpose

Irradiation shut down time

Time down Time up Total down time

V. Terminal survey and inspection:

1. Source activated Power ON and LOCKED

2. Control panel survey $\mathrm{mR} / \mathrm{Hr}$

3. Control house LOCKED Survey meter OFF

\section{All gates LOCKED}

4. Sections II and IV completed

User's signature

VI. Miscellancous notes and observations:

VII. (Radiation control use only)

Dosimeter data recorded 
$\log$ sheet. The first person to enter the radiation field after lowering the source shall carry the survey meter into the field to verify that the source is completely down. When the source is re-activated, another dose rate measurement at the control panel is made and recorded.

Any worker entering the radiation field shall place a padlock through the winch and carry the key on his person so that the source cannot be raised until all workers have checked out through the control house.

E. Inspections of Facility and Leak Tests

Visual inspection of indicator and warning lights, winch, cables, pulleys, interlocks, and other hardware associated with the source is conducted during each visit to the facility and noted on the log sheet. Visual inspection of the security fences and gates shall be made at least every two weeks. Any malfunctions and/or damage of any component of the facility shall be recorded on the log sheet, reported to the Radiation Control Officer and principal investigator, and appropriate action initiated as soon as possible. Should any damage or malfunction create a possible radiation hazard to persons or livestock, the source must be shut down unt il the facility is repaired.

Every six months, a sample of oil shall be withdrawn from the lead shield source container and quantitatively assayed for the presence of radioactivity. Results shall be submitted to the Radiation Control Officer and to the State of Colorado, Department of Public Health. If a sample of oil contains more than $0.05 \mathrm{microcuries}$ per $\mathrm{m}$ illiliter, the source must be shut down immediately and corrective action taken in accordance with State of Colorado regulations.

F. Normal Operating Procedures

1. Upon entry into the control house, complete sections I and Il of Log Sheet. Mlake certain that appropriate pocket dosimeters and film badges are worn by each individual planning to enter the radiation field.

2. Verify proper operation of GM survey meter and complete. section III, items 1-3 on Log Sheet. Measure dose rate at control panel and record on Log Sheet (section III, iten, 4). A reading of less than $0.05 \mathrm{mR} / \mathrm{hr}$ indicates source 
is down. A reading in excess of $0.1 \mathrm{mR} / \mathrm{hr}$ indicates source is up.

3. Inference regarding status of source from survey meter reading should agree $w$ ith indication from control panel

lights. The possible indicator light combinations and their meanings are given below:

Control Panel

Indicator Lights

Red

Amber

(a)

Green

Magnet current

Magnet position

Source position ${ }^{*}$

\begin{tabular}{lllll}
\multicolumn{5}{c}{ Combinations } \\
\hline on off & off & on & off & off \\
on on & on & off & off & off \\
off off & on & off & off & on \\
on on & on & off & off & off \\
up intermediate down & up & intermediate & down \\
up intermediate down & down & down & down
\end{tabular}

Source position must never be inferred from indicator lights alone. A malfunction or improper operation could lead to a false indication.

If the status of the source as. determined from the survey meter does not agree with its position according to the control panel indicator lights, an abnormal situation is indicated. For example, if the control panel lights indicate source to be in the "up" or "intermediate" positions and the survey meter reads less than $0.05 \mathrm{mR} / \mathrm{hr}$, the magnet should be lowered until the green indicator light is on and the winch cable rider is in the "down" position. With the magnet current on, it should now be possible to raise the source. Should the survey meter indicate greater than $0.1 \mathrm{mR} / \mathrm{hr}$ when the control panel lights indicate source "down", an abnormal situation exists. If the discrepancy cannot be accounted for by burned-out indicator lights, EMERGENCY PROCEDURES (Section G) must be followed.

Any abnormal condition must be reported at once to the Radiation Control Officer and the principal investigator for evaluation and corrective action. 
4. The source is normally in the "up". position upon the worker's arrival. When items F. 1. through F. 3. have been completed and it is determined that the status of the source is as expected, the source may be lowered. To lower the source:

a. Remove padlock from winch.

b. Prepare to observe survey meter and record time.

c. Release winch ratchet cog.

d. Lower magnet and source by turning winch handle clockwise at the rate of about 1 turn every second. As the source is lowered, observe cables to ascertain that slippage or fouling does not occur. Survey meter readings should momentarily increase and then decrease rapidly as the source is lowered. Record the time on the log sheet when the survey meter indicates less than $0.05 \mathrm{mR} / \mathrm{hr}$. When the source is about 18 inches from the "down" position, decrease the rate of lowering to about 1 turn every 30 seconds to allow the oil time to flow past the source. Continue until the green indicator light is on.

e. Engage winch ratchet cog.

f. Place padlock in winch.

g. Switch magnet current off.

5. Radiation field may be entered only after additional survey meter readings indicate that source is down.

6. Never lower source by'sw itching magnet off unless othe $r$ methods have failed and one of the security fences is damaged. If the source cannot be lowered by the normal method, EMERGENCY PROCEDURES (Section G) must be followed.

7. To raise source:

a. Make certain that all persons are out of the radiation field.

b. Lock gates at inner security fence and control house. 
c. Shut and lock south door of control house.

d. Prepare to observe survey meter and record time.

e. Remove padlock (s) from winch.

f. Release winch ratchet cog.

g. Turn magnet current on (amber indicator light should turn on).

h. Raise magnet and source by turning winch handle counter clockwise. Raise source slowly ( 1 turn per 60 seconds) for the first 18 inches to allow oil to drain past source. Observe cables to ascertain that slippage or fouling does not occur. Turn winch at the rate of 1 turn every second after oil has seeped beneath source. Record time on $\log$ sheet when survey meter indicates more than $0.1 \mathrm{mR} / \mathrm{hr}$. Survey meter readings should approach $2.5 \mathrm{mR} / \mathrm{hr}$ when source is in intermediate position and then decrease as source approaches sky-shield. Approach up position at a somewhat slower rate until red indicator light is on.

i. Engage winch ratchet $\operatorname{cog}$.

j. Place padlock in winch.

k. Ascerta in that winch-operated bolt is across south door of control house.

8. Complete Sections IV, V, and VI of log sheet.

9. Lock all doors and gates as facility is vacated.

\section{G. EMERGENCY PROCEDURES}

1. If any of the following conditions are found to exist, emergency action must be taken immediately:

a. Physical Damage to either fence or to control house that would be sufficient to permit easy entry of humans or livestock into the radiation or high radiation areas. 
b. Malfunction of Source such that source is frozen in the "up" or "intermediate" positions and cannot be lowered by normal means.

c. Source Leakage sufficient to allow measurable contamination beyond the source capsule.

d. Any other condition which would indicate the safety of the facility to be questionable.

\section{EMERGENCY ACTION}

a. Lower radiation source if possible.

b. Make certain that no persons or livestock are in the radiation field.

c. Make certain that no persons or livestock can inadvertently enter radiation field.

d. Contact the Radiation Control Officer and the project's principal investigator as soon as possible.

Nearest telephones: Pawnee Site Headquarters, International Biological Program and Central Plains Experimental Range Headquarters, U.S.D.A.

Radiation Control Officer:

Keith J. Schiager, Fort Collins, Colorado State University:

$491-6745$

$491-6746$

Home: 484-0971

Principal Investigator:

F. Ward Whicker, Fort Collins, Colorado State University:

$491-5343$

$491-5222$

Home: 482-2022

Leslie Fraley, Jr., Fort Collins, Colorado State University: $491-5343$ $491-5222$

Home: $\quad 484-0655$ 
e: DO NOT ATTEMPT TO ENTER RADIATION FLELD
OR TO MAKE RYIAIRS.

3. Emergency Inspection and Repair

a. Entry into the radiation field with the source "up" or "intermediate" shall be performed only under the direct supervision of the Radiation Control Officer. No individual, including the Radiation Control Officer, shall work alone during emergency inspection and repair :

b. All personnel involved with emergency inspection and repair shall wear both a film badge and a $200 \mathrm{mR}$ pocket dosimeter. A high range monitoring instrument shall be provided for use in addition to the survey meter normally available at the facility.

c. In the event that any malfunction of the facility cannot be properly corrected by Colorado State University personnel without exceeding the permissible exposure limits specified in the University's Radiation Control Manual, technical assistance $w i l l$ be requested from elsewhere. 
0

O

APPENDIX 3

O

O 
Table 23 . Temperature and prec1p1tation for Apri1 1968 through December 1970 at the grasslands irradiation study area weather station.

\begin{tabular}{|c|c|c|c|c|c|}
\hline Year & Month & $\begin{array}{c}\text { Average } \\
\text { Maximum } \\
\text { Temperature } \\
\left({ }^{\circ} \text { Celcius }\right) \\
\end{array}$ & $\begin{array}{c}\text { Average } \\
\text { Minimum } \\
\text { Temperature } \\
\left({ }^{\circ} \text { Celcius }\right) \\
\end{array}$ & $\begin{array}{c}\text { Average } \\
\text { Average } \\
\text { Temperature } \\
\text { (ocelcius) } \\
\end{array}$ & $\begin{array}{c}\text { Precipitation } \\
(\mathrm{cm})\end{array}$ \\
\hline \multirow[t]{9}{*}{1968} & Apr & 11.7 & -1.6 & 5.0 & 4.0 \\
\hline & Miry & 18.4 & 3.7 & 11.1 & 7.5 \\
\hline & Jun & 26.0 & 9.4 & 17.7 & 5.9 \\
\hline & Ju 1 & 28.8 & 11.6 & 20.2 & 3.3 \\
\hline & Aug & 27.0 & 10.5 & 18.7 & 4.3 \\
\hline & Sep & 24.0 & 4.9 & 14.4 & .7 \\
\hline & Oct & 18.5 & .7 & 9.6 & 1.7 \\
\hline & Nov & 7.1 & -7.2 & 0 & 2.1 \\
\hline & Dec & 4.4 & -11.5 & -3.5 & 1.4 \\
\hline \multirow[t]{12}{*}{1969} & Jan & 7.0 & -10.0 & -1.5 & .3 \\
\hline & Feb & 7.2 & -8.1 & -.4 & .7 \\
\hline & Mar & 6.3 & -8.8 & -1.2 & .8 \\
\hline & Apr & 17.6 & .4 & 9.0 & 4.4 \\
\hline & May & 21.1 & 6.1 & 13.6 & 7.4 \\
\hline & Jun & 20.9 & 7.7 & 14.3 & 7.3 \\
\hline & Jul & 30.5 & 12.9 & 21.7 & 2.4 \\
\hline & Aug & 30.9 & 12.6 & 21.7 & 1.4 \\
\hline & Sep & 25.6 & 8.3 & 16.9 & 5.0 \\
\hline & Oct & 9.4 & -1.6 & 3.9 & 6.2 \\
\hline & Nov & 11.3 & -5.6 & 2.8 & 1.0 \\
\hline & Dec & 6.5 & -7.8 & -.7 & .2 \\
\hline
\end{tabular}


Table 23 . (continued)

\begin{tabular}{|c|c|c|c|c|c|}
\hline Year & Month & $\begin{array}{c}\text { Average } \\
\text { Maximum } \\
\text { Temperature } \\
\left({ }^{\circ} \mathrm{Ce} 1 \text { clus }\right) \\
\end{array}$ & $\begin{array}{c}\text { Average } \\
\text { Minimum } \\
\text { Temperature } \\
\left({ }^{\circ} \mathrm{Ce} 1 \mathrm{c} \text { ius }\right) \\
\end{array}$ & $\begin{array}{c}\text { Average } \\
\text { Average } \\
\text { Temperature } \\
\text { (o' }{ }^{\circ} \text { celus) }\end{array}$ & $\begin{array}{c}\text { Precipitation } \\
(\mathrm{cm})\end{array}$ \\
\hline \multirow[t]{12}{*}{1970} & Jan & 5.8 & -10.5 & -2.4 & .1 \\
\hline & Feb & 11.1 & -8.1 & 1.5 & .1 \\
\hline & Mar & 5.4 & -7.7 & -1.1 & 3.2 \\
\hline & Apr & 12.1 & -2.7 & 4.7 & 3.8 \\
\hline & May & 22.2 & 4.2 & $13: 2$ & 2.0 \\
\hline & Jun & 25.5 & 7.7 & 16.6 & 3.1 \\
\hline & Jul & 30.9 & 13.7 & 22.3 & 3.7 \\
\hline & Aug & 31.4 & 13.2 & 22.3 & .4 \\
\hline & sep & 22.2 & 4.9 & 13.5 & 3.3 \\
\hline & Oct & 13.1 & -1.7 & 5.7 & 3.2 \\
\hline & Nov & 9.4 & -5.5 & 2.0 & .8 \\
\hline & Dec & 5.7 & -10.1 & -2.2 & .4 \\
\hline
\end{tabular}

Summary (Averages for temperature and total for precipitation)

\begin{tabular}{|c|c|c|c|c|}
\hline 1968 & $\star$ & * & * & $30.7 * *$ \\
\hline 1969 & 16.2 & .6 & 8.4 & $37.1 * * *$ \\
\hline 1970 & 16.3 & -.2 & 8.0 & 24.1 \\
\hline
\end{tabular}

*Data from April through rest of year for 1968, therefore average not available.

**Apri1 through December only.

***Fifteen year CPER average (Kipple and Costello, 1960) was $30.4 \mathrm{~cm}$. 
Table 24. Coefficient of community as a function of exposure rate in sector 2 for selected sampling dates.

\begin{tabular}{|c|c|c|c|c|c|}
\hline \multirow{2}{*}{$\begin{array}{c}\text { exposure } \\
\text { rate } \\
(\mathrm{R} / \mathrm{hr}) \\
\end{array}$} & \multicolumn{5}{|c|}{ samp11ng date } \\
\hline & $4-69$ & $6-69$ & $9-69$ & $4-70$ & $6-70$ \\
\hline 650 & .51 & 0 & 0 & 0 & 0 \\
\hline 315 & .39 & 0 & 0 & 0 & 0 \\
\hline 185 & .55 & .06 & 0 & 0 & 0 \\
\hline 115 & .42 & .19 & 0 & 0 & 0 \\
\hline 68 & .49 & .35 & .03 & .07 & .02 \\
\hline 45 & .67 & .44 & .03 & 0 & 0 \\
\hline 28 & .74 & .56 & .36 & .46 & .16 \\
\hline 18 & .51 & .48 & $: 37$ & .45 & .34 \\
\hline 12 & .74 & .60 & .59 & .46 & .50 \\
\hline 7.2 & .63 & .58 & .61 & .67 & .60 \\
\hline 4.8 & .48 & .49 & .49 & .41 & .45 \\
\hline 3.4 & .56 & .56 & .54 & .53 & .52 \\
\hline 2.2 & .66 & .68 & .74 & .58 & .64 \\
\hline 1.3 & .54 & .58 & .56 & .53 & .62 \\
\hline .72 & .63 & .71 & .73 & .69 & .64 \\
\hline .41 & .59 & .66 & .66 & .73 & .71 \\
\hline .22 & .66 & .55 & .67 & .66 & .60 \\
\hline .11 & .76 & .59 & .68 & .58 & .59 \\
\hline .056 & .61 & .61 & .62 & .68 & .64 \\
\hline .029 & .55 & .46 & .66 & .59 & .56 \\
\hline .016 & .61 & .43 & .56 & .44 & .50 \\
\hline :010 & .59 & .38 & .43 & .44 & .48 \\
\hline
\end{tabular}


Table 25. Coefficient of community as a function of exposure rate in sector 3 for selected sampling dates.

\begin{tabular}{|c|c|c|c|c|c|}
\hline \multirow{2}{*}{$\begin{array}{c}\text { exposure } \\
\text { rate } \\
\text { (R/hr) }\end{array}$} & \multicolumn{5}{|c|}{ sampling date } \\
\hline & $4-69$ & $6-69$ & $9-69$ & $4-70$ & $6-70$ \\
\hline 650 & .45 & 0 & 0 & 0 & 0 \\
\hline 315 & .76 & .21 & 0 & 0 & 0 \\
\hline 185 & .61 & .21 & 0 & 0 & 0 \\
\hline 115 & .76 & .36 & 0 & 0 & 0 \\
\hline 68 & .56 & .38 & .08 & 0 & 0 \\
\hline 45 & .55 & .34 & .10 & .46 & .06 \\
\hline 28 & .52 & .38 & .36 & .44 & .06 \\
\hline 18 & .63 & .47 & .60 & .46 & .06 \\
\hline 12 & .65 & .61 & .40 & .59 & .41 \\
\hline 7.2 & .63 & .57 & .47 & .66 & .61 \\
\hline 4.8 & .60 & .73 & .55 & .67 & .58 \\
\hline 3.4 & .54 & .58 & .54 & .56 & .56 \\
\hline 2.2 & .69 & .63 & .74 & .73 & .59 \\
\hline 1.3 & .57 & .65 & .62 & .69 & .63 \\
\hline .72 & .54 & .56 & .58 & .61 & .58 \\
\hline .41 & .66 & .59 & .51 & .64 & .66 \\
\hline .22 & .77 & .68 & .67 & .73 & .64 \\
\hline .11 & .64 & .52 & .45 & .49 & .56 \\
\hline .056 & .69 & .48 & .68 & .58 & .62 \\
\hline .029 & .70 & .71 & .73 & .68 & .66 \\
\hline .016 & .38 & .32 & .53 & .37 & .47 \\
\hline .010 & .45 & .46 & .47 & .47 & .50 \\
\hline
\end{tabular}


Table 26. Coefficient of communtty as a function of exposure rate in sector 4 for selected sampling dates.

\begin{tabular}{|c|c|c|c|c|c|}
\hline \multirow{2}{*}{$\begin{array}{c}\text { exposure } \\
\text { rate } \\
(\mathrm{R} / \mathrm{hr}) \\
\end{array}$} & \multicolumn{5}{|c|}{ sampling datce } \\
\hline & $4-69$ & $6-69$ & $9-69$ & $4-70$ & $6-70$ \\
\hline 650 & .66 & 0 & .22 & 0 & .10 \\
\hline 315 & .56 & .21 & .21 & 0 & .30 \\
\hline 185 & .66 & .36 & .31 & 0 & .23 \\
\hline 115 & .63 & .36 & .68 & .58 & .38 \\
\hline 68 & .66 & .51 & .60 & .63 & .43 \\
\hline 45 & .69 & .57 & .72 & .63 & .55 \\
\hline 28 & .55 & .42 & .48 & .50 & .49 \\
\hline 18 & .61 & .52 & .40 & .56 & .58 \\
\hline 12 & .38 & .58 & .53 & .58 & .60 \\
\hline 7.2 & .64 & .63 & .79 & .63 & .57 \\
\hline 4.8 & .40 & .52 & .49 & .38 & .58 \\
\hline 3.4 & .37 & .52 & .53 & .60 & .63 \\
\hline 2.2 & .45 & .56 & .48 & .56 & .53 \\
\hline 1.3 & .76 & .69 & .7 .2 & .60 & .65 \\
\hline .72 & .57 & .69 & .60 & .64 & .64 \\
\hline .41 & .50 & .56 & .60 & .41 & .55 \\
\hline .22 & .45 & .56 & .50 & .39 & .57 \\
\hline .11 & .72 & .72 & .74 & .58 & .61 \\
\hline .056 & .55 & .70 & .65 & .74 & .65 \\
\hline .029 & .51 & .59 & .61 & .69 & .58 \\
\hline .016 & .59 & .56 & .60 & .55 & .57 \\
\hline .010 & .44 & .55 & .47 & .51 & .54 \\
\hline
\end{tabular}


Table 27. Coefficient of community as a

function of exposure rate in sector 5 for

(1)

- selected sampling dates.

\begin{tabular}{|c|c|c|c|c|}
\hline \multirow{2}{*}{$\begin{array}{c}\text { exposure } \\
\text { rate } \\
\text { (R/hr) }\end{array}$} & \multicolumn{4}{|c|}{ sampling date } \\
\hline & $7-69$ & $9-69$ & $4-70$ & $6-70$ \\
\hline 650 & .59 & 0 & 0 & .34 \\
\hline 315 & .63 & .37 & 0 & 0 \\
\hline 185 & .67 & .34 & 0 & .33 \\
\hline 115 & .70 & .55 & .07 & .50 \\
\hline 68 & .62 & .62 & .35 & .70 \\
\hline 45 & .64 & .56 & .54 & .56 \\
\hline 28 & .59 & .49 & .54 & .58 \\
\hline 18 & .55 & .56 & .41 & .64 \\
\hline 12 & .53 & .61 & .65 & .60 \\
\hline 7.2 & .47 & .62 & .73 & .67 \\
\hline 4.8 & .66 & .74 & .73 & .68 \\
\hline 3.4 & .66 & .79 & .73 & $: 68$ \\
\hline 2.2 & .73 & .74 & .73 & .69 \\
\hline 1.3 & .63 & .79 & .65 & .60 \\
\hline .72 & .67 & .67 & .73 & .71 \\
\hline .41 & .48 & .61 & .61 & .62 \\
\hline .22 & .56 & .66 & .58 & .64 \\
\hline .11 & .61 & .74 & .73 & .59 \\
\hline .056 & .48 & .50 & .40 & .57 \\
\hline .029 & .50 & .61 & .58 & .59 \\
\hline .016 & .41 & .38 & .41 & .42 \\
\hline .010 & .60 & .61 & .55 & .52 \\
\hline
\end{tabular}


Table 28. Coefficient of community as a function of exposure rate in sector 6 for selected sampling dates.

\begin{tabular}{|c|c|c|c|}
\hline \multirow{2}{*}{$\begin{array}{c}\text { exposure } \\
\text { rate } \\
(\mathrm{R} / \mathrm{hr})\end{array}$} & \multicolumn{3}{|c|}{ sampling date } \\
\hline & $9-69$ & $4-70$ & $6-70$ \\
\hline 650 & .38 & .46 & 0 \\
\hline 315 & .54 & .59 & .16 \\
\hline 185 & .54 & .74 & .32 \\
\hline 115 & .37 & .50 & .27 \\
\hline 68 & .54 & .56 & .29 \\
\hline 45 & .54 & .59 & .47 \\
\hline 28 & .59 & .73 & .51 \\
\hline 18 & .55 & .65 & .59 \\
\hline 12 & .79 & .64 & .64 \\
\hline 7.2 & .73 & .60 & .63 \\
\hline 4.8 & .67 & .67 & .66 \\
\hline 3.4 & .59 & .73 & .52 \\
\hline 2.2 & .71 & .74 & .58 \\
\hline 1.3 & .55 & .58 & .55 \\
\hline .72 & .67 & .66 & .61 \\
\hline .41 & .74 & .73 & .58 \\
\hline .22 & .73 & .73 & .54 \\
\hline .11 & .72 & .73 & .59 \\
\hline .056 & .74 & .58 & .49 \\
\hline .029 & .62 & .60 & .60 \\
\hline .016 & .60 & .69 & .54 \\
\hline .010 & .47 & .52 & .48 \\
\hline
\end{tabular}


Table 29. Diversity index as a function of exposure rate in sector 1 for selected sampling dates.

\begin{tabular}{|c|c|c|c|c|c|c|}
\hline \multirow{2}{*}{$\begin{array}{c}\text { exposure } \\
\text { rate } \\
(\mathrm{R} / \mathrm{hr}) \\
\end{array}$} & \multicolumn{6}{|c|}{ sampling date } \\
\hline & $4-69$ & $6-69$ & $7-69$ & $9-69$ & $4-70$ & $6-70$ \\
\hline 650 & .68 & 1.98 & 3.34 & 1.16 & .48 & 2.81 \\
\hline 315 & .94 & 3.29 & 5.14 & 2.23 & 1.77 & 4.70 \\
\hline 185 & 1.00 & 4.89 & 5.74 & 2.30 & 1.88 & 6.03 \\
\hline 115 & .41 & 3.27 & 4.23 & 1.43 & .41 & 4.48 \\
\hline 68 & .81 & 3.41 & 3.74 & .84 & 1.60 & 4.33 \\
\hline 45 & 1.40 & 4.07 & 5.39 & 1.94 & 1.14 & 4.41 \\
\hline 28 & .91 & 2.98 & 3.70 & 2.06 & 1.57 & 3.87 \\
\hline 18 & 1.19 & 3.32 & 4.51 & 2.08 & 1.46 & 4.81 \\
\hline 12 & .91 & 2.91 & 3.43 & 1.86 & 1.36 & 4.95 \\
\hline 7.2 & 2.15 & 4.10 & 5.42 & 1.98 & 1.60 & 5.08 \\
\hline 4.8 & 2.13 & 4.03 & 5.57 & 2.65 & 1.98 & 5.52 \\
\hline 3.4 & 1.36 & 3.21 & 3.53 & 1.56 & 1.06 & 3.23 \\
\hline 2.2 & 1.63 & 3.75 & 5.14 & 2.79 & 2.13 & 4.24 \\
\hline 1.3 & 1.85 & 3.72 & 4.72 & 2.22 & 2.47 & 4.28 \\
\hline .72 & 1.13 & 3.25 & 3.76 & 1.47 & 1.53 & 4.75 \\
\hline .41 & .91 & 1.72 & 2.85 & 1.34 & 1.40 & 2.80 \\
\hline .22 & .41 & 4.86 & 5.27 & 1.14 & 2.12 & 4.97 \\
\hline .11 & 1.23 & 3.27 & 4.03 & 1.71 & .93 & 4.57 \\
\hline .056 & 1.49 & 2.35 & 3.89 & 1.20 & 1.47 & 3.25 \\
\hline .029 & 1.01 & 2.26 & 2.79 & 1.72 & .50 & 3.06 \\
\hline .016 & 1.43 & 2.91 & 3.57 & 1.43 & 1.23 & 4.33 \\
\hline .010 & 1.66 & 4.02 & 4.03 & .93 & 1.39 & 4.70 \\
\hline
\end{tabular}


Table 30. Diversity index as a function of exposure rate in sector 2 for selected sampling dates.

\begin{tabular}{|c|c|c|c|c|c|c|}
\hline \multirow{2}{*}{$\begin{array}{c}\text { exposure } \\
\text { rate } \\
\text { (R/hr) } \\
\end{array}$} & \multicolumn{6}{|c|}{ sampling date } \\
\hline & $4-69$ & $6-69$ & $9-69$ & $4-70$ & $6-70$ & $9-70$ \\
\hline 650 & .68 & 0 & 0 & 0 & 0 & 0 \\
\hline 315 & 1.11 & 0 & $0^{\prime}$ & 0 & 0 & 0 \\
\hline 185 & 1.83 & .30 & 0 & $\stackrel{0}{i}$ & 0 & 0 \\
\hline 115 & 1.56 & .72 & 0 & 0 & 0 & 0 : \\
\hline 68 & 1.60 & 1.19 & .50 & .30 & $! 30$ & .43 \\
\hline 45 & 1.78 & 2.16 & .30 & 0 & 0 & 0 \\
\hline 28 & 1.91 & 2.85 & 1.02 & .72 & 1.22 & 1.25 \\
\hline 18 & 1.86 & 2.12 & .52 & .75 & 1.19 & .79 \\
\hline 12 & 1.80 & 3.19 & 1.81 & 1.02 & 2.68 & 1.50 \\
\hline 7.2 & 2.03 & 1.56 & 2.19 & : 89 & $3.29 !$ & 1.06 \\
\hline 4.8 & 1.41 & 1.92 & 1.22 & .61 & 3.66 & 2.80 \\
\hline 3.4 & 1.11 & 2.41 & 1.35 & .71 & 4.12 & 2.68 \\
\hline 2.2 & 1.54 & 2.88 & 1.00 & .71 & 4.37 & 1.61 \\
\hline 1.3 & 1.11 & 3.25 & 1.61 & 1.18 & $4: 31$ & 1.70 \\
\hline .72 & 1.93 & 3.10 & 2.16 & 1.93 & 4.85 & 3.34 \\
\hline .41 & 1.03 & 3.78 & 2.35 & 1.56 & 5.09 & 2.71 \\
\hline .22 & 1.54 . & 3.41 & 1.74 & 1.73 & $5: 07$ & 2.48 \\
\hline .11 & .71 & 3.19 & 1.43 & .84 & 5.00 & 2.16 \\
\hline .056 & 2.12 & 4.30 & 2.15 & 1.76 & 5.39 & 2.99 \\
\hline .029 & 2.52 & 3.01 & 2.36 & 2.33 & 5.17 & 2.46 \\
\hline .016 & 2.40 & 4.11 & 2.22 & 2.30 & 6.10 & 2.63 \\
\hline .010 & 1.69 & 3.71 & 1.69 & 3.24 & $5: 46$ & 3.74 \\
\hline
\end{tabular}


Table 31. Diversity index as a function of exposure rate in sector 3 for selected sampling dates.

\begin{tabular}{|c|c|c|c|c|c|}
\hline \multirow{2}{*}{$\begin{array}{l}\text { exposure } \\
\text { rate } \\
(\mathrm{R} / \mathrm{hr})\end{array}$} & \multicolumn{5}{|c|}{ sampling date } \\
\hline & $4-69$ & $6-69$ & $9-69$ & $4-70$ & $6-70$ \\
\hline 650 & .17 & 0 & 0 & 0 & 0 \\
\hline 315 & .92 & .43 & 0 & 0 & 0 \\
\hline 185 & 1.43 & .45 & 0 & 0 & 0 \\
\hline 115 & 1.17 & 1.05 & 0 & 0 & 0 \\
\hline 68 & 1.09 & .90 & .50 & 0 & 0 \\
\hline 45 & 1.61 & 1.72 & .72 & .72 & .30 \\
\hline 28 & 1.02 & 1.60 & 1.25 & 1.22 & .43 \\
\hline 18 & 2.41 & 1.94 & 1.64 & .61 & .50 \\
\hline 12 & 1.53 & 2.40 & 2.78 & .79 & 2.50 \\
\hline 7.2 & 2.26 & 3.60 & 3.06 & 1.80 & 4.62 \\
\hline 4.8 & 1.80 & 3.13 & 1.97 & 1.63 & 3.70 \\
\hline 3.4 & .81 & 2.66 & 1.11 & .65 & 3.22 \\
\hline 2.2 & 1.35 & 2.92 & 1.29 & .99 & 4.63 \\
\hline 1.3 & 1.27 & 2.93 & 1.02 & 1.43 & 5.43 \\
\hline .72 & .84 & 3.21 & 1.78 & 1.32 & 5.79 \\
\hline .41 & 1.40 & 4.26 & 1.83 & 1.44 & 6.11 \\
\hline .22 & 1.24 & 3.20 & 1.56 & 1.04 & 5.39 \\
\hline .11 & .98 & 3.06 & 1.10 & 1.01 & 4.53 \\
\hline .056 & 1.56 & 3.86 & 1.83 & 1.04 & 5.07 \\
\hline .029 & 1.93 & 3.32 & 2.29 & 1.47 & 6.42 \\
\hline .016 & 1.28 & 2.02 & .74 & 1.04 & 3.65 \\
\hline .010 & 1.83 & 3.90 & 1.29 & 1.59 & 5.08 \\
\hline
\end{tabular}


Table 32. Diversity index as a function of exposure rate in sector 4 for selected sampling dates.

\begin{tabular}{|c|c|c|c|c|c|c|}
\hline \multirow{2}{*}{$\begin{array}{c}\text { exposure } \\
\text { rate } \\
\text { (R/hr) } \\
\end{array}$} & \multicolumn{6}{|c|}{ sampling date } \\
\hline & $4-69$ & $6-69$ & $9-69$ & $4-70$ & $6-70$ & $9-70$ \\
\hline 650 & .46 & 0 & .46 & 0 & .99 & .52 \\
\hline 315 & .79 & .52 & .82 & 0 & 2.53 & .98 \\
\hline 185 & 1.53 & .88 & 1.48 & 0 & 2.54 & 1.56 \\
\hline 115 & .72 & .83 & 2.13 & 1.25 & 2.48 & 1.91 \\
\hline 68 & 1.23 & 1.70 & 1.78 & .75 & 2.62 & 1.70 \\
\hline 45 & 1.43 & 3.18 & 2.56 & .88 & 4.12 & 2.93 \\
\hline 28 & 1.24 & 2.72 & 2.19 & 1.33 & 3,19 & 1.13 \\
\hline 18 & .74 & 2.55 & 2.46 & .41 & 5.49 & 1.66 \\
\hline 12 & .71 & 2.85 & 1.43 & .84 & 3.56 & 1.23 \\
\hline 7.2 & 2.04 & 5.26 & 2.17 & .88 & 4.86 & 2.69 \\
\hline 4.8 & 1.90 & 3.55 & 1.50 & 1.60 & 4.98 & 2.13 \\
\hline 3.4 & .75 & 5.48 & 2.92 & 1.84 & 7.07 & 3.33 \\
\hline 2.2 & 0 & 3.40 & 2.51 & 1.81 & 5.81 & 2.21 \\
\hline 1.3 & 1.26 & 4.24 & 2.42 & 1.90 & 5.77 & 2.95 \\
\hline .72 & 1.65 & 3.13 & 1.7 .2 & .93 & 4.24 & 2.54 \\
\hline .41 & 1.00 & 3.10 & 1.04 & .22 & 4.98 & 1.56 \\
\hline .22 & .11 & 1.86 & .54 & .41 & 3.38 & 1.14 \\
\hline .11 & 1.35 & 2.94 & 1.04 & .51 & 3.43 & 2.09 \\
\hline .056 & 1.12 & 2.79 & 2.11 & 1.14 & 5.09 & 2.55 \\
\hline .029 & 1.33 & 3.34 & 1.81 & 1.52 & 6.14 & 2.00 \\
\hline .016 & 1.10 & 2.98 & 1.73 & 1.93 & 5.65 & 2.39 \\
\hline .010 & 1.48 & 5.23 & 1.50 & 2.50 & 6.23 & 1.93 \\
\hline
\end{tabular}


Table 33. Diverstty index as a function of exposure rate in sector 5 for sélected sampling dates.

\begin{tabular}{|c|c|c|c|c|c|}
\hline \multirow{2}{*}{$\begin{array}{c}\text { exposure } \\
\text { rate } \\
(\mathrm{R} / \mathrm{hr}) \\
\end{array}$} & \multicolumn{5}{|c|}{ sampling date } \\
\hline & $7-69$ & $9-69$ & $4-70$ & $6-70$ & $9-70$ \\
\hline 650 & 5.51 & 0 & 0 & 2.33 & 0 \\
\hline 315 & 5.75 & .30 & 0 & 0 & .79 \\
\hline 185 & 5.38 & .79 & 0 & 2.40 & 2.36 \\
\hline 115 & 5.23 & 1.88 & .30 & 3.36 & 2.44 \\
\hline 68 & 4.07 & 2.05 & .45 & 4.86 & 2.14 \\
\hline 45 & 4.76 & 2.93 & 1.42 & 4.64 & 3.50 \\
\hline 28 & 4.67 & 2.31 & 1.14 & 4.00 & 2.77 \\
\hline 18 & 4.89 & 2.83 & 2.03 & 5.98 & 3.42 \\
\hline 12 & 2.96 & 2.85 & 1.07 & 4.07 & 2.57 \\
\hline 7.2 & 3.36 & 2.29 & .91 & 5.26 & 2.78 \\
\hline 4.8 & 3.28 & 1.74 & 1.10 & 4.93 & 2.60 \\
\hline 3.4 & 3.51 & 2.16 & 1.42 & 5.25 & 3.09 \\
\hline 2.2 & 3.68 & 1.59 & 1.01 & 5.11 & 2.56 \\
\hline 1.3 & 3.66 & 1.61 & 1.29 & 4.34 & 2.65 \\
\hline .72 & 3.24 & 1.12 & .97 & 4.10 & 2.38 \\
\hline .41 & 3.44 & 1.32 & 1.25 & 4.75 & 1.54 \\
\hline .22 & 4.46 & 1.56 & 1.03 & 5.14 & 1.93 \\
\hline .11 & 4.23 & 1.56 & 1.18 & 7.23 & 2.40 \\
\hline 056 & 3.59 & 1.42 & .89 & 5.45 & 1.46 \\
\hline .029 & 3.04 & 1.56 & 1.30 & 4.21 & 1.78 \\
\hline .016 & 2.06 & .64 & .95 & 2.80 & .22 \\
\hline .010 & 3.70 & 1.46 & 1.89 & 4.88 & .84 \\
\hline
\end{tabular}


Table 34. Diversity index as a function of exposure rate in sector 6 for selected sampling dates.

\begin{tabular}{|c|c|c|c|c|}
\hline \multirow{2}{*}{$\begin{array}{c}\text { exposure } \\
\text { rate } \\
(\mathrm{R} / \mathrm{hr}) \\
\end{array}$} & \multicolumn{4}{|c|}{ sampling date } \\
\hline & $9-69$ & $4-701$ & $6-70$ & $9-70$ \\
\hline 650 & 1.73 & 1.00 & 0 & 0 \\
\hline 315 & 2.24 & .97 & .52 & 0 \\
\hline 185 & 3.42 & 1.43 & 1.52 & .50 \\
\hline 115 & 1.53 & 1.89 & 2.40 & 1.32 \\
\hline 68 & 2.92 & 1.29 & 1.56 & 1.40 \\
\hline 45 & 2.87 & .99 & 14.72 & 2.95 \\
\hline 28 & 1.90 & $: 76$ & 3.46 & 1.93 \\
\hline 18 & 3.28 & 1.44 & 4.58 & 3.24 \\
\hline 12 & 2.26 & 1.41 & 4.55 & 3.15 \\
\hline 7.2 & 2.52 & 1.57 & 6.07 & 3.43 \\
\hline 4.8 & 3.08 & 1.74 & $5.59^{\circ}$ & 2.95 \\
\hline 3.4 & 1.34 & 1.04 & 3.38 & 2.16 \\
\hline 2.2 & 1.81. & 1.59 & 2.82 & 2.28 \\
\hline 1.3 & 2.59 & 2.16 & 6.94 & 3.71 \\
\hline .72 & .81 & 1.51 & 6.62 & 3.33 \\
\hline .41 & 1.26 & .54 & $6.25^{\circ}$ & 2.23 \\
\hline .22 & 1.63 & 1.38 & 7.48 & 3.20 \\
\hline .11 & 1.88 & .72 & 5.11 & 3.47 \\
\hline .056 & 1.83 & ]. .33 & 5.1 .6 & 1.80 \\
\hline .029 & 1.71 & 2.59 & 5.52 & 1.88 \\
\hline .016 & 1.96 & 2.01 & 3.50 & 1.10 \\
\hline .010 & 1.79 & 2.11 & 4.47 & 2.33 \\
\hline
\end{tabular}


